\title{
A Single Pass Butt-Welded Pipe Finite Element Method Computer Simulation
}

\author{
by \\ Romeo-Florin Stanescu \\ B.Eng., Metallurgy, Polytechnic Institute Bucharest, Romania, 1990 \\ A thesis submitted to \\ the Faculty of Graduate Studies and Research \\ in partial fulfillment of the requirements for the degree of \\ Master of Applied Science \\ Department of Mechanical and Aerospace Engineering \\ Ottawa - Carleton Institute for Mechanical and Aerospace Engineering \\ Carleton University \\ Ottawa, Ontario \\ Canada
}

April 12, 2005 


$\begin{array}{ll}\begin{array}{l}\text { Library and } \\ \text { Archives Canada }\end{array} & \begin{array}{l}\text { Bibliothèque et } \\ \text { Archives Canada }\end{array} \\ \begin{array}{l}\text { Published Heritage } \\ \text { Branch }\end{array} & \begin{array}{l}\text { Direction du } \\ \text { Patrimoine de l'édition }\end{array} \\ \begin{array}{l}\text { 395 Wellington Street } \\ \text { Ottawa ON K1A ON4 }\end{array} & \begin{array}{l}\text { 395, rue Wellington } \\ \text { Ottawa ON K1A ON4 } \\ \text { Canada }\end{array}\end{array}$

Your file Votre référence

ISBN: 0-494-10093-1

Ourfile Notre référence

ISBN: 0-494-10093-1

NOTICE:

The author has granted a nonexclusive license allowing Library and Archives Canada to reproduce, publish, archive, preserve, conserve, communicate to the public by telecommunication or on the Internet, loan, distribute and sell theses worldwide, for commercial or noncommercial purposes, in microform, paper, electronic and/or any other formats.

The author retains copyright ownership and moral rights in this thesis. Neither the thesis nor substantial extracts from it may be printed or otherwise reproduced without the author's permission.
AVIS:

L'auteur a accordé une licence non exclusive permettant à la Bibliothèque et Archives Canada de reproduire, publier, archiver, sauvegarder, conserver, transmettre au public par télécommunication ou par l'Internet, prêter, distribuer et vendre des thèses partout dans le monde, à des fins commerciales ou autres, sur support microforme, papier, électronique et/ou autres formats.

L'auteur conserve la propriété du droit d'auteur et des droits moraux qui protège cette thèse. $\mathrm{Ni}$ la thèse ni des extraits substantiels de celle-ci ne doivent être imprimés ou autrement reproduits sans son autorisation.
In compliance with the Canadian

Privacy Act some supporting forms may have been removed from this thesis.

While these forms may be included in the document page count, their removal does not represent any loss of content from the thesis.
Conformément à la loi canadienne sur la protection de la vie privée, quelques formulaires secondaires ont été enlevés de cette thèse.

Bien que ces formulaires aient inclus dans la pagination, il n'y aura aucun contenu manquant.

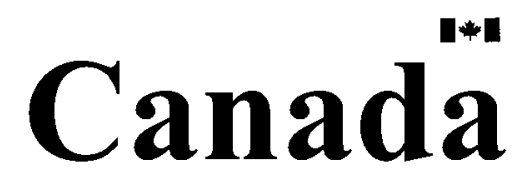


The undersigned recommend to the Faculty of Graduate Studies and Research acceptance of the thesis:

\section{A Single Pass Butt-Welded Pipe \\ Finite Element Method Computer Simulation}

submitted by

\section{Romeo-Florin Stanescu}

in partial fulfillnent of the requirements for

the degree of

Master of Applied Science

Thesis Supervisor

Chair, Department of Mechanical and Aerospace Engineering

Carleton University 


\section{Abstract}

The aim of the thesis is to investigate both transient and residual deformations and stresses during welding of a single butt-welded pipe by using SimManTec, a research software accounting for the latest implementation of computational weld mechanics.

A three-dimensional finite element method using brick elements was proposed for the numerical simulation. The analysis was conducted by solving a coupled problem governed by the conservation of energy, mass and momentum. The presented method is based on a Lagrangian finite element formulation. The material model uses temperature dependant properties.

The computed prediction were compared both with published experimental data and published results of a finite element analysis using shell elements. A good agreement was obtained. 


\section{Acknowledgments}

I would like to thank Dr. John A. Goldak, my supervisor, for his invaluable guidance, patience and support; Mr. Stanislav Tchernov, Dr. Jianguo Zhou and Mr. Shaodong Wang for their part of software development; Mr. Dan Downey for his computer system support.

The financial support of Mechanical and Aerospace Department, Carleton University and an OGS scholarship from the Province of Ontario are highly appreciated. 


\section{Nomenclature}

\begin{tabular}{|c|c|}
\hline$G$ & Chemical bond free energy. \\
\hline$T$ & Temperature. \\
\hline$p$ & Pressure. \\
\hline$\mu_{i}$ & Chemical potential. \\
\hline$\Omega$ & Physical domain. \\
\hline$m$ & Number of elements in the domain. \\
\hline$N_{i}(r, s, t)$ & Element $i$ basis functions. \\
\hline $\mathbf{R}(r, s, t)$ & Row matrix of basis functions. \\
\hline$x, y, z$ & Cartesian coordinate system. \\
\hline$r, s, t$ & Natural coordinate system. \\
\hline $\mathbf{T}$ & Nodal vector of temperature in an element. \\
\hline$\overline{\mathbf{X}}_{\mathbf{i}}$ & Column matrix of nodes $\mathrm{x}$ coordinates. \\
\hline$q$ & Heat flux per unit area. \\
\hline$Q$ & Density of heat generation. \\
\hline$\dot{h}$ & Time rate of specific enthalpy. \\
\hline$\Gamma$ & Boundary of the domain. \\
\hline$e_{p}$ & Specific heat. \\
\hline
\end{tabular}


$L \quad$ Specific heat.

$k_{t} \quad$ Coefficient of thermal conductivity.

$C_{\sigma} \quad$ Stefan-Boltzmann constant.

$\nabla T$ Temperature gradient.

$\varepsilon \quad$ Strain Field and Strain Vector.

$\sigma \quad$ Stress field.

$u \quad$ Displacement field.

u Displacement vector.

$n \quad$ Number of nodes in an element.

B The divergence matrix operator.

vi 


\section{Contents}

Acceptance Sheet ................... ii

Abstract ...................... iii

Acknowledgements $\ldots \ldots \ldots \ldots \ldots \ldots \ldots \ldots \ldots$ iv

Nomenclature ............................... v

Table of Contents . . . . . . . . . . . . . . . . vii

List of Tables ..................... ix

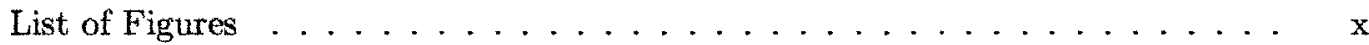

Thesis Organization $\ldots \ldots \ldots \ldots \ldots \ldots \ldots \ldots \ldots \ldots \ldots \ldots \ldots$ xiii

1 Welding Process - General View 1

1.1 Definition and process characteristics . . . . . . . . . . . 1

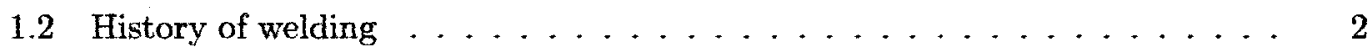

1.3 Physics and chemistry fundamentals ... . . . . . . . . 10

1.4 Classification . . . . . . . . . . . . . . . . 12

1.5 Efficiency considerations . . . . . . . . . . . . 16

vii 
1.6 Phenomena during welding $\ldots \ldots \ldots \ldots \ldots \ldots$

2 Computational Weld Mechanics - Literature Review 20

2.1 Definition ................................... 20

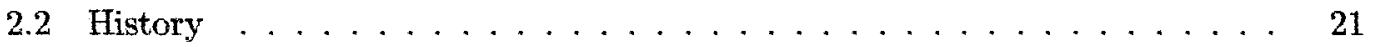

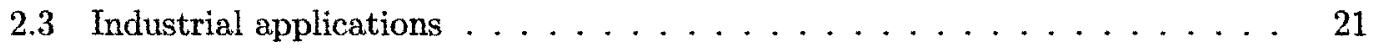

2.4 Numerical methods and modelling techniques . . . . . . . . . 23

2.5 Areas of modelling - FEM formulation . . . . . . . . . . 24

2.5 .1 Modelling material properties . . . . . . . . . . . 25

2.5.2 Geometric modelling - Domain discretization $\ldots \ldots \ldots 26$

2.5 .3 Heat source-metal interaction $\ldots \ldots \ldots . \ldots \ldots$

2.5 .4 Heat and fluid flow . . . . . . . . . . . 40

2.5.5 Displacernent, Strain and Stress . . . . . . . . . 46

2.5.6 Weld solidification microstructure and phase transformation ... 50

2.5 .7 The coupled problem . . . . . . . . . . . . 51

2.5 .8 Time discretization and integration . . . . . . . . 53

$3 \quad$ Butt-Welded Pipe - A Case Study $\quad 54$

3.1 Introduction . . . . . . . . . . . . . 55

3.2 Experiment and Simulations . . . . . . . . . . . . . 57

3.2 .1 Butt-welded pipe experiment $[13] \ldots \ldots \ldots \ldots \ldots$

3.2.2 FE Analysis using shell elements for a butt-welded pipe model [14] . $\quad 65$

3.2.3 3D FEM computer simulation using brick elements $\ldots \ldots 71$ viii 
3.3 Discussion and conclusion $\ldots \ldots \ldots \ldots \ldots \ldots \ldots$

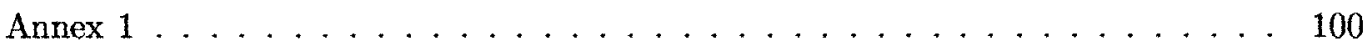

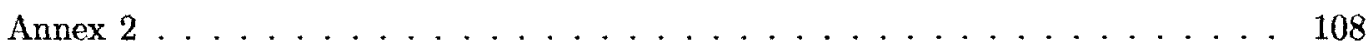

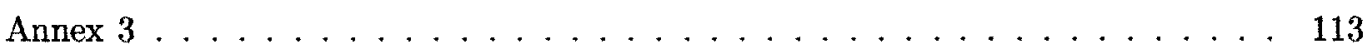

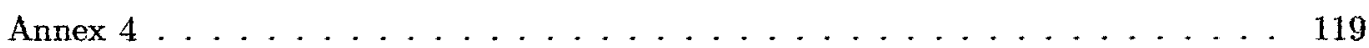




\section{List of Tables}

1.1 Welding processes and letter designation $I \ldots \ldots \ldots \ldots$

1.2 Welding processes and letter designation $I I \ldots \ldots \ldots \ldots . \ldots \ldots$

1.3 Welding processes and letter designation III . . . . . . . 15

3.1 Physical experiment - Principal dimensions. . . . . . . . . . 58

3.2 SIS 2172 Steel - Chemical composition in weight percent. . . . . . . . 60

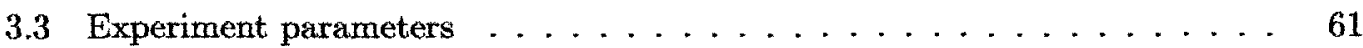

3.4 Location of points for residual stress measurement. . . . . . . . . 62

3.5 Discretization of the FE mesh. ................. 68

$3.6 \quad \mathrm{FE}$ analysis parameters. . . . . . . . . . . . . 71

3.7 Discretization parameters for 3 D FEM simulation. $\ldots \ldots \ldots \ldots \ldots$

3.8 Temperature dependent material properties $\ldots \ldots \ldots \ldots \ldots . \ldots 77$

3.9 3D FEM computer simulation parameters. . . . . . . . . . 79

3.10 Last time step - Error analysis results. . . . . . . . . . . . 88 


\section{List of Figures}

2.1 Gaussian flux distribution $[7] \ldots \ldots \ldots \ldots \ldots \ldots \ldots$

2.2 Classical Rosenthall/Ryalkin heat source $[7] \ldots \ldots \ldots \ldots$

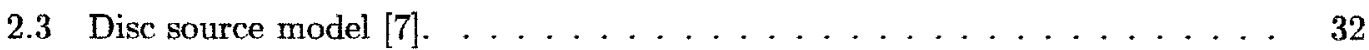

2.4 Hemispherical power density distribution $[7] \ldots \ldots \ldots \ldots \ldots$

2.5 Double ellipsoid heat source model $[6] . \ldots \ldots \ldots \ldots$

2.6 Phenomena occuring during welding $[3] . \ldots \ldots \ldots \ldots \ldots$

3.1 Geometry of butt-welded pipe experiment $[13], \ldots \ldots \ldots \ldots$

3.2 Measured Diametrical Deflection $[13] \ldots \ldots \ldots \ldots . \ldots . \ldots . \ldots 64$

3.3 Measured transient and residual axial stress [13]. . . . . . . . 65

3.4 Measured transient and residual hoop stress $[13] . \ldots \ldots \ldots \ldots 6$

3.5 FE mesh with shell elements $[13] . \ldots \ldots \ldots \ldots \ldots \ldots$

3.6 Material properties: Young's Modulus and Thermal Dilatation [13] . . . . 69

3.7 Material properties: Yield Stress and Poisson's Ratio [13]. . . . . . . 70

3.8 Calculated diametrical deflection $[14] . \ldots \ldots \ldots \ldots \ldots$

xi 
3.9 Calculated residual axial stresses on the outer surface -FE analysis [14]. . $\quad 73$

3.10 Calculated residual hoop stresses on the outer surface -FE analysis [14]. . . 74

3.11 But-welded pipe model - Graded brick mesh. . . . . . . . . . 75

3.12 Small Plate Mesh. . . . . . . . . . . . . . . . . 78

3.13 Temperature field through pipe thickness. . . . . . . . . . . . 80

3.14 Residual Axial Stresses on outer surface of the pipe - 3D FEM computer simulation. .......................... 82

3.15 Residual Hoop Stresses on outer surface of the pipe -3D FEM computer

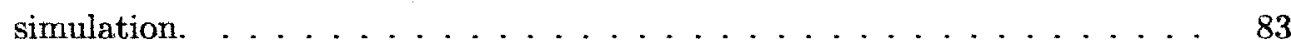

3.16 Dianetrical Deflection - 3D FEM sinulation. . . . . . . . . . . . 85

3.17 Axial residual stress on the outer surface of the pipe - compared results. . . 91

3.18 Hoop residual stress on the outer surface of the pipe - compared results. . . 92

3.19 Diametrical deflection - compared results. . . . . . . . . . . . . 94

3.20 Density versus Temperature $[18] . \ldots \ldots \ldots \ldots \ldots$

3.21 Coefficient of Thermal Expansion versus Temperature $[18] \ldots \ldots$. . . . 101

3.22 Young's Modulus versus Temperature $[18] . \ldots \ldots \ldots \ldots . \ldots . \ldots 102$

3.23 Yield Stress versus Temperature $[18] . \ldots \ldots \ldots \ldots$

3.24 Poisson's Ratio versus Temperature $[18] \ldots \ldots \ldots \ldots 104$

3.25 Specific Heat versus Temperature $[18] . \ldots \ldots \ldots \ldots . \ldots . \ldots 105$

3.26 Coefficient of Thermal Conductivity versus Temperature $[18] \ldots \ldots 106$

3.27 Volumetric Strain versus Temperature $[18] \ldots \ldots \ldots \ldots$

xii 
3.28 Temperatures field in the small plate. . . . . . . . . . . . 109

3.29 Temperatures field mapped to the pipe model (Welding start phase). . . . 110

3.30 Temperatures field mapped to the pipe model (Welding steady state phase). 111

3.31 Temperatures field mapped to the pipe model (Cooling phase) . . . . . . 112

3.32 Transient effective stress. . . . . . . . . . . . . . . . 114

3.33 Longitudinal stress. . . . . . . . . . . . . . . . 115

3.34 Stress transverse to weld. . . . . . . . . . . . 116

3.35 Radial or throughthickness stress. . . . . . . . . . . . 117

3.36 Deformations during welding and cooling - 3D FEM simulation. . . . . 118

3.37 Transient global strain energy error. . . . . . . . . . . . . 120

xiii 


\section{Organization of the Thesis}

Chapter 1 gives an overview of the welding process.

Chapter $\mathbf{2}$ is an introduction in Computational Weld Mechanics as an applied science.

Chapter 3 presents the single pass butt-welded pipe test 3D FEM computer simulation, summarizes the main results and compares the obtained results with an experimental test and a FE analysis using shell elements.

\section{Appendices}

Annex 1 - Temperature dependent material properties used in 3D FEM computer simulation of welding for a butt-welded pipe model.

Annex 2 - Transient temperature fields in 3D FEM computer simulation of welding for a butt-welded pipe model.

Annex 3 - Stress and deformation fields in 3D FEM computer simulation of welding for a butt-welded pipe model.

Annex 4 - Transient global strain energy error.

xiv 


\section{Chapter 1}

\section{Welding Process - General View}

\subsection{Definition and process characteristics}

The American Welding Society (AWS) definition for a welding process is "a materials joining process which produces coalescence of materials by heating them to suitable temperatures with or without the application of pressure or by the application of pressure alone and with or without the use of filler material".

Welding processes characteristics are:

- join similar metallic parts,

- bring adjacent surfaces into intimate contact (the two surfaces have to be brought together within atomic distances) by removing the oxide layers using one of the following procedures: 
- melting and fusing a small volume of the base metals (fusion welding),

- compressing the joint surfaces (pressure welding),

- by rubbing the surfaces together (friction welding),

- employ localized heat input,

- create weld joints which are usually stronger than or as strong as the base metals being joined. The mechanical, metallurgical and chemical properties of the weld should be identical or superior to those of the parts being joined.

\subsection{History of welding}

Welding can trace its historic development back to ancient times [1]. The earliest examples come from the Bronze Age. Small gold circular boxes were made by pressure welding lap joints together. It is estimated that these boxes were made more than 2000 years ago. During the Iron Age the Egyptians and people in the eastern Mediterranean area learned to weld pieces of iron together. Many tools were found which were made approximately 1000 B.C.

During the Middle Ages, the art of blacksmithing was developed and many items of iron were produced which were welded by hammering. It was not until the 19 th century that welding, as we know it today, was invented.

Edmund Davy of England is credited with the discovery of acetylene in 1836 . The pro- 
duction of an arc between two carbon electrodes using a battery is credited to Sir Humphry Davy in 1800 . In the mid-nineteenth century, the electric generator was invented and arc lighting became popular. During the late $1800 \mathrm{~s}$, gas welding and cutting was developed. Arc welding with the carbon arc and metal arc was developed and resistance welding became a practical joining process.

Auguste De Meritens, working in the Cabot Laboratory in France, used the heat of an arc for joining lead plates for storage batteries in the year 1881. It was his pupil, a Russian, Nikolai N. Benardos, working in the French laboratory, who was granted a patent for welding. He, with a fellow Russian, Stanislaus Olszewski, secured a British patent in 1885 and an American patent in 1887. The patents show an early electrode holder. This was the beginning of carbon arc welding. Bemardos' efforts were restricted to carbon arc welding, although he was able to weld iron as well as lead. Carbon arc welding became popular during the late 1890 s and early 1900 s.

In 1890, C.L. Coffin of Detroit was awarded the first U.S. patent for an arc welding process using a metal electrode. This was the first record of the metal melted from the electrode carried across the arc to deposit filler metal in the joint to make a weld.

In approximately 1900, Strohmenger introduced a coated metal electrode in Great Britain. There was a thin coating of clay or lime, but it provided a more stable arc. Oscar Kjellberg of Sweden invented a covered or coated electrode during the period of 1907 to 1914. Stick electrodes were produced by dipping short lengths of bare iron wire in thick mixtures of carbonates and silicates, and allowing the coating to dry. Meanwhile, resistance 
welding processes were developed, including spot welding, seam welding, projection welding and flash butt welding. Elihu Thompson originated resistance welding. His patents were dated 1885-1900. In 1903, a German named Goldschmidt invented thermite welding that was first used to weld railroad rails.

Gas welding and cutting were perfected during this period as well. The production of oxygen and later the liquefying of air, along with the introduction of a blow pipe or torch in 1887 , helped the development of both welding and cutting. Before 1900, hydrogen and coal gas were used with oxygen. However, in about 1900 a torch suitable for use with low-pressure acetylene was developed.

World War I brought a tremendous demand for armament production and welding was pressed into service. Many companies sprang up in America and in Europe to manufacture welding machines and electrodes to meet the requirements.

Immediately after the war in 1919 , twenty members of the Wartime Welding Committee of the Emergency Fleet Corporation under the leadership of Comfort Avery Adams, founded the Anerican Welding Society as a nomprofit organization dedicated to the advancenent of welding and allied processes.

In 1920, automatic welding was introduced. It utilized bare electrode wire operated on direct current and utilized arc voltage as the basis of regulating the feed rate. Automatic welding was invented by P.O. Nobel of the General Electric Company. It was used to build up worn motor shafts and worn crane wheels. It was also used by the automobile industry to produce rear axle housings. 
In 1929, Lincoln Electric Company produced extruded electrode rods that were sold to the public. By 1930, covered electrodes were widely used. Welding codes appeared which required higher-quality weld metal, which increased the use of covered electrodes.

Alternating current become popular in the 1930s when the heavy-coated electrode found widespread use.

During the 1920 s there was considerable research in shielding the arc and weld area by externally applied gases. The atmosphere of oxygen and nitrogen in contact with the molten weld metal caused brittle and sometime porous welds. Research work was done utilizing gas shielding techniques. Alexander and Langmuir did work in chambers using hydrogen as a welding atmosphere. They utilized two electrodes starting with carbon electrodes but later changing to tungsten electrodes. The hydrogen was changed to atomic hydrogen in the arc. It was then blown out of the arc forming an intensely hot flame of atomic hydrogen. This arc produced half again as much heat as an oxyacetylene flame. This became the atomic hydrogen welding process. Atomic hydrogen never became popular but was used during the 1930 s and 1940s for special applications of welding and later on for welding of tool steels.

H.M. Hobart and P.K. Devers were doing similar work but using atmospheres of argon and helium. In their patents applied for in 1926, arc welding utilizing gas supplied around the arc was a forerunner of the gas tungsten arc welding process. They also showed welding with a concentric nozzle and with the electrode being fed as a wire through the nozzle. This was the forerunner of the gas metal arc welding process. These processes were developed much later. 
Stud welding was developed in 1930 at the New York Navy Yard, specifically for attaching wood decking over a metal surface. Stud welding became popular in the shipbuilding and construction industries.

The automatic process that became popular was the submerged arc welding process. This under powder or smothered arc welding process was developed by the National Tube Company for a pipe mill at McKeesport, Pennsylvania. It was designed to make the longitudinal seams in the pipe. The process was patented by Robinoff in 1930 and was later sold to Linde Air Products Company, where it was renamed Unionmelt welding. Submerged arc welding was used during the defense buildup in 1938 in shipyards and in ordnance factories. It is one of the most productive welding processes and remains popular today.

Gas tungsten arc welding (GTAW) had its beginnings from an idea by C.L. Coffin to weld in a nonoxidizing gas atmosphere, which he patented in 1890 . The concept was further refined in the late 1920s by H.M. Hobart, who used helium for shielding, and P.K. Devers, who used argon. This process was ideal for welding magnesium and also for welding stainless steel and aluminum. It was perfected in 1941, patented by Meredith, and named Heliarc welding. It was later licensed to Linde Air Products, where the water-cooled torch was developed. The gas tungsten arc welding process has become one of the most important.

The gas shielded metal arc welding (GMAW) process was successfully developed at Battelle Memorial Institute in 1948 under the sponsorship of the Air Reduction Company. This development utilized the gas shielded arc similar to the gas tungsten arc, but replaced the tungsten electrode with a continuously fed electrode wire. One of the basic changes 
that made the process more usable was the small-diameter electrode wires and the constantvoltage poser source. This principle had been patented earlier by H.E. Kennedy. The initial introduction of GMAW was for welding nonferrous metals. The high deposition rate led users to try the process on steel. The cost of inert gas was relatively high and the cost savings were not immediately available.

In 1953, Lyubavskii and Novoshilov announced the use of welding with consumable electrodes in an atmosphere of $\mathrm{CO}_{2}$ gas. The $\mathrm{CO}_{2}$ welding process immediately gained favor since it utilized equipment developed for inert gas metal arc welding, but could now be used for welding steels economically. The $\mathrm{CO}_{2}$ arc is a hot arc and the larger electrode wires required fairly high currents. The process became widely used with the introduction of smaller-diameter electrode wires and refined power supplies. This development was the short-circuit arc variation which was known as Micro-wire, short-arc, and dip transfer welding, all of which appeared late in 1958 and early in 1959. This variation allowed all-position welding on thin materials and soon became the most popular of the gas metal arc welding process variations.

Another variation was the use of inert gas with small amounts of oxygen that provided the spray-type arc transfer. It became popular in the early 1960s. A recent variation is the use of pulsed current. The current is switched from a high to a low value at a rate of once or twice the line frequency.

Soon after the introduction of $\mathrm{CO}_{2}$ welding, a variation utilizing a special electrode wire was developed. This wire, described as an inside-outside electrode, was tubular in cross 
section with the fluxing agents on the inside. The process was called Dualshield, which indicated that external shielding gas was utilized, as well as the gas produced by the flux in the core of the wire, forarc shielding. This process, invented by Bernard, was announced in 1954, but was patented in 1957, when the National Cylinder Gas Company reintroduced it.

In 1959, an inside-outside electrode was produced which did not require external gas shielding. The absence of shielding gas gave the process popularity for noncritical work. This process was named Innershield.

The electroslag welding process was announced by the Soviets at the Brussels World Fair in Belgium in 1958. It had been used in the Soviet Union since 1951, but was based on work done in the United States by R.K. Hopkins, who was granted patents in 1940 . The Hopkins process was never used to a very great degree for joining. The process was perfected and equipment was developed at the Paton Institute Laboratory in Kiev, Ukraine, and also at the Welding Research Laboratory in Bratislava, Czechoslovakia. The first production use in the U.S. was at the Electromotive Division of General Motors Corporation in Chicago, where it was called the Electro-molding process. It was announced in December 1959 for the fabrication of welded diesel engine blocks. The process and its variation, using a consumable guide tube, is used for welding thicker materials.

The Arcos Corporation introduced another vertical welding method, called Electrogas, in 1961. It utilized equipment developed for electroslag welding, but employed a flux-cored electrode wire and an externally supplied gas shield. It is an open arc process since a 
slag bath is not involved. A newer development uses self-shielding electrode wires and a variation uses solid wire but with gas shielding. These methods allow the welding of thinner materials than can be welded with the electroslag process.

Robert F. Gage invented plasma arc welding in 1957. This process uses a constricted arc or an arc through an orifice, which creates an arc plasma that has a higher temperature than the tungsten arc. It is also used for metal spraying and for cutting.

The electron beam welding process, which uses a focused beam of electrons as a heat source in a vacuum chamber, was developed in France. J.A. Stohr of the French Atomic Energy Commission made the first public disclosure of the process on November 23, 1957. In the United States, the automotive and aircraft engine industries are the major users of electron beam welding.

Friction welding, which uses rotational speed and upset pressure to provide friction heat, was developed in the Soviet Union. It is a specialized process and has applications only where a sufficient volume of similar parts is to be welded because of the initial expense for equipment and tooling. This process is called inertia welding.

Laser welding is one of the newest processes. The laser was originally developed at the Bell Telephone Laboratories as a communications device. Because of the tremendous concentration of energy in a small space, it proved to be a powerful heat source. Starting with $1965-1967 \mathrm{CO}_{2}$ lasers are developed for cutting and welding used in space programs. Various further developments of laser welding technology and equipment made it affordable for automotive metalworking operations. 
In 1991 TWI of Cambridge England developed the Friction Stir Weld (FSW) process in its laboratory. This process differs from conventional rotary technology whereby a hard, non-consurnable, cylindrical tool causes friction, plasticizing two metals into a solid-state bond. No shielding gas or filler metal is required. XASA is the first US venture which used FSW in the manufacturing process of the massive fuel tank for the Space Shuttle.

\subsection{Physics and chemistry fundamentals}

Diffusion or other forms of solid state bonding can form interfacial bonds of exceptional strength provided the interface is not contaminated or otherwise flawed. In materials such as iron, titanium or copper, which dissolve all or most of their usual surface contaminants, a nearly perfect bond can be made; but in aluminum or other metals with refractory oxides which are insoluble in the base metal the process does not work so well.

It is obvious that if one can eliminate the surface contamination one can achieve an excellent joint by using this procedure.

The free energy of any bond is related to: temperature, pressure, and chemical potential of the system:

$$
G=G\left(T, p, \mu_{i}\right)
$$

Since the most important contaminants are oxides by reducing the partial pressure of oxygen (we can use several methods: vacuum, reactive or inert gases atmosphere) and 
elevating the temperature we can reduce oxides of intermediate stability.

The common method to manipulate the third variable, the chemical potential of a species, is to provide a system (known as a flux) of low chemical potential for the surface contaminants; hence the surface film of contaminants will be absorbed into the flux.

Temperature is the major variable since, as for example in fusion welding, this solve both the chemical and geometrical problem of joining two surfaces. Melting the base metal permits the surface contaminants to float or dissolve away while the liquid metal conforms perfectly to the solid mating surface.

Temperature variation in welding is obtained by applying a local heat source. The increase of the surface temperature is a function of both surface power density of the heat source and time. On the other hand the necessary interaction time to form the weld pool is dependant on: material properties (such as thermal diffusivity), the type of heat source, and power rating of the equipment. While material properties cannot be altered and equipment power has natural limits (we do not want to cause vaporization of the weld pool) only the heat source type is possible to be undified. For a constant power, a decrease in the spot size will produce a squared increase in the thermal flux. It is also easier to make a spot smaller than to increase the power rating of the equipment.

In addition, one generally wishes to melt a small volume of material, even though this implies costly automation. If the spot is smaller, one can divide the interaction time into the heat source diameter and obtain an increased travel speed for the welding process. This implies a rapid response time. Processes such as laser or electrode beam welding must be 
automated in order to be controlled with respect to process fluctuations.

Another important welding process parameter that is related to the power density of the heat source is the width of the heat affected zone (HAZ). At low power densities $\left(10^{4}\right.$ $W / \mathrm{cm}^{2}$ ) the HAZ width is controlled by the interaction time and the thermal diffusivity of the material. In the case of high power density $\left(10^{7} \mathrm{~W} / \mathrm{cm}^{2}\right)$ the HAZ width is controlled by the cooling time necessary to remove the heat from the metal.

The heat utilization efficiency is very high for high heat intensities (nearly all of the heat is used to melt the material and little is wasted in preheating the surroundings) but when the heat intensity decreases less heat is entering the plate (50\% in arc welding, $10 \%$ in oxyacetylene).

Finally the thermal flux distribution also controls the depth-to-width ratio of the molten pool. This can vary from 0.1 in low heat intensity processes to more than $10 \mathrm{in}$ high heat intensity processes.

\subsection{Classification}

The welding processes, in their AWS groupings, and the letter designation for each process are shown in Tables 1.1 to 1.3. The letter designation assigned to the process can be used for identification on drawings, tables, etc. 


\begin{tabular}{|c|c|c|}
\hline Group & Welding Process & Letter Designation \\
\hline Arc welding & $\begin{array}{l}\text { Carbon Arc } \\
\text { Flux Cored Arc } \\
\text { Gas Metal Arc } \\
\text { Gas Tungsten Arc } \\
\text { Plasma Arc } \\
\text { Shielded Metal Arc } \\
\text { Stud Arc } \\
\text { Submerged Arc }\end{array}$ & $\begin{array}{l}\text { CAW } \\
\text { FCAW } \\
\text { GMAW } \\
\text { GTAW } \\
\text { PAW } \\
\text { SMAW } \\
\text { SW } \\
\text { SAW }\end{array}$ \\
\hline Brazing & $\begin{array}{l}\text { Diffusion Brazing } \\
\text { Dip Brazing } \\
\text { Furnace Brazing } \\
\text { Induction Brazing } \\
\text { Infrared Brazing } \\
\text { Resistance Brazing } \\
\text { Torch Brazing }\end{array}$ & $\begin{array}{l}\text { DFB } \\
\text { DB } \\
\text { FB } \\
\text { IB } \\
\text { IRB } \\
\text { RB } \\
\text { TB }\end{array}$ \\
\hline Oxyfuel Gas Welding & $\begin{array}{l}\text { Oxyacetylene Welding } \\
\text { Oxyhydrogen Welding } \\
\text { Pressure Gas Welding }\end{array}$ & $\begin{array}{l}\text { OAW } \\
\text { OHW } \\
\text { PGW }\end{array}$ \\
\hline
\end{tabular}

Table 1.1: Welding processes and letter designation I 


\begin{tabular}{|c|c|c|}
\hline Group & Welding Process & Letter Designation \\
\hline Resistance Welding & $\begin{array}{l}\text { Flash Welding } \\
\text { High Frequency Resistance } \\
\text { Percussion Welding } \\
\text { Projection Welding } \\
\text { Resistance-Seam Welding } \\
\text { Resistance-Spot Welding } \\
\text { Upset Welding }\end{array}$ & $\begin{array}{l}\text { FW } \\
\text { HFRW } \\
\text { PEW } \\
\text { RPW } \\
\text { RSEW } \\
\text { RSW } \\
\text { UW }\end{array}$ \\
\hline Solid State Welding & $\begin{array}{l}\text { Cold Welding } \\
\text { Diffusion Welding } \\
\text { Explosion Welding } \\
\text { Forge Welding } \\
\text { Friction Welding } \\
\text { Friction Stir Welding } \\
\text { Hot Pressure Welding } \\
\text { Roll Welding } \\
\text { Ultrasonic Welding }\end{array}$ & $\begin{array}{l}\text { CW } \\
\text { DFW } \\
\text { EXW } \\
\text { FOW } \\
\text { FRW } \\
\text { FSW } \\
\text { HPW } \\
\text { ROW } \\
\text { USW }\end{array}$ \\
\hline
\end{tabular}

Table 1.2: Welding processes and letter designation II 


\begin{tabular}{||l|l|l||}
\hline \hline Group & Welding Process & Letter Designation \\
\hline \hline Soldering & Dip Soldering & DS \\
& Furnace Soldering & FS \\
& Induction Soldering & IS \\
& Infrared Soldering & IRS \\
& Iron Soldering & INS \\
& Resistance Soldering & RS \\
& Torch Soldering & TS \\
& Wave Soldering & WS \\
\hline Other Welding Processes & Electron Beam & EBW \\
& Electroslag & ESW \\
& Induction & TW \\
\hline \hline
\end{tabular}

Table 1.3: Welding processes and letter designation III 


\subsection{Efficiency considerations}

In order to design and fabricate a quality welded structure, it is essential to have an adequate design, a proper selection of materials, adequate equipment and proper welding procedures, skilled workmanship, and strict quality control.

The advantages of welded structures as compared to riveted structures are listed below

- A welded joint is stronger than the material joined.

- The fused joints create a compact and rigid structure due to the continuity across the joint.

- Welded joints are better for fatigue loads, impact loads and severe vibration.

- Welding is an ideal technology to assemble structures which require water and air tightness.

- The weight of a hull structure (and therefore the static loading) can often be reduced by at least 10 to 20 per cent if welding is used.

- Welding permits the architect and structural engineer to develop and use modern and economical design principles.

- Reduction in fabrication time and cost. Less time is required on detailing, layout and 
fabrication since fewer pieces are used. Punching, drilling, reaming or countersinking are eliminated.

- Automation is also easier to achieve in the case of welding.

Despite the obvious advantages associated with welded structures there are a number of disadvantages as listed below:

- Defects such as: hot and cold cracking and porosities due to hydrogen, oxygen and nitrogen contamination may occur.

- The microstructure and hence properties of Heat Affected Zone (HAZ) are difficult to control.

- Material sensitivity plays a role as the physical properties of the metals or alloys being joined influence the efficiency and applicability of the various welding processes The thermal conductivity and the thermal expansion of the materials being welded have a direct effect on the distortion of the weldment. In the case of resistance welding, base metal resistivity, thermal conductivity and specific heat influence the power requirements. For the arc welding process, the arc initiation and stability are influenced by the ionization potentials of the metal being welded.

- Residual stress and distortion resulting from the welding process increase the cost of fabricating welded structures and may influence their performance or external appearance. 


\subsection{Phenomena during welding}

Welding is a complex processes dealing with:

- Arc physics,

- Heat transfer and fluid flow,

- Surface tension effects,

- Solidification,

- Solid-state transformations,

- Development of mechanical properties for the fusion zone (FZ) and the HAZ,

- Plastic deformation and the creation of residual stress and distortion.

An ideal weld process will have to consider each of these phenomenas in relation one with the other. The multitude of influencing parameters and their nonlinear, transient and temperature dependent effect have to be considered in order to produce an accurate weldment design.

Traditional welding procedures nave been based largely on experience, materials science, and extensive testing [2].

Engineers who were preoccupied with predicting the behavior of welded structures defined mathematical models used for preliminary calculations that relied on laboratory experiments. Development has been slow because of the inherent geometrical and process 
complexity. The explosive growth in computer performance combined with rapid development in numerical methods and geometric modelling enabled computational weld mechanics to perform such complex analysis in a cheaper way with faster and more accurate results [12]. 


\section{Chapter 2}

\section{Computational Weld Mechanics -}

\section{Literature Review}

\subsection{Definition}

Computational Weld Mechanics (CWM) is a part of computational mechanics. CWM is devoted to the study of physical phenomena in welds by using mathematical modeling in computer simulation.

CWM is an important element of computer aided design (CAD) and computer aided manufacturing (CAM). CWM can be viewed as a set of tools for determining the mechanical response of a workpiece to a given welding procedure and furthermore predicting the behavior of welded products or systems in the real world [3]. 


\subsection{History}

The failure of welded bridges in Europe in the 1930s and American Liberty ships in World War II stimulated research in welding and revealed the necessity for serious scientific studies in weld mechanics.

In USA the greatest attention was focused on research involving tests and experiments relying on metallurgical and fracture mechanics. Russia approached this research as welded structure analysis.

The strategy of computer assisted weld analysis using the numerical methods (finite difference and finite element analysis) began in the 1970s. Pioneers like Ueda, Hibbit, Marcal, Friedman, Masubuchi and Andersson performed early welding simulations [7].

With the growing computer capacity the finite element method became the main technique for the thermo-mechanical analysis of welding.

\subsection{Industrial applications}

Typically, the application of the CWM is currently only used in industrial areas where safety aspects are very important e.g., the aerospace industry and nuclear power plants, pipe transport for hazardous materials or when a large economic gain can be achieved.

The advantage in using CWM is that the cost and number of experiments will be dramatically reduced and the accuracy and significance of the data obtained for each experiment 
will be enhanced even though it will not eliminate the need for experiments that simulate or prototype processes or products [3].

CWM is very efficient in the areas were the phenomenas are sufficiently understood and on the basis of the experimentally achieved knowledge it is possible to create complete models for computer analysis.

The computation process has to be designed so that the information that flows between the stages of the welding process is continuous and complete. Three stages of design must be considered:

- Structural design - specifies the geometry and material for each of the parts to be welded, the location of each weld, the loads and service conditions that the joint must withstand.

- Weld procedure design - specifies the welding procedure for each pass in a weld joint : weld process type, consumables, current and voltage, speed, weld pool shape and size, preheat and post heat.

- Weld production design - specifies the sequence of weld joints in a structure, the start and end of each weld, the fixturing to be used.

The aim of using CWM is to predict residual stress and corresponding deformations, hot cracking, evolution of material microstructure and prediction for lifetime and performance of a component. 


\subsection{Numerical methods and modelling techniques}

The differential equations that describe the physical phenomena can only be solved analytically for a very limited class of problems and only for simple geometries. More complex tasks require numerical approaches. Among these approaches, we should mention the Finite Difference Method (FDM), the Finite Volume Method (FVM), the Finite Element Method (FEM), and the Boundary Element Method (BEM).

The finite element method (FEM) is used for solving partial differential equations (PDE) approximately. Solutions are approximated by rendering the PDE into an equivalent ordinary differential equation, which is then solved using standard techniques. The basic concept in the physical FEM is the subdivision of the mathematical model into disjoint (non-overlapping) components of simple geometry called elements. The response of each element is expressed in terms of a finite number of degrees of freedom characterized as the value of an unknown function, or functions, at a set of nodal points. The response of the mathematical model is then considered to be approximated by that of the discrete model obtained by connecting or assembling the collection of all elements.

The finite difference method (FDM) approximates differential equations by a difference approach whereas the finite element method approximates differential equations by an integral approach.

The boundary element method (BEM) has the important distinction that only the boundary of the domain of interest requires discretization. This method is usually used 
when dealing with problems involving infinite or semi-infinite domains.

The finite volume method (FVM) is a method for representing and evaluating partial differential equations as algebraic equations. FVM refers to the small volume surrounding each node point on a mesh. In the finite volume method, volume integrals in a partial differential equation that contain a divergence term are converted to surface integrals, using the divergence theorem. These terms are then evaluated as fluxes at the surfaces of each finite volume.

\subsection{Areas of modelling - FEM formulation}

During welding, the development of the weld pool is determined by the arc-metal interaction, heat flow and fluid flow, the thermophysical properties of the material, and the associated boundary conditions. Because of the complexity of the process and the presence of the arc plasma, direct experimental investigations are often impossible.

Melting and solidification as physical welding phenomena implies modeling of turbulence, multiphase flow, electromagnetic and surface tension flow, transient heat transfer, and evaporation.

By solving the mass conservation, momentum and energy equations for appropriate boundary conditions one can compute the transient temperature, velocity, and pressure in weld pools. There are several possible simplifying approximations that can be made:

- the geometry of the weld pool is assumed to be known, 
- the velocity of the liquid on the liquid-solid boundary is assumed to be zero,

- the traction is assumed to be known on the liquid surface,

- the body forces due to buoyancy and electromagnetic forces are assumed to be known,

- the viscosity is assumed to be known.

\subsubsection{Modelling material properties}

Material modelling is an important aspect in CWM. Pertinent data must represent the real material behavior with sufficient accuracy [2].

In general, material properties depends on chemical composition, microstructure, grain size, shape and orientation, and dislocation density. Therefore they are dependent on the thermal history primarily through microstructural effects such as precipitation, transformations, annealing, recovery, etc. They are dependent on plastic strain primarily through the density distribution of dislocations and vacancies [3].

Material properties which are important for CWM include: chemical composition, density, specific heat, thernal conductivity, heat capacity, latent heats, convection coefficient, radiation coefficient, fraction of solid, melting temperature, liquidus temperature, volumetric strain, elasticity and hardening modulus, yield stress. 


\subsubsection{Geometric modelling - Domain discretization}

In FEM used by CWM the solid, known as a continuum or a spatial domain, is divided into an assembly of finite elements. This assembly is called a mesh. The elements are assumed to be interconnected at a discrete number of points called nodes situated on their boundaries, no elements intersect and the union of the elements is the solid.

If we consider our domain denoted with $\Omega$ and the mesh has $m$ elements $e_{1}, e_{2}, \ldots, e_{m}$ the mathematical formulation for element properties is:

$$
\begin{aligned}
& e_{1} \cup e_{2} \cup \ldots \cup e_{m}=\Omega \\
& e_{1} \cap e_{2} \cap \ldots \cap e_{m}=\emptyset
\end{aligned}
$$

The mesh design is based on engineering judgement and is related to the element properties. The advantage of the discretization is that the analysis needs only to be applied to the individual elements of certain simple geometry rather than the entire solid of complex geometry.

Each element has associated an element type, which is characterized by:

- a set of nodes, typically located at vertices, midedges and similar locations;

- a set of specific interpolation functions. These functions are usually polynomial in order to be easy to integrate and differentiate and are used to approximate the field parameter within the element with respect of the values at the element nodes,

- a reference element - for ease of integration. 
The basis functions are denoted as a $1 \times n$ matrix (a row vector) where $n$ is the number of respective element nodes.

$$
\mathbf{R}(r, s, t)=\left(N_{1}(r, s, t), \quad N_{2}(r, s, t), \quad \ldots \quad, N_{n}(r, s, t)\right)
$$

where $N_{i}(x, y, z)$ are the basis functions dependent only on the type of element and its geometry.

The physical quantities to be determined in the element, e.g., temperature, can be obtained from the values at the nodes through certain basis, shape or interpolation functions as described by the following equation:

$$
T(x, y, z, \text { time })=\sum_{i=1}^{n o d e s} N_{i}(x, y, z) \bar{T}_{i}(\text { time })
$$

The time dependence is included in the nodal values of the temperature as $\bar{T}_{i}($ time) .

For isoparametric elements the same basis functions are used to map the reference element to the physical element:

$$
x(r, s, t)=\sum_{i=1}^{\text {nodes }} N_{i}(x, y, z) \bar{x}_{i}
$$

or in matrix form:

$$
x(r, s, t)=\mathbf{R}(r, s, t) \overline{\mathbf{X}}_{\mathbf{i}}
$$

where $\overline{\mathbf{X}}_{\mathbf{i}}$ is the column matrix of the nodes $x$ coordinate. 
The need to map partial derivatives from one coordinate system to another introduces the Jacobian as

$$
J=\left(\begin{array}{ccc}
x_{, r} & x_{, s} & x_{, t} \\
y_{, r} & y_{, s} & y_{, t} \\
z_{, r} & z_{, s} & z_{, t}
\end{array}\right)
$$

The gradient of the physical quantity can be mapped easily through the gradient of the basis functions matrix :

$$
\mathbf{R}_{x y z}=\left(\begin{array}{l}
\mathbf{R}_{, x} \\
\mathbf{R}_{, y} \\
\mathbf{R}_{, z}
\end{array}\right)=J^{-T}\left(\begin{array}{l}
\mathbf{R}_{, r} \\
\mathbf{R}_{, s} \\
\mathbf{R}_{, t}
\end{array}\right)=J^{-T} \nabla \mathbf{R}_{r s t} .
$$

\subsubsection{Heat source-metal interaction}

Heat source-metal interaction affects heat and mass transfer, fluid flow, and consequently, the structure and properties of the weld pool.

The principal phenomena that take place at and above the weld pool surface:

- transmission of power through the medium containing plasma, metal vapors, and solid and liquid particles,

- intense vaporization,

- deformation of the free weld pool surface,

- dissolution of nitrogen, oxygen and hydrogen. 


\section{Heat Source Models}

An efficient leat source model should accurately predict the temperature field in the weldment.

Real heat sources produce high heat fluxes which range from $10^{4}$ to $2 \times 10^{4} \mathrm{~J} / \mathrm{mm}^{2}$ for arc sources to $10^{8} \mathrm{~J} / \mathrm{mm}^{2}$ for focused electron and laser beams. Experimental measures suggest a Gaussian distribution for the heat flux [7].

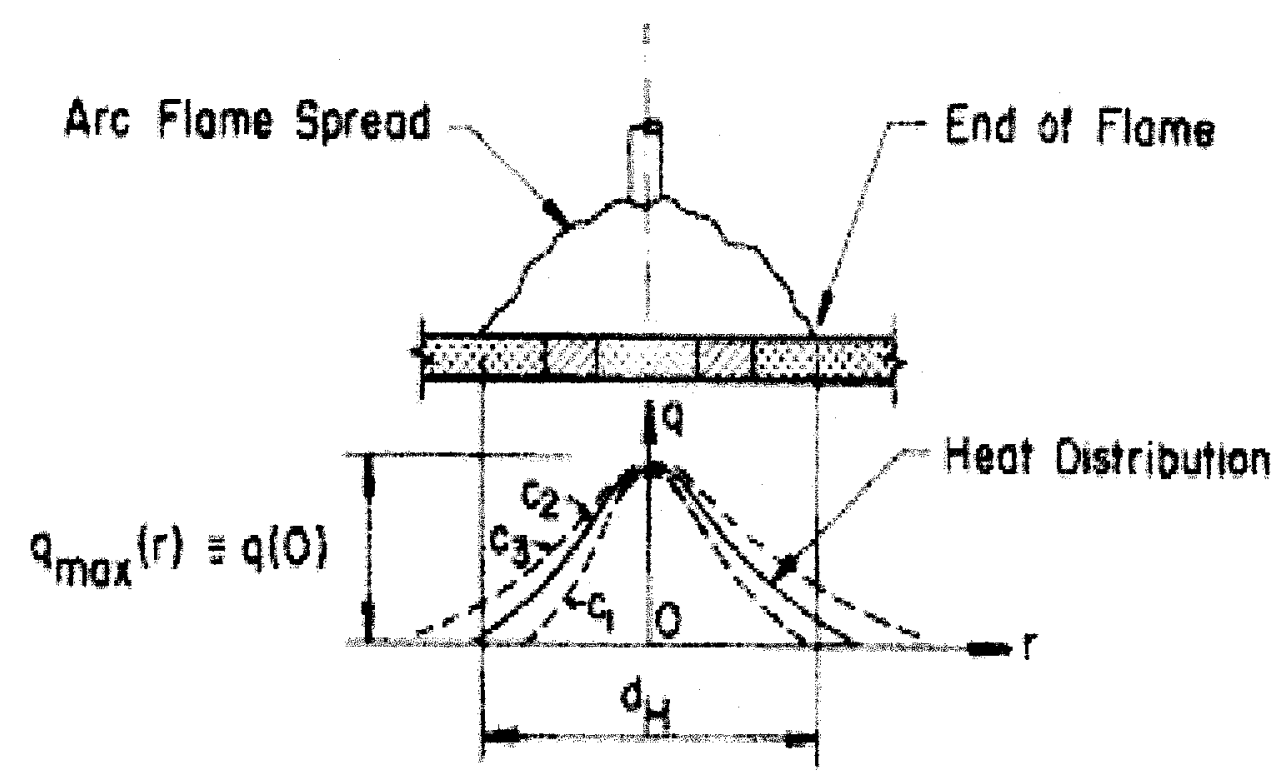

Figure 2.1: Gaussian flux distribution [7].

Gas velocities and current densities in the plasma are high. The surface of the weld pool is depressed (it can be seen that in plasma, laser and electron beam welds the depression often penetrates the plate to form a keyhole). The molten zone is stirred intensively.

The latest attempts to model plasma physics, stirring and mixing effects, or depression 
on the weld pool surface and its effects on heat transfer [7] are important steps forward but a rigorous model has to solve both the magneto-hydrodynamies of the are and the fluid mechanics of the molten zone.

Most current weld analysis assume simpler models that do not explicitly incorporate stirring in the weld pool or digging of the arc to depress the weld pool surface.

\section{Point, line and plane heat source models}

Rosenthal and Rykalin [5] proposed point, line, and plane models for the heat source. For example,

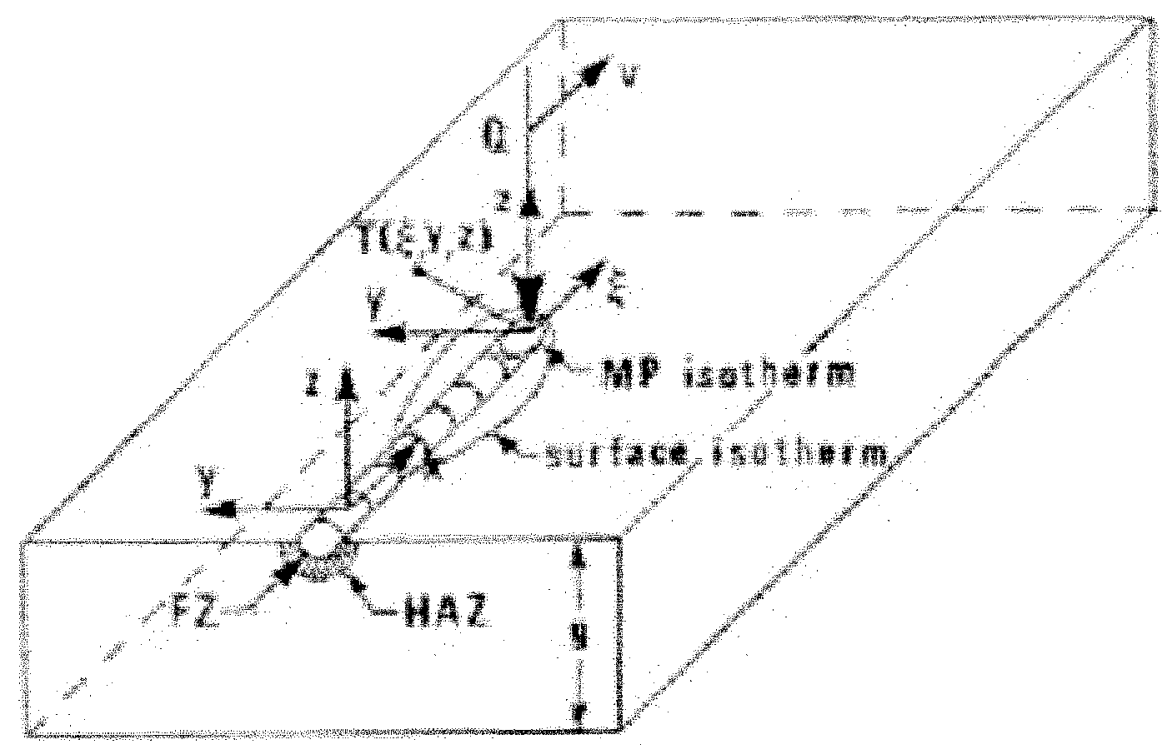

Figure 2.2: Classical Rosenthall/Ryalkin heat source [7]. 
where:

$$
T\{\xi, y, z\}=T_{0}+\frac{\dot{Q}}{2 \pi k} \exp \left(\frac{-V \xi}{2 \lambda}\right)\left\{\sum_{n=-\infty}^{\infty} \frac{1}{R_{n}} \exp \left(\frac{-V R_{n}}{2 \lambda}\right)\right\}
$$

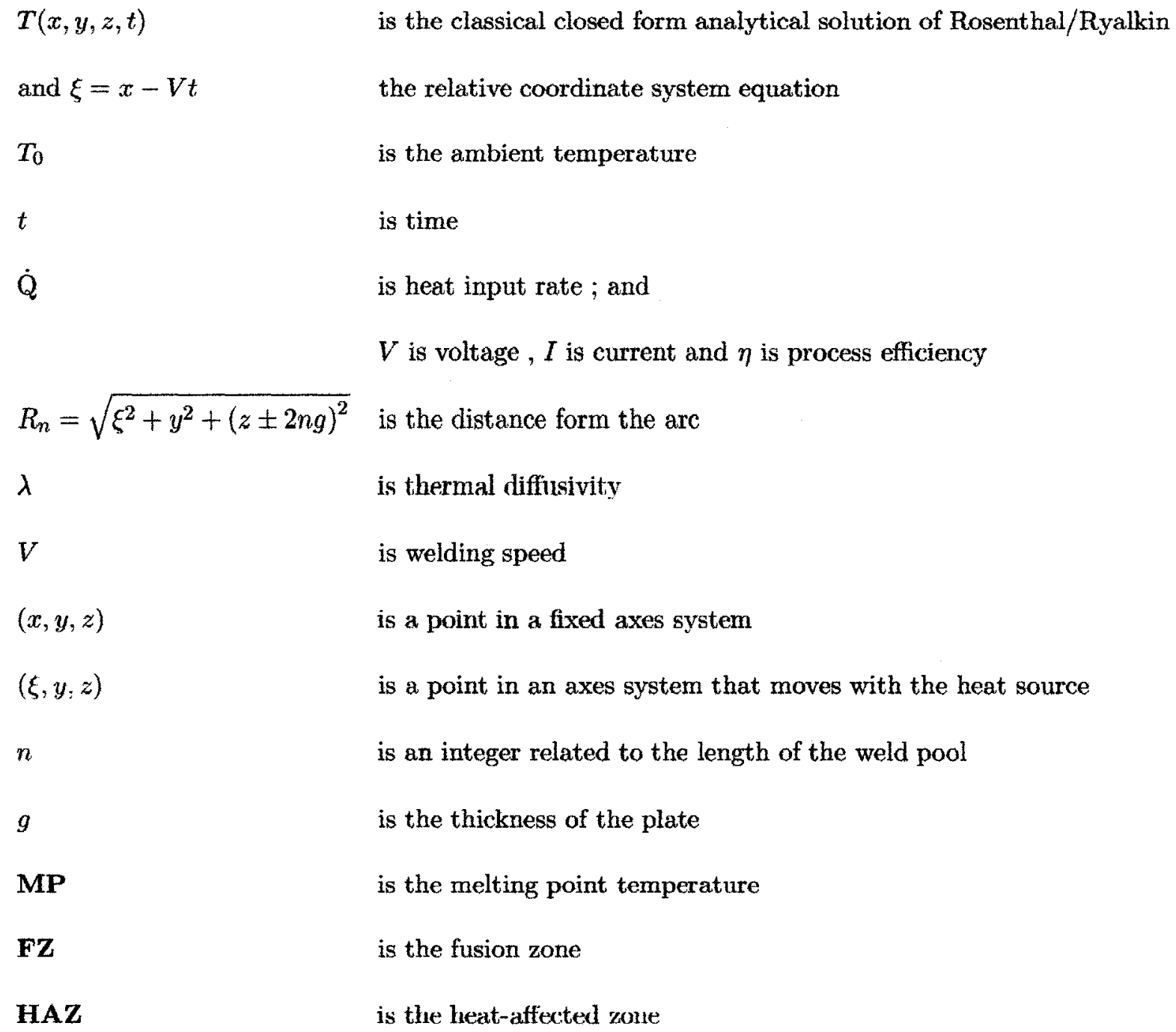

HAZ

is the heat-affected zone 
The weaknesses of these models include:

- a source geometry which is highly idealized to intinite plates or bars,

- the model idealizes a physically distributed heat source as a point, line or a plane,

- at the source, the error in the temperature is infinite.

\section{Disc heat source models}

Pavelic proposed a circular disc model with Gaussian flux distribution on the surface of the workpiece as shown in Figure 2.3. The main weakness of Pavelic's model is that it ignores the effect of digging of the welding arc in distributing the energy [7].

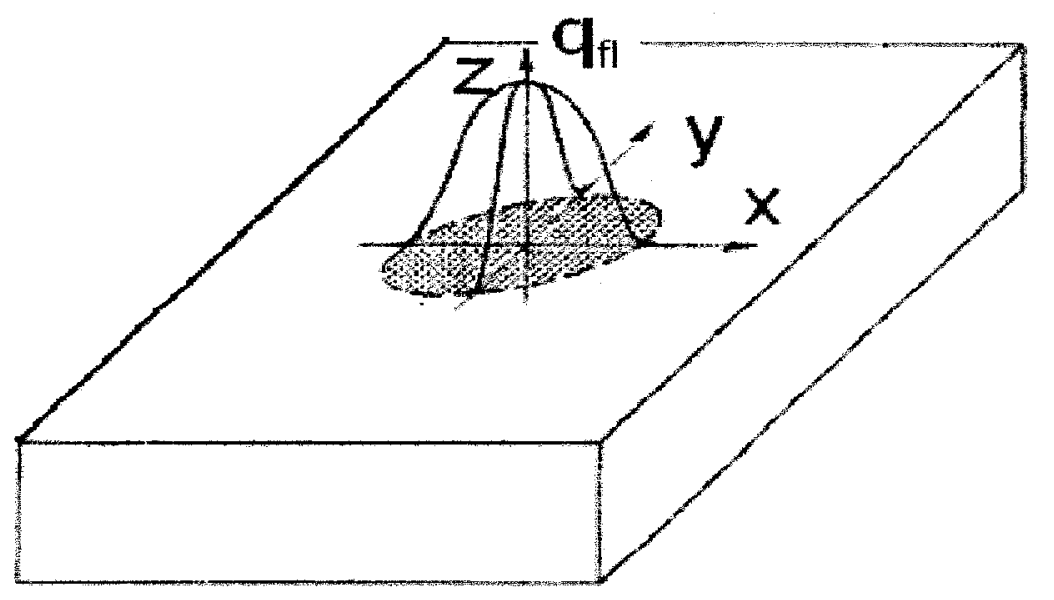

Figure 2.3: Disc source model [7]. 
In Pavelic's model the thermal flux has a Gaussian distribution in $z$ plane,

$$
q(r)=q(0) e^{-C r^{2}}
$$

where:

$q(r)$ is surface flux at radius $r\left(W / m^{2}\right)$

$q(0)$ is peak flux $\left(W / m^{2}\right)$

$C \quad$ is concentration coefficient $\left(m^{2}\right)$

$r \quad$ is radial distance from the center of the heat source projection $(m)$

The coefficient $C$ is related to the source width by the formula $d=2 / \sqrt{C}$ where $d$ is the diameter of the heat flux distribution on the plate.

Friedman and Kurtz and Segerlind [7] proposed an alternative from the disc model which take into consideration the welding speed.

$$
q(r, \xi)=\frac{3 Q}{\pi C} e^{-3 x^{2} / c^{2}} e^{-3 \xi^{2} / c^{2}}
$$

where: 
$Q \quad$ is the energy input rate $(W) ; Q=\eta V I$ and

$V$ is voltage,

$I$ is current, and

$\eta$ is process efficiency

$c \quad$ is the rharacteristic radius of flux distribution $(m)$

$(x, \xi)$ is the moving coordinate system

If one want to express this equation in a fixed coordinate system $(x, y, t)$, and considering movement along $y$ axis, one have to apply the transformation between the two coordinates systems:

$$
\xi=y+v(\tau-t)
$$

where

$v$ is the traveling speed $(\mathrm{m} / \mathrm{s})$,

$\tau$ is time $(s)$,

$t \quad$ is initial time $(s)$.

The equation becomes:

$$
q(r, \xi)=\frac{3 Q}{\pi C} e^{-3 x^{2} / c^{2}} e^{-3[y+v(\tau-t)]^{2} / c^{2}}
$$

The weaknesses of the model include: 
- it does not permit the analysis of transients during weld start, stop, run-on and run-off situations, where the size and shape of the melting pool must change,

- it is only suitable for a small effective depth of penetration.

\section{Hemispherical power density model}

A step forward to a more realistic model introduced the Gaussian distribution of the power density in the volume of the material [7].

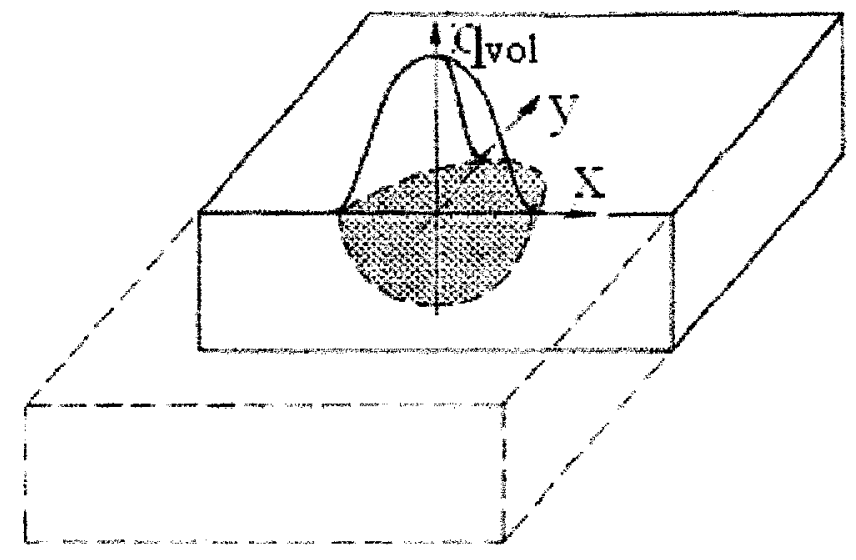

Figure 2.4: Hemispherical power density distribution $[7]$.

The governing equation is:

$$
q(r, \xi, z)=\frac{6 \sqrt{3} Q}{\pi \sqrt{\pi} c^{3}} e^{-3 x^{2} / c^{2}} e^{-3 \xi^{2} / c^{2}} e^{-3 z^{2} / c^{2}}
$$

where: $q(r, \xi, z)$ is the power density $\left(W / m^{2}\right)$ expressed for a moving coordinate system. 
In practical analysis the temperature can be set to a maximum at the center of the weldpool/arc interface and decay to the melting temperature at the $\mathrm{FZ} / \mathrm{HAZ}$ interface.

The main limitation of the model is that in many welds the molten pool is far from hemispherical.

\section{Ellipsoidal power density distribution model}

This model is a development of the hemispherical model with the difference that the Gaussian distribution of the power density is this time an ellipsoid [7].

Considering again a welding along the $y$ axis the model is described by the equation:

$$
q(r, \xi, z)=q(0) e^{A x^{2}} e^{-B \xi^{2}} e^{-C z^{2}}
$$

where $q(0)$ is the maximum value of the power intensity at the center of the ellipsoid and can be calculated from the equation of conservation of energy:

$$
2 Q=\int_{0}^{x} \int_{0}^{\xi} \int_{0}^{z} q(0) e^{A x^{2}} e^{-B \xi^{2}} e^{-C z^{2}} d x d \xi d z
$$

where:

$Q \quad$ is the energy input rate $q=\eta V I$; and $V$ is voltage, $I$ is current and $\eta$ is process efficiency,

$A, B, C$ are constants depending on the ellipsoid dimensions.

Evaluating equation 2.11 produces: 


$$
2 Q=\frac{q(0) \pi \sqrt{\pi}}{\sqrt{A B C}} \text { or } q(0)=\frac{2 Q \sqrt{A B C}}{\pi \sqrt{\pi}}
$$

To evaluate the constants we consider that the semi axes of the ellipsoid are $a, b, c$ in the direction of the $x, y, z$ axes respectively and are evaluated such that the power density falls to $5 \%$ at the surface of the ellipsoid. This gives

$$
q(a, 0,0)=q(0) e^{A a^{2}}=0.05 q(0) \Rightarrow>A=\frac{\ln 20}{a^{2}} \approx \frac{3}{a^{2}}
$$

Similarly $B \approx \frac{3}{b^{2}}$ and $C \approx \frac{3}{c^{2}}$.

Substituting $A, B, C$ and $q(0)$ back into equation 2.8 we will obtain

$$
q(r, \xi, z)=\frac{6 \sqrt{3} Q}{a b c \pi \sqrt{\pi}} e^{-3 x^{2} / a^{2}} e^{-3 \xi^{2} / b^{2}} e^{-3 z^{2} / c^{2}}
$$

which in a fixed coordinate system will be

$$
q(r, \xi, z)=\frac{6 \sqrt{3} Q}{a b c \pi \sqrt{\pi}} e^{-3[y+v(\tau-t)]^{2} / a^{2}} e^{-3 \xi^{2} / b^{2}} e^{-3 z^{2} / c^{2}}
$$

This model does not permit the analysis of transients during weld start, stop, run-on and rum-off situations, where the size and shape of the melting pool must change.

\section{Double ellipsoid heat source models}

Goldak et. al. [6] propased the most popular model to date. This model consists of a double ellipsoid disc with a Gaussian distribution of flux on the surface of the weld, together with a double ellipsoid function with a Gaussian distribution of power density (that models 
the direct impingement of the arc) and a second double ellipsoid with Gaussian distribution for energy distribution (that models the stirring of the molten metal)

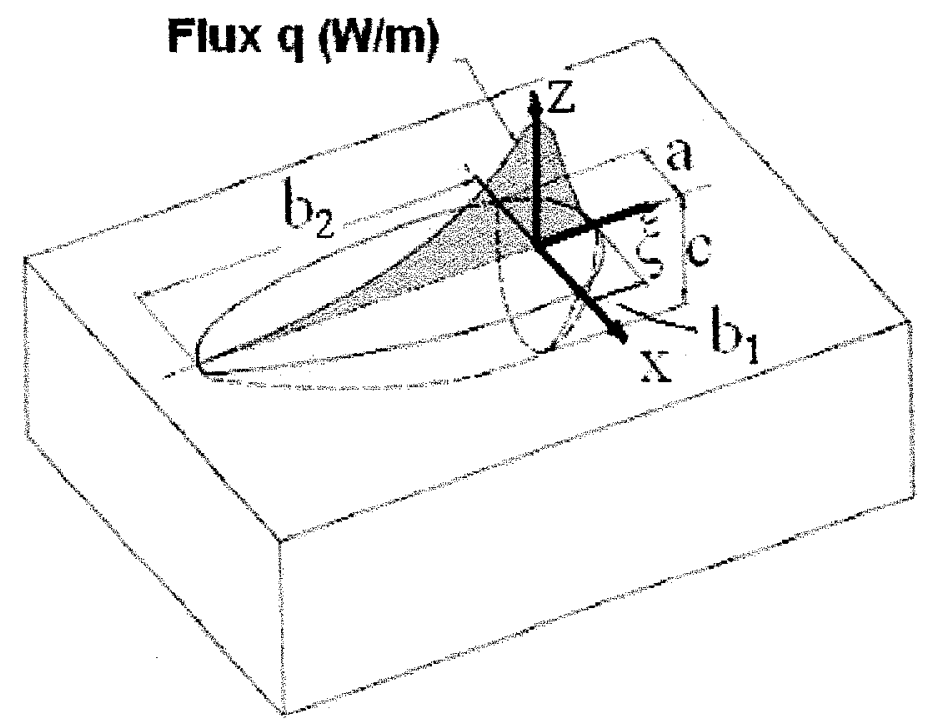

Figure 2.5: Double ellipsoid heat source model [6].

Based on calculation experience with the ellipsoidal heat source the authors revealed that between the temperature gradient in front and at the trailing edge of the heat source are differences. They proposed a combination of two ellipsoidal sources, one for the front as a quadrant of one ellipsoid and another one for the rear as a quadrant of another ellipsoid. The fractions of the heat deposited in front $f_{f}$ and that for the rear $f_{r}$ are connected by the relation $f_{f}+f_{r}=2$.

The power distribution inside the front quadrant becomes: 


$$
q(r, \xi, z)=\frac{6 \sqrt{3} f_{f} Q}{a b c \pi \sqrt{\pi}} e^{-3[y+v(\tau-t)]^{2} / a^{2}} e^{-3 \xi^{2} / b^{2}} e^{-3 z^{2} / c^{2}}
$$

and for the rear quadrant similarly:

$$
q(r, \xi, z)=\frac{6 \sqrt{3} f_{r} Q}{a b c \pi \sqrt{\pi}} e^{-3[y+v(\tau-t)]^{2} / a^{2}} e^{-3 \xi^{2} / b^{2}} e^{-3 z^{2} / c^{2}}
$$

The advantages of the model include:

- the most accurate model to date for high power arc welds,

- it is connected with the real process by the process parameters such as: weld current, voltage, welding speed, arc efficiency, and dimensional pararneters such as the size and position of the discs and ellipsoids (experimental determined from cross-sectional metallographic data and from surface ripple marking).

\section{Connected phenomena models}

Prediction on the weld shape depends on the coupling the arc and the free surface of the weld pool. Experiments and theoretical works have tried to understand heat sourcemetal interaction phenomena but at this time no straightforward, simple models have been developed. Results indicate that the deformation of the free surface geometry depends on welding process and welding material, but cannot explain why the surface is pulsating in nature.

Even though it is possible to calculate vaporization rates in some specific conditions, the role of plasma is not well understood on alloying element vaporization rate. 


\subsubsection{Heat and fluid flow}

Studies $[4,5]$ show that the principal mechanisms of the heat transfer in the weld pools are: convection (heat is transported by motion of the liquid not by diffusivity), buoyancy, electromagnetism, Maragoni effect and arc pressure.

Therefore it is important to study not only the weld pool but weld pool and arc as a single coupled problem.

The heat flow models are usually limited to the uncoupled conservation of energy equation, due to the difficulties in obtaining experimental data for the following:

- pressure velocity from the arc,

- the surface tension as a function of composition and temperature,

- viscosity, density and vapor pressure of the liquid metal in the weld pool.

\section{Thermal Analysis - FEM theory and implementation}

The conservation of energy equation:

$$
\dot{h}+\nabla \cdot q+Q=0
$$


where:

$\dot{h}$ is the time rate of specific enthalpy,

$q$ is the therrnal flux,

$Q$ is the density of heat generation.

The specific enthalpy derivative with respect of time has the following form:

$$
\dot{h}=c_{p} \frac{\partial T}{\partial t}+L \cdot \dot{f} s
$$

where:

$c_{p}$ is the specific heat,

$L \quad$ is the latent heat,

$f^{s}$ is the rate of change of solid fraction.

Considering the thermal flux now, we are going to approach the heat transfer theory. In studies of heat transfer three distinct modes of heat transfer are considered: conduction, convection and radiation. The temperature distribution in a medium is controlled by the combined effects of these three modes of heat transfer. In the welding processes the concentrated heat input generated by the welding source propagates rapidly through the workpiece components by conduction. Radiation and convection play an important role in heat losses in and near the welding arc and at the surface of the components. 


\section{A. Law of Heat Conduction}

Conduction is the mode of heat transfer in which energy flows from a region of high temperature to a region of low temperature by the kinetic motion or direct impact of molecules with no mass flow. In a solid that is a good electrical conductor, a large number of free electrons move about the lattice. Electrons are also carriers of heat and therefore materials that are good electric conductors are generally good thermal heat conductors.

Fourier's law of heat conduction, based on experimental observations, states that the heat flow density or flux $q\left[J / \mathrm{m}^{2} s\right]$ is proportional to the temperature gradient $\nabla T[\mathrm{~K} / \mathrm{m}]$ through the coefficient of thermal conductivity $k_{t}[J / m s K]$ :

$$
q_{c o n d}=-k_{t} \nabla T
$$

where:

- the temperature gradient is a vector normal to the isothermal surface,

- the heat flux vector $q(r, t)$ represents the heat flow per unit time, per unit area of the isothermal surface in the direction of decreasing temperature,

- the thermal conductivity of an isotropic material can be represented by a positive, scalar quantity times the $3 \times 3$ identity matrix. Since the heat flux vector points in the direction of decreasing temperature, the minus sign is included in the equation to refiect that the heat flows down the temperature gradient.

Thermal conductivity is an important property, which controls the heat flow in the 
medium and it depends on the chemical composition, the microstructural state and the temperature of the material.

\section{B. Convection boundary conditions}

Convection is the mode of heat transfer described by the following mechanism: a fluid which flows over a solid body or inside a channel while the temperatures of the fluid and the solid surface are different, transfers heat between the fluid and the solid surface as a consequence of the motion of fluid relative to the surface. As the temperature in the fluid is influenced by the fluid motion, heat transfer by convection is a complicated phenomenon.

In engineering applications, to simplify heat transfer calculations the heat flux is considered proportional to the difference between the surface temperature $T$ and the mean temperature $T_{\infty}$ of the fluid flowing outside the thermal boundary layer, usually ambient temperature :

$$
q_{c o n v}=h_{c o n v}\left(T-T_{\infty}\right)
$$

where the coefficient of convective heat transfer $h_{\text {con } v}$ is the conductance of the thermal boundary layer and depends on the flow conditions on the surface, on the surface properties and on the properties of the flowing medium. 


\section{Radiation boundary conditions}

The Stefan-Boltzmann's law for heat transfer through radiation states that the heat flux $q_{r a d}$ radiated per unit area and time from a heated body is proportional to the fourth power of the surface temperature $T$ through $\sigma^{1}$ the radiation coefficient:

$$
q_{r a d} \propto C_{\sigma} T^{4}
$$

where the radiation coefficient $C_{\sigma}=5.67 e^{-14}\left[J / \mathrm{mm}^{2} \mathrm{~K}^{4}\right]$ applies to an "absolutely black body". A grey body is characterized by the blackness degree $\varepsilon<1.0$.

For the case of a relatively small body in extensive surroundings (encountered in welding technology), heat dissipation occurs by means of radiation according to the equation:

$$
q_{r a d}=\varepsilon C_{\sigma}\left(T^{4}-T_{0}^{4}\right)
$$

where $T_{0}$ is the temperature radiating back to the body.

Next we will apply the Finite Element Method.

We will choose an isoparametric mapping thus the basis functions which map the element from $(x, y, z)$ coordinates system into the reference element in $(r, s, t)$ coordinate system are the same as the basis functions as for determining the physical quantities.

\footnotetext{
${ }^{1}$ We will denote Boltzmann's constant with $C_{\kappa}$ for avoiding later confusions with stress
} 


$$
\dot{h}+\nabla \cdot\left(-k_{t} \nabla T\right)+Q=0
$$

By applying Galerkin's Method the equation can be solved numerically for an approximate solution ${ }^{2}$.

$$
\dot{h}+\nabla \cdot\left(-k_{t} \nabla T_{h}\right)+Q=\varepsilon \neq 0
$$

where $T_{h}$ is the approximate solution.

For evaluating in a neighborhood of a point:

$$
\int_{\Omega} R^{T}\left(\nabla \cdot\left(-k_{t} \nabla T\right)+Q\right) d \Omega=0
$$

By applying Green's second identity and the divergence theorem equation 2.24 become:

$$
\int_{\Omega} \nabla R^{T} k_{t} \nabla R T d \Omega-\oint_{\Gamma} \nabla R^{T} n_{\Gamma} \cdot\left(-k_{t} \nabla T\right) d \Gamma+\int_{\Omega} R^{T} Q d \Omega=0
$$

These integrals are usually evaluated using Gauss-Legendre numerical integration :

\footnotetext{
${ }^{2}$ For the ease of demonstration we will not consider here time integration
} 


$$
\left(\int_{r} \int_{s} \nabla R^{T} k_{t} \nabla R \operatorname{det} J d r d s d t\right) \mathbf{T}=\oint_{\Gamma} \nabla R^{T} n_{\Gamma} \cdot\left(-k_{t} \nabla T\right) d \Gamma-\int_{r} \int_{s} \int_{t} R^{T} Q \operatorname{det} J d r d s d(2.26)
$$

where:

$\left.\int_{r} \int_{s} \int_{t} \nabla R^{T} k_{t} \nabla R \operatorname{det} J d r d s d t\right)$ is the "stiffness" matrix, $n_{\Gamma}$ is the outward normal on the surface

so $\oint_{\Gamma} \nabla R^{T} n_{\Gamma} \cdot\left(-k_{t} \nabla T\right) d \Gamma$ being the heat loss vector due to flux boundary conditions, and $\int_{r} \int_{s} \int_{t} R^{T} Q \operatorname{det} J d r d s d t$ is the heat gain due to internal generation.

\subsubsection{Displacement, Strain and Stress}

For sufficiently small strains materials behave elastically. There are three theories of elastic behavior: elasticity, hyperelasticity and hypoelesticity.

- Elasticity is the fundamental assumption that a natural state exists (thermodynamic equilibrium). A body cut in tiny cubes which are separated (the stress and strain in each cube should be zero) when reassembled will have the original stress and strain values, no matter how the cubes were chosen or the order in which they are assembled,

- Hyperelasticity - the fundamental assumption is reversible thermodynamics or that the elastic strain energy is an analytic function of strain and temperature,

- Hypoelasticity or Rate Theory - stress and strain at any particular moment in time may are considered dependent on the history. 
Simple experiments show that the displacement and strain varies with time when a load is applied or after the load is removed. This is described by visco-elastic or visco-plastic models.

Further more the models behave elastically until a critical load. If we do not consider the time dependence explicitly this lead to the plasticity models. By introducing the time constant as part of a numerical technique we can develop a viscoplastic model.

Temperature in welding steel varies from 3000 Celsius degrees to ambient temperature (that can be -50 Celsius degree in special conditions). Thus the models for stress analysis may require different approaches to capture the physics in each different temperature range.

For temperatures less than $50 \%$ of the melting point, rate independent models should be used. In this the elasticity tensor, yield strength and hardening modulus characterize the solid.

Between $50 \%$ - $80 \%$ of the melting point, rate dependent models are appropriate once the thermally activated flow of dislocations is the dominant mechanism at low strain rates and high temperatures. In this case, the elasticity tensor, viscosity and deformation resistance describe the solid behavior.

For temperatures above $80 \%$ of the melting point, a linear viscous plasticity model can be considered. The diffusion of dislocations in the solid and momentum in the liquid are the driving forces [9].

The quasi-static thermal stress analysis computes the stress strain and displacement fields by solving four equations: 
- conservation of momentum

$$
\nabla \sigma+b=0
$$

- conservation of mass

$$
\dot{\rho}+\rho \nabla \cdot v=0
$$

- constitutive equations

$$
\sigma=D\left(\varepsilon^{t o t}-\varepsilon\right)
$$

- strain - displacement compatibility

$$
\varepsilon=\frac{1}{2}\left(\nabla u+\nabla u^{T}\right)
$$

where:

$\sigma \quad$ is the stress,

$b$ is the sum of body forces,

$D$ is the material property tensor,

$\rho \quad$ is density,

$\dot{\rho} \quad$ is the rate of change of density of a material point,

$\varepsilon^{t o t}$ is total strain, elastic and non elastic,

$\varepsilon \quad$ is the infinitesimal elastic strain,

$u \quad$ is the displacement.

By combining the eq. $(2.28)$ and (2.29) yields: 


$$
\sigma=D \varepsilon=D B u_{i}
$$

where the new introduced $B$ is a strain-to-displacement mapping matrix and it has the following form for $2 \mathrm{D}$ and $3 \mathrm{D}$ analyses:

$$
\begin{aligned}
& \text { in 2D analysis in 3D analysis } \\
& \mathbf{B}=\left(\begin{array}{cc}
\mathbf{R}_{, x} & 0 \\
0 & \mathbf{R}_{, y} \\
\mathbf{R}_{, y} & \mathbf{R}_{, x}
\end{array}\right) \quad \mathbf{B}=\left(\begin{array}{ccc}
\mathbf{R}_{, x} & 0 & 0 \\
0 & \mathbf{R}_{, y} & 0 \\
0 & 0 & \mathbf{R}_{, z} \\
\mathbf{R}_{, y} & \mathbf{R}_{, x} & 0 \\
0 & \mathbf{R}_{r, z} & \mathbf{R}_{, x} \\
\mathbf{R}_{, z} & 0 & \mathbf{R}_{, y}
\end{array}\right)
\end{aligned}
$$

The FEM formulation for the stress problem becomes:

$$
\int_{\Omega} B^{T} D B u_{i} d \Omega=\int_{\Omega} R^{T} b d \Omega+\oint_{\partial \Omega} R^{T}(\sigma \cdot n) d \Gamma
$$

Denoting $B^{T} D B=K$ as the stiffness matrix we reach the standard FEM formulation:

$$
K \bar{u}=\bar{b}
$$

where :

$-\bar{u}$ is the nodal displacement vector and,

$-\bar{b}$ is the sum of the boundary vector and the load vector.

49 
Furthermore if the rigid body model is constrained (i.e., there are prescribed sufficient boundary conditions for displacements) then the $K$ matrix is not singular and then a unique solution can be obtained.

\subsubsection{Weld solidification microstructure and phase transformation}

The solidification microstructures associated with welding result from a number of fundamental material behaviours including:

- heterogenous nucleation of grains in the bulk of the liquid,

- epitaxial growth of columnar grains from the mushy zone,

- the growth selection process and growth kinetics,

- preferential growth directions of dendrites,

- microsegregation,

- diffusion of solute elements in the liquid and solid phases,

- capillarity and attachment kinetics,

All of these have to be connected with the thermal history of the weldment.

Microstructure modeling in weldments is based on calculations combining thermodynamic data with kinetic theory. 
From the point of view of phase transformation theory the domain is divided into two representative distinct zones:

- the fusion zone (FZ),

- the heat affected zone (HAZ).

The development of microstructure in FZ is can be modelled as a function of alloy chemistry, entrappement of the non-metallic particles during solidification, and joint design.

In the HAZ there are made assumptions that equilibrium transformation temperatures during heating actually represent true transformation temperatures with no kinetic effects.

\subsubsection{The coupled problem}

CWM involves analysis of the evolution of temperature, stress and strain at the macroscopic level in welded structures together with the evolution of microstructure at the microscopic level. Volumetric strains due to thermal expansion and phase transformations are a dominate load in the stress analysis. The microstructure evolution influences the constitutive equations. In particular, as the temperature changes from above the melting point to room temperature, the stress-strain relationship changes from linear viscous, to viscoplastic to rate independent plasticity. In high strength steels, transformation plasticity has a major affect in reducing the longitudinal residual stress in welds.

Figure 2.6 describes the nature of the thermal-mechanical-microstructural coupling of phenomena in the welding process. 


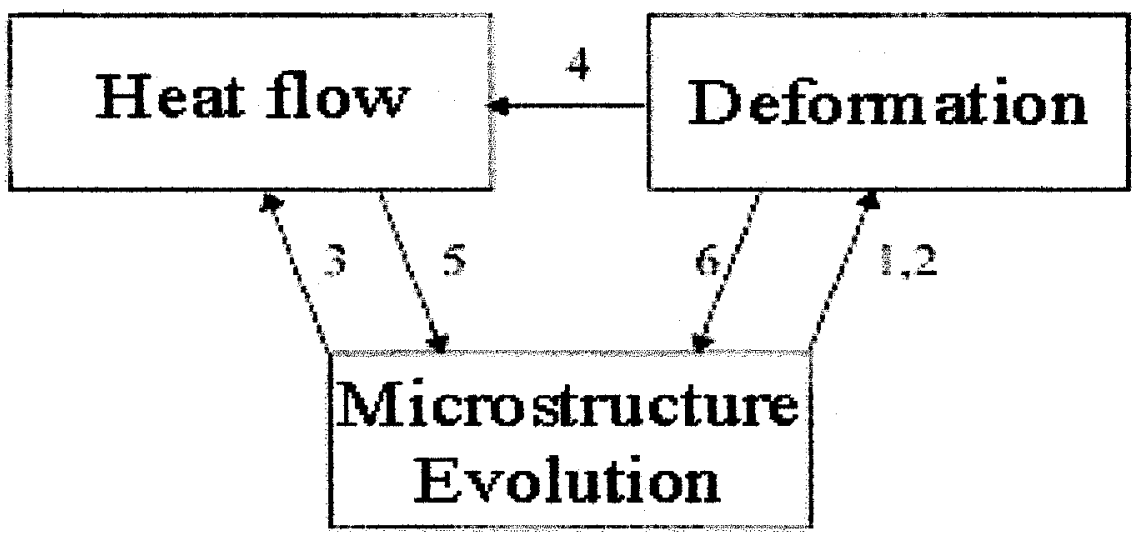

Figure 2.6: Phenomena occuring during welding [3].

In 1, thermal expansion depends on the microstructure of material.

In addition volume changes occur due to phase changes.

In 2, elastic and plastic material behavior depends on the microstructure of material.

In 3 , both thermal conductivity and heat capacity depend on microstructure of material and latent heats result from phase changes.

In 4, deformation changes the thermal boundary conditions, heat evolves from elastic strain, thermal strain and plastic dissipation (plastic strain rate).

In 5, microstructure evolution depends on temperature.

In 6, microstructure evolution depends on deformation. 


\subsubsection{Time discretization and integration}

The use of two point integration in the time domain implies linear interpolation in time. The time step length is the one variable which determines the error amplitude [3].

The prescribed thermal loads, fluxes, and power densities are converted to an equivalent nodal thermal load specified at the beginning of each time step and another at the end of each time step. These are linearly interpolated to a $\theta$ point. There are several integration schemes depending on the choice of $\theta$ :

- $\operatorname{explicit}(\theta=0)$,

- Crank-Nicholson $(\theta=0.5)$,

- Galerkin $(\theta=2 / 3)$,

- implicit $(\theta=1.0)$.

Studies [3] show that the integration scheme to be chosen depends on the element size and loads characteristics. 


\section{Chapter 3}

\section{Butt-Welded Pipe - A Case Study}




\subsection{Introduction}

During welding operations, the heating action of the heat source; e.g. flame, arc, laser or electron beam, causes thermal expansion of the weld and microstructural modifications of the fusion and heat-affected zones and may affect the rest of the plate [11]. Depending on the welding process parameters, the resulting stresses can cause undesired phenomena such as cracking, dimensional changes, fragility or geometric nonconformance. Since the surrounding cold metal and any jigs-fixtures provide a considerable amount of constraint, plastic deformation usually occurs in the vicinity of the weld and beyond it [10]. The residual stress field which is produced varies strongly with spacial position in the weldment [1].

The generation of residual stress in welded structures is a cause of concern because of influence on the mechanical behavior of the joint and the fatigue properties. The resulting permanent distortion can exceed the design specifications resulting in nonconforming welded parts with immediate influence on the associated costs, since the welding is often a long way down the manufacturing stream.

The aim of this chapter is to compare experimental measurements and numerical predicted results for residual stresses and diametrical deflection in a butt-welded pipe. Three different methods are discussed:

- Experimental welding for a butt-welded pipe. This experiment was conducted by M. Jonsson and B.L. Josefson at the Division of Solid Mechanics laboratories, De- 
partment of Applied Physics and Mechanical Engineering, Luleo University of Technology, Sweden [13].

- Finite Element Analysis using shell elements. This numerical analysis was performed by Mats O. Nasstrom at the Division of Computer Aided Design Laboratories, Department of Applied Physics and Mechanical Engineering, Luleo University of Technology, Sweden [14].

- 3D FEM method computer simulation using brick elements performed by the author in the MMO Laboratory, Mechanical and Aerospace Department, Carleton University, Ottawa, Canada. 


\subsection{Experiment and Simulations}

\subsubsection{Butt-welded pipe experiment [13]}

The experiment was conducted by M. Jonsson and B.L. Josefson at the Division of Solid Mechanics laboratories, Department of Applied Physics and Mechanical Engineering, Luleo University of Technology, Sweden [13].

\section{Experiment Description}

A single pass butt-welded pipe is studied. Dimensions and geometry are shown in Figure 3.1 and Table 3.1 .

The experiment was performed on one single pipe in which the groove was made by turning. This course of action was chosen instead of welding two pipe parts together in order to eliminate the risk of mismatch and to avoid the use of tack-welds. The pipe was stress-relieved annealed prior to the welding operation. The aim of this work was to acquire experimental data during the welding and the cooling phases. Deformations and stresses resulting from welding as well as residual stresses and diametrical shrinkage, were of special interest. 


\begin{tabular}{|l|l|l|}
\hline Dimension Name & Value & Value \\
\hline \hline Outer Diameter & $203 \mathrm{~mm}$ & $0.203 \mathrm{~m}$ \\
\hline Interior Diameter & $185.2 \mathrm{~mm}$ & $0.1852 \mathrm{~m}$ \\
\hline Outer Radius & $101.5 \mathrm{~mm}$ & $0.1015 \mathrm{~m}$ \\
\hline Interior Radius & $92.6 \mathrm{~mm}$ & $0.0926 \mathrm{~m}$ \\
\hline Pipe Thickness & $8.8 \mathrm{~mm}$ & $0.0088 \mathrm{~m}$ \\
\hline Total Length & $350 \mathrm{~mm}$ & $0.350 \mathrm{~m}$ \\
\hline Groove Type & $\mathrm{V}$ & V \\
\hline Groove Depth & $5.5 \mathrm{~mm}$ & $0.0055 \mathrm{~m}$ \\
\hline Groove Angle & $60 \mathrm{deg}$ & $1.04667 \mathrm{rad}$ \\
\hline
\end{tabular}

Table 3.1: Physical experiment - Principal dimensions. 


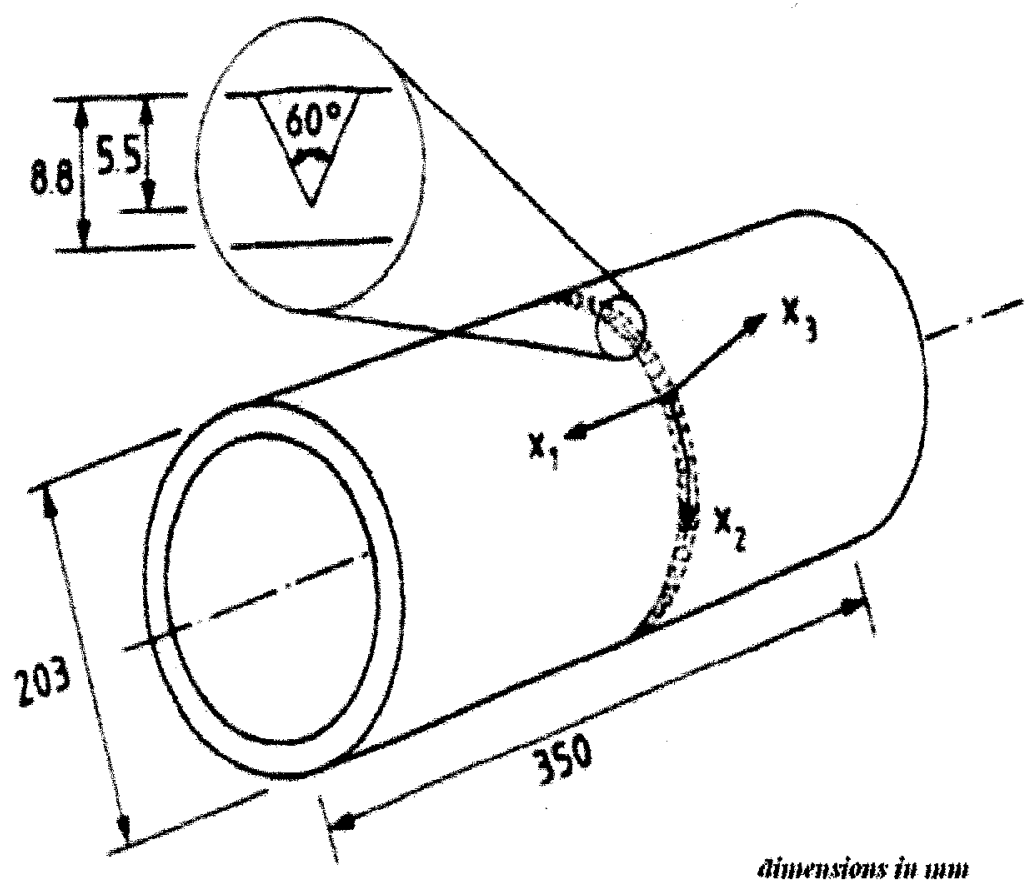

Figure 3.1: Geometry of butt-welded pipe experiment [13].

\section{Material}

Pipe material is a carbon-manganese steel (the composition is given in Table 3.2) with SIS 2172 steel (Swedish Standard) denomination, ASTM A572 Steel being the approximate American equivalent. 


\begin{tabular}{|l|l|l|l|l|}
\hline $\mathrm{C}$ & $\mathrm{Mn}$ & $\mathrm{Si}$ & $\mathrm{Cr}$ & $\mathrm{Cu}$ \\
\hline \hline $0.18 \%$ & $1.3 \%$ & $0.3 \%$ & $0.3 \%$ & $0.4 \%$ \\
\hline
\end{tabular}

Table 3.2: SIS 2172 Steel - Chemical composition in weight percent.

\section{Welding Procedure}

The welding method used was GMAW (gas metal arc welding). In the experiment, positional welding was used, i.e. the welding torch was held fixed and the pipe was rotated with constant velocity. The fillex material (ESAB OK Autorod 12.51) was deposited from the outside into the $5.5 \mathrm{~mm} \mathrm{V-groove.} \mathrm{The} \mathrm{arc} \mathrm{protective} \mathrm{atmosphere} \mathrm{was} \mathrm{chosen} \mathrm{to} \mathrm{be}$ argon. Welding parameters are given in Table 3.3.

The welding started at $x_{2}=0$ and progressed in the positive $x_{2}$ direction. The axis of rotation was held in the horizontal plane. The pipe was welded in one pass. It was considered that the starting time is $\mathrm{t}=0 \mathrm{~s}$. The welding finished after $89 \mathrm{~s}$. The experiment continued during the cooling phase and the data was harvested for another $13911 \mathrm{~s}$.

\section{Investigation Parameters}

For the investigation of diametrical shrinkage the pipe was cut parallel to the weld line at a definite distance from the weld. This distance was chosen so that the part of the pipe which does not contain the weld is free from plastic strain. The diametrical change due to this cutting was measured. The pipes was cut apart with a cold saw at $x_{1}=13 \mathrm{~mm}$ and $x_{1}=-13 \mathrm{~mm}$. The saw was cooled with cutting fluid and the rate of speed was low in order to minimize introduction of new stresses. The diameter change was measured on both sides 


\begin{tabular}{|l|l|l|}
\hline Welding Parameters & Symbol & Value \\
\hline \hline Welding Velocity & $\mathrm{v}$ & $0.0071 \mathrm{~m} / \mathrm{s}$ \\
\hline Starting time & $\mathrm{t}$ initial & $0 \mathrm{~s}$ \\
\hline Welding end time & $\mathrm{t}$ welding & $89 \mathrm{~s}$ \\
\hline Cooling end time & $\mathrm{t}$ end cooling & $14000 \mathrm{~s}$ \\
\hline Gross Heat Input & $\mathrm{Q}$ & $0.73 \mathrm{MJ} / \mathrm{m}$ \\
\hline
\end{tabular}

\section{Table 3.3: Experiment parameters}

of the weld to see if the shrinkage was symmetric with respect to the center plane. The diametrical shrinkage was evaluated in three circumferential positions $\left(\Phi=0^{\circ}, 60^{\circ}\right.$ and $120^{\circ}$ ) and twenty five axial positions (from 15 to $170 \mathrm{~mm}$ away from the weld center) on each side of the weld. The diameter was measured with a micrometer screw.

After the welding and cooling, the residual stress field in the pipe was measured with a set of strain gauges of type MicroMeasurement EA-06-062RE-120. The residual stresses were measured on the outer surface for three axial positions, and ten points.

For measuring the transient strain, the pipe was equipped with fourteen strain gauges. Strains were measured for two axial positions on the pipe. The gauges used were of type KYOWA KH-5-350-G4 with a gauge length and width of $5 \mathrm{~mm}$ and $1 \mathrm{~mm}$, respectively. This gauge type can be used at temperatures up to $300^{\circ} \mathrm{C}$ and is attached to the object by spot welding. Strains were recorded every second from $t=0 \mathrm{~s}$ to $t=1200 \mathrm{~s}$ and every tenth second from $t=1420 \mathrm{~s}$ to $\mathrm{t}=13900 \mathrm{~s}$. Measured strains were recorded and stored in 


\begin{tabular}{|l|l|l|}
\hline Gauge Location & Angular (deg) & Circumferential \\
\hline \hline 1 & 30 & $53 \mathrm{~mm}$ \\
\hline 2 & 150 & $266 \mathrm{~mm}$ \\
\hline 3 & 270 & $478 \mathrm{~mm}$ \\
\hline 4 & 330 & $585 \mathrm{~mm}$ \\
\hline 5 & 30.15 & $53 \mathrm{~mm}$ \\
\hline 6 & 150.15 & $266 \mathrm{~mm}$ \\
\hline 7 & 270.15 & $478 \mathrm{~mm}$ \\
\hline 8 & 30.30 & $585 \mathrm{~mm}$ \\
\hline 9 & 150.30 & $53 \mathrm{~mm}$ \\
\hline 10 & 270.30 & $266 \mathrm{~mm}$ \\
\hline
\end{tabular}

Table 3.4: Location of points for residual stress measurement. 
a microcomputer via an 8-bit $\mathrm{A} / \mathrm{D}$ interface. In order to be able to separate mechanical strains from measured strains, a separate investigation was made to determine the apparent thermal strain. Thermal apparent strain was measured with one strain gauge attached to a piece of pipe material placed in a heating oven, for temperatures up to300 $\mathrm{C}$.

During welding, transient temperatures were measured at two axial positions where strain gauges were attached. This information together with the measured apparent thermal strain makes it possible to determine the mechanical strains from the measured strains during the welding. Temperatures were measured with thermocouples that were spot welded to the pipe. Also the temperatures were recorded and stored in the microcomputer.

\section{Experiment results}

The measured change in diameter is shown in Figure 3.2 for three different angular locations and for both negative and positive values for the $x_{1}$ coordinate. Experimentally measured results for axial stresses are shown in Figure 3.3. Experimentally measured results for hoop stresses are shown in Figure 3.4. 


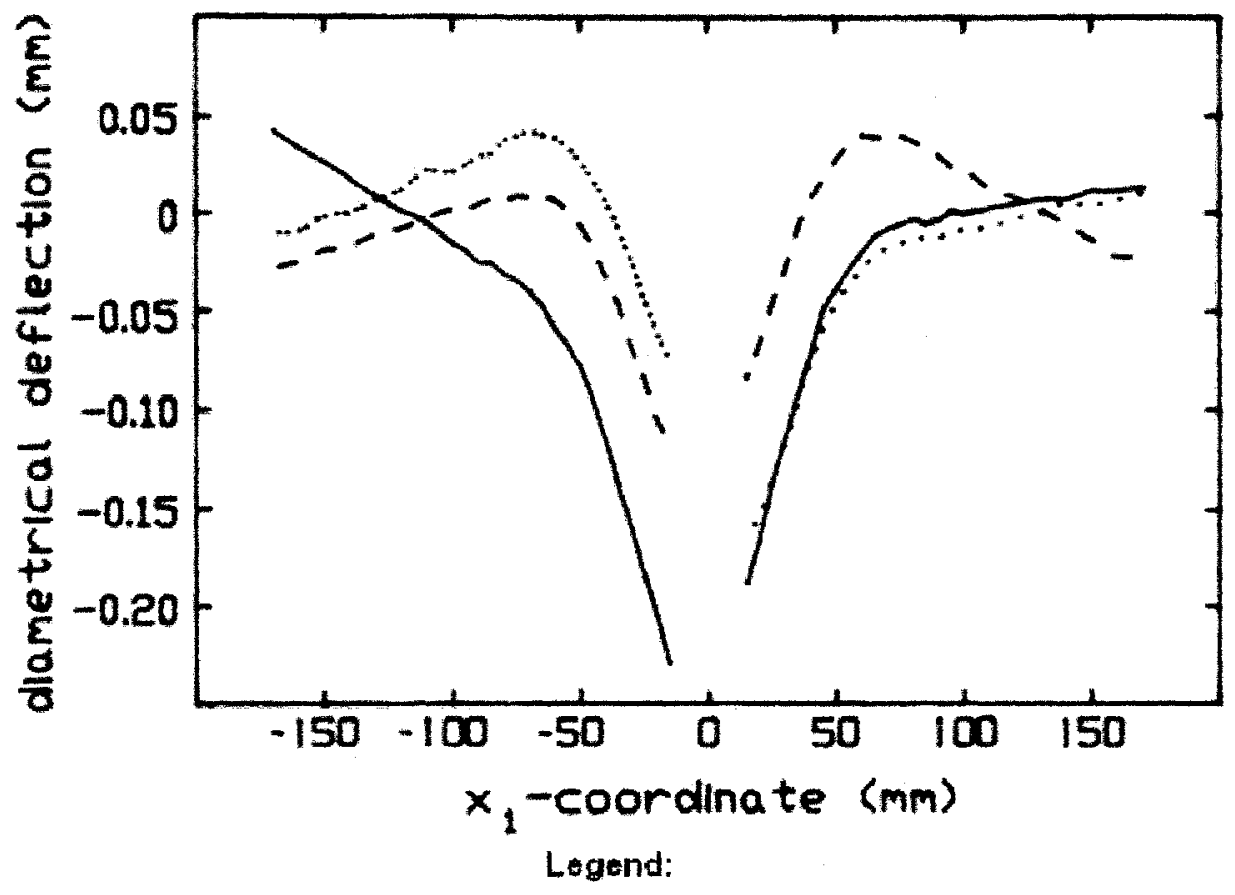

4 is the angle fr om the atat pastion of the weld

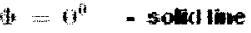

$$
\begin{aligned}
& \text { fo... } 6 f^{\circ} \text { - tashed bue }
\end{aligned}
$$

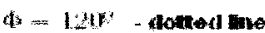

Figure 3.2: Measured Diametrical Deflection [13]. 


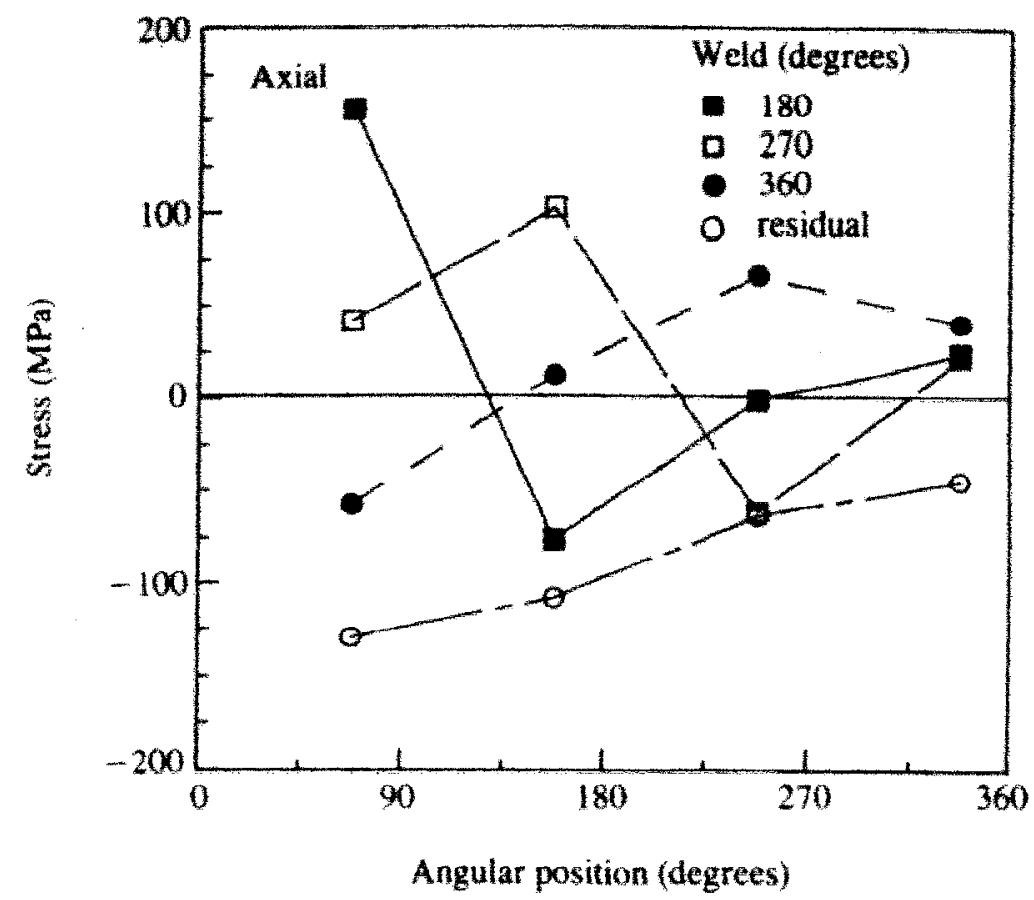

Figure 3.3: Measured transient and residual axial stress [13].

\subsubsection{FE Analysis using shell elements for a butt-welded pipe model [14]}

The analysis was conducted by Mats O. Nasstrom at the Division of Computer Aided Design Laboratories, Department of Applied Physics and Mechanical Engineering, Luleo University of Technology, Sweden.

\section{Theoretical Analysis}

The analytical solution for the heat flow due to a moving point heat source in a thick/thin infinite plate (considered homogenous) can be applied to a pipe if the radius of the pipe is 


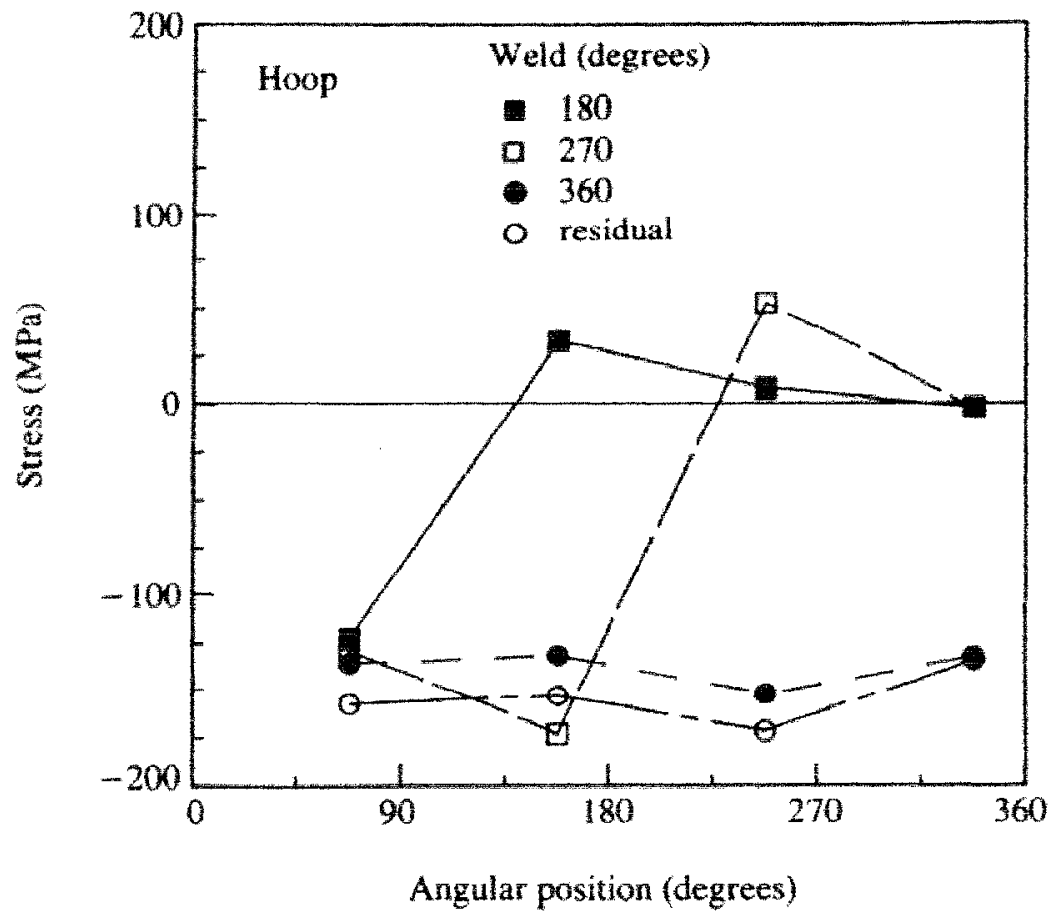

Figure 3.4: Measured transient and residual hoop stress [13].

much larger than its thickness, and the temperature is assumed to be constant through the thickness of the pipe.

\section{Domain and Discretization}

Because of the symmetry of the model only a half was analyzed (Figure 3.5). Table 3.5 contains the discretization parameters. 


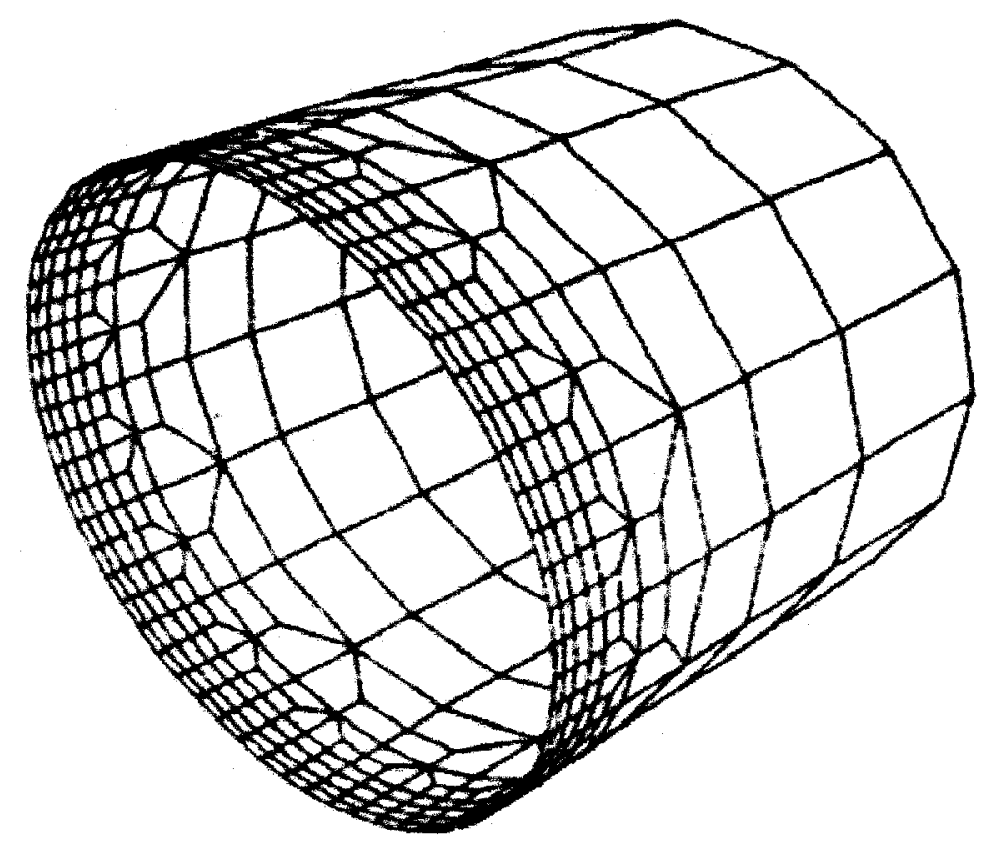

Figure 3.5: FE mesh with shell elements [13].

\section{Boundary conditions}

It was considered that the ambient temperature is $300 \mathrm{~K}$.

On the plane of symmetry axial displacements were set to zero. At the end of the pipe, all displacements were set to zero.

\section{Material Model}

The material was assumed to be thermo-elastoplastic with temperature dependent properties. Volume changes due to phase transformations were accounted for in [15] by use of thermal dilatation given in Figure 3.6. In the study the solid curve in the dilatation diagram 


\begin{tabular}{|l|l|}
\hline Total number of elements & 448 \\
\hline Total number of nodes & 488 \\
\hline Element type & 4 node shell \\
\hline Element dimensions (smallest) & $3.2 \times 3.2 \mathrm{~mm}$ \\
\hline $\begin{array}{l}\text { Thickness of the element } \\
\text { in front of the arc } \\
\text { in front of the arc }\end{array}$ & $6 \mathrm{~mm}$ \\
\hline
\end{tabular}

Table 3.5: Discretization of the FE mesh.

was followed both during heating and cooling.

Temperature dependent modulus of elasticity $\mathrm{E}$ is given in Figure 3.6. Temperature dependences of Poisson's ratio and yield stress are shown in Figure 3.7.

All material points (integration points) follow the solid curve or the yield stress during heating and cooling. At high temperatures the yield stress is assigned low values varying from $20 \mathrm{MPa}$ at $1000^{\circ} \mathrm{C}$ to $10 \mathrm{MPa}$ at the melting temperature. 


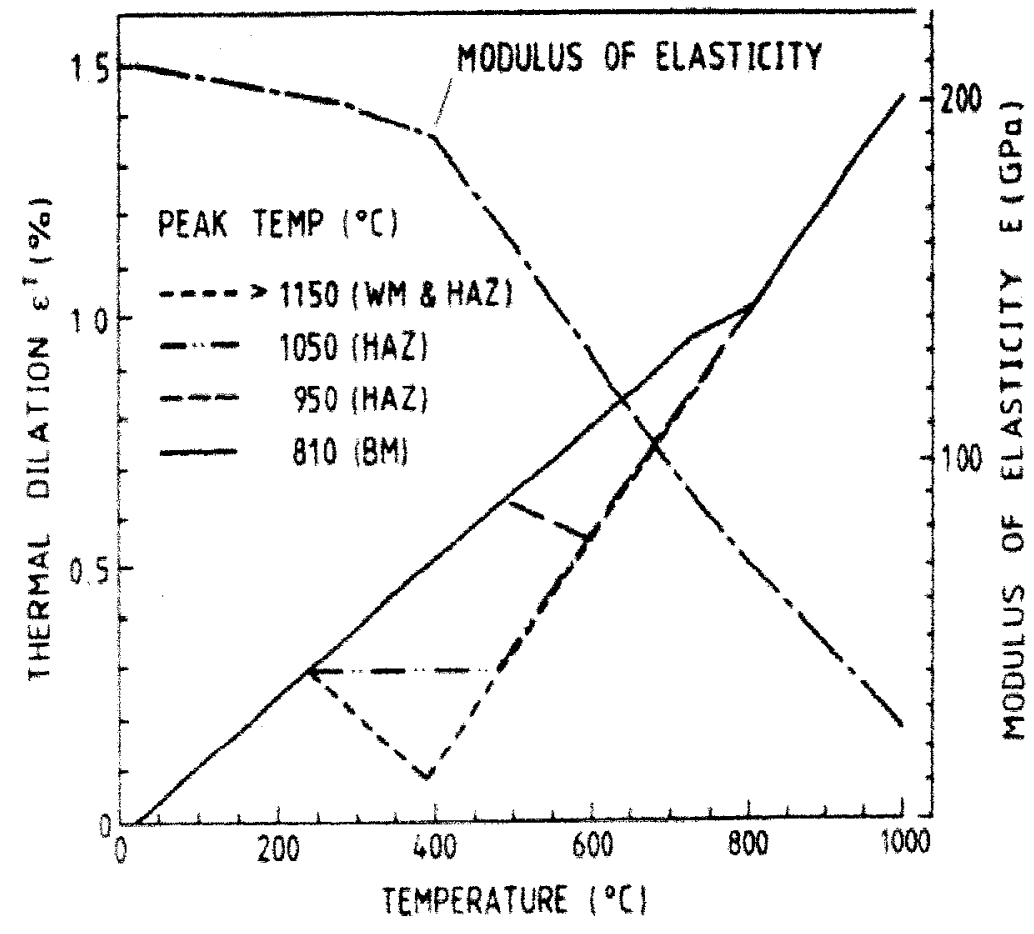

Figure 3.6: Material properties: Young's Modulus and Thermal Dilatation [13].

\section{FE Analysis Data}

Finite element analysis parameters are presented in Table 3.6.

Constant temperature is nsed in each element of the finite elements. This is consistent with the variation of the displacements within an element. A three-point Lobatto quadrature rule was used for numerical integration in the thickness direction.

\section{Calculated results}

Calculated values for diametrical deflection by using FE analysis with shell elements is shown in Figure 3.8 . 


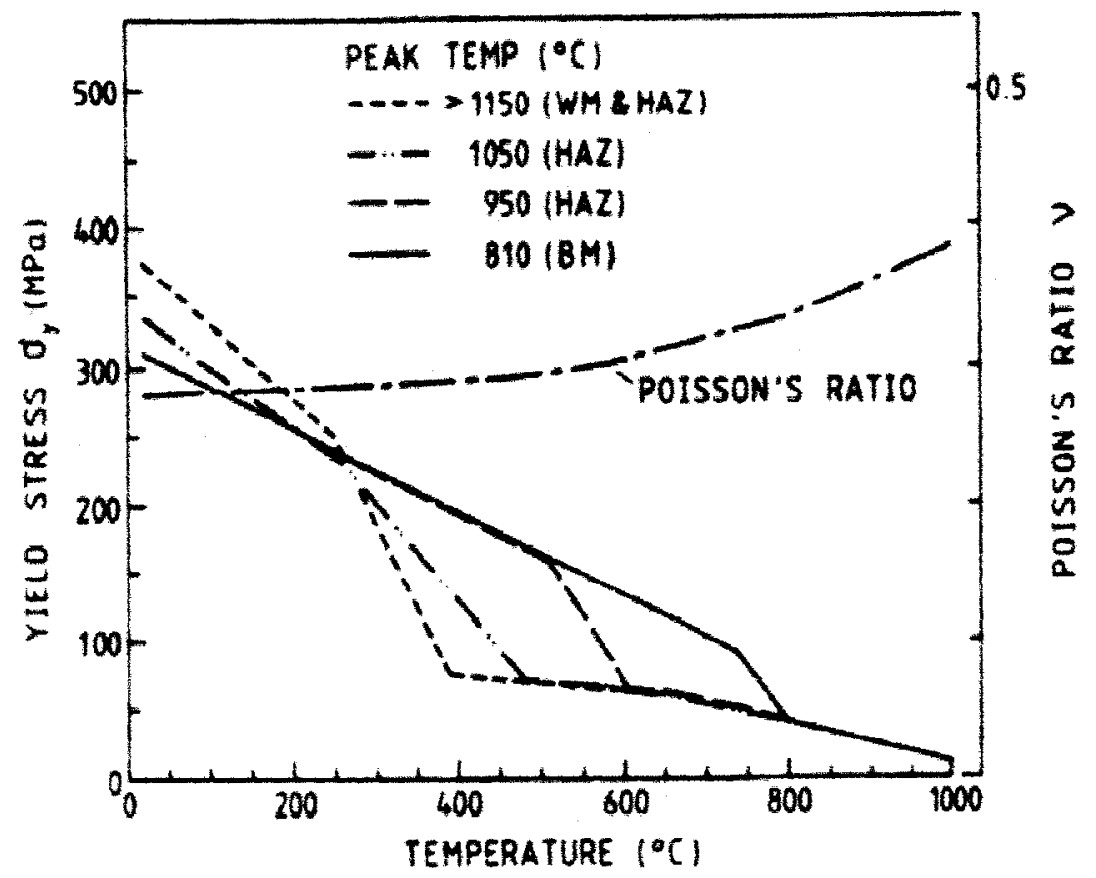

Figure 3.7: Material properties: Yield Stress and Poisson's Ratio [13].

Residual axial stresses results calculated by using FEA with shell elements are illustrated in Figure 3.9.

Calculated results for residual hoop stresses by using FEA with shell elements are illustrated in Figure 3.10. 


\begin{tabular}{|l|l|}
\hline Start time & $0 \mathrm{~s}$ \\
\hline End welding time & $89 \mathrm{~s}$ \\
\hline End cooling time & $14000 \mathrm{~s}$ \\
\hline Welding time step size & $1 \mathrm{~s}$ \\
\hline Number of time steps for welding & 89 \\
\hline Number of time steps for cooling & 25 \\
\hline
\end{tabular}

Table 3.6: FE analysis parameters.

\subsubsection{D FEM computer simulation using brick elements}

The simulation was performed in MMO Laboratory, Mechanical and Aerospace Department, Carleton University, Ottawa, Canada. A Pentium III computer with $600 \mathrm{MHz}$ CPU and $512 \mathrm{Mb}$ RAM was used. The operating system was Redhat Linux 7.0.

\section{Theoretical Analysis}

SimManTec, the software platform used in this simulation, is research software which incorporates the latest implementation of computational weld mechanics.

The $3 \mathrm{D}$ transient analysis of the single pass weld solves for temperatures and thermal stresses.

Constitutive equations change type as functions of temperature. Above 0.8 of the melting point, a linear viscous model is used. Below 0.5 of the melting point, a rate independent plasticity model is used. Between 0.5 and 0.8 a rate dependent visco-plastic model is used. 


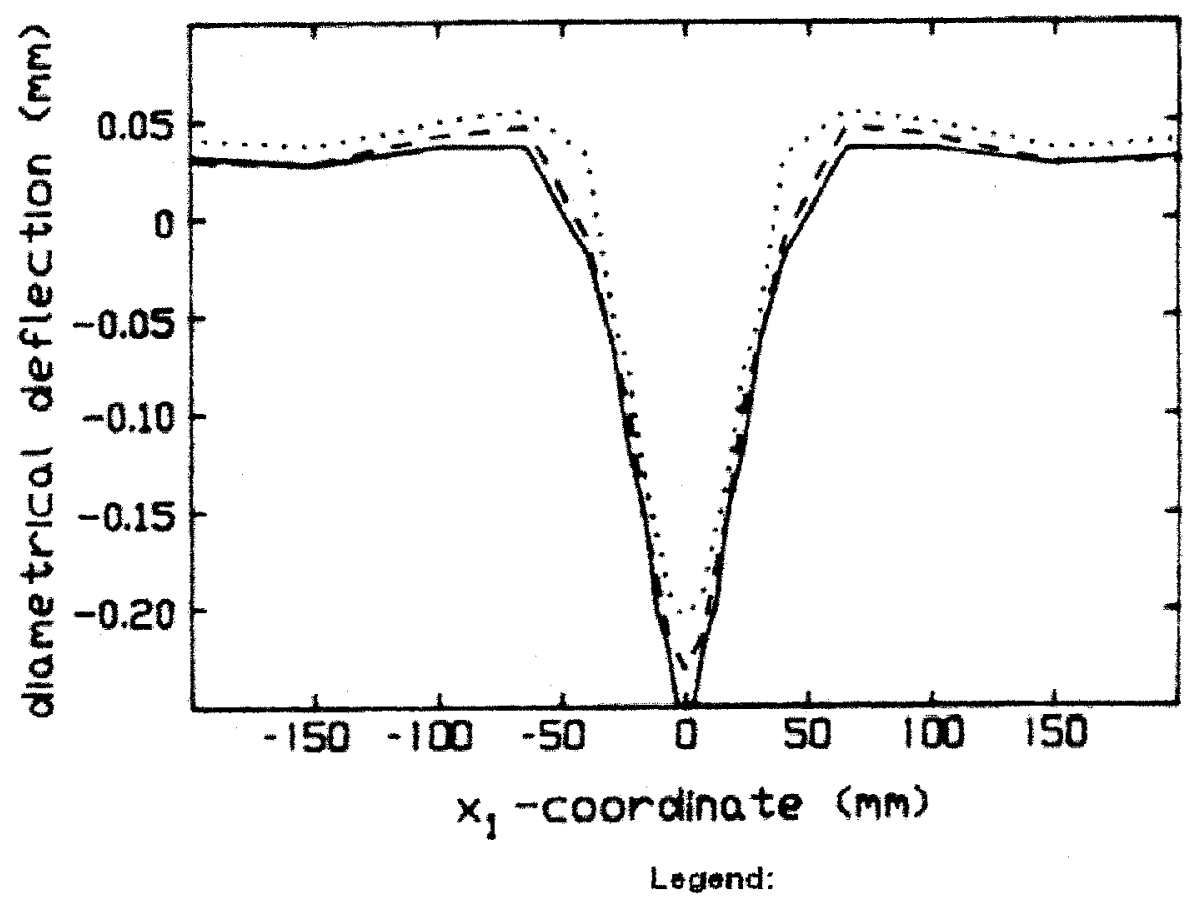

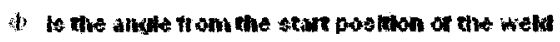

$$
\begin{aligned}
& \text { d }=\theta^{\prime \prime} \text { - solki line } \\
& \text { it - off - thohed hat } \\
& 4=1240 \text { - dotat ane }
\end{aligned}
$$

Figure 3.8: Calculated diametrical deflection [14].

This develops the capability to do stress analysis of welds near the weld pool and it can be used to predict hot cracking also. The energy equation is solved using 8-node bricks with backward Euler time integration, in a Lagrangian formulation.

Iterative solvers such as conjugate gradient, GMRES and multigrid are used. 


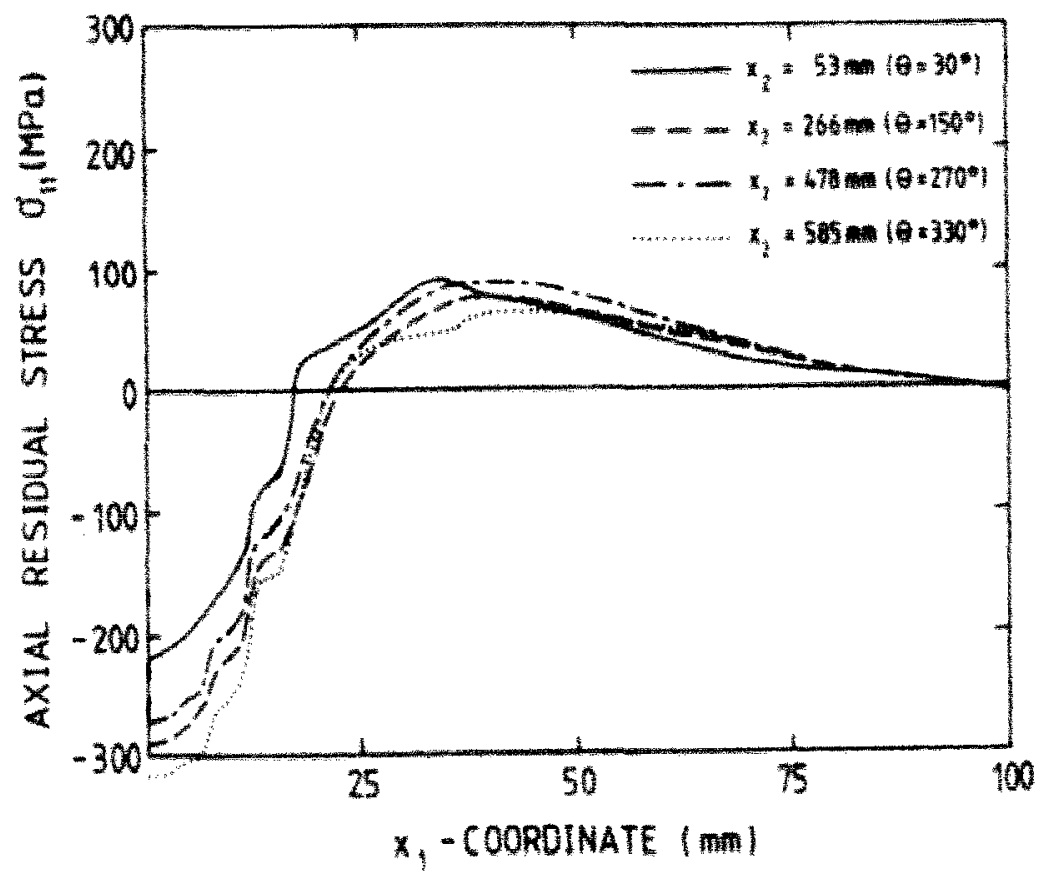

Figure 3.9: Calculated residual axial stresses on the outer surface-FE analysis [14].

\section{Domain and Discretization}

A model of the whole pipe was considered the finite element analysis domain. The discretization used a graded mesh with three zones. This helped to increase the accuracy of the temperature and stress gradients near the weld pool, where the mesh is finer. Also it reduced the simulation time by using bigger elements far away from the weld pool.

The three dimensional mesh for the pipe model is illustrated in Figure 3.11.

Discretization details are given in Table 3.7 . 


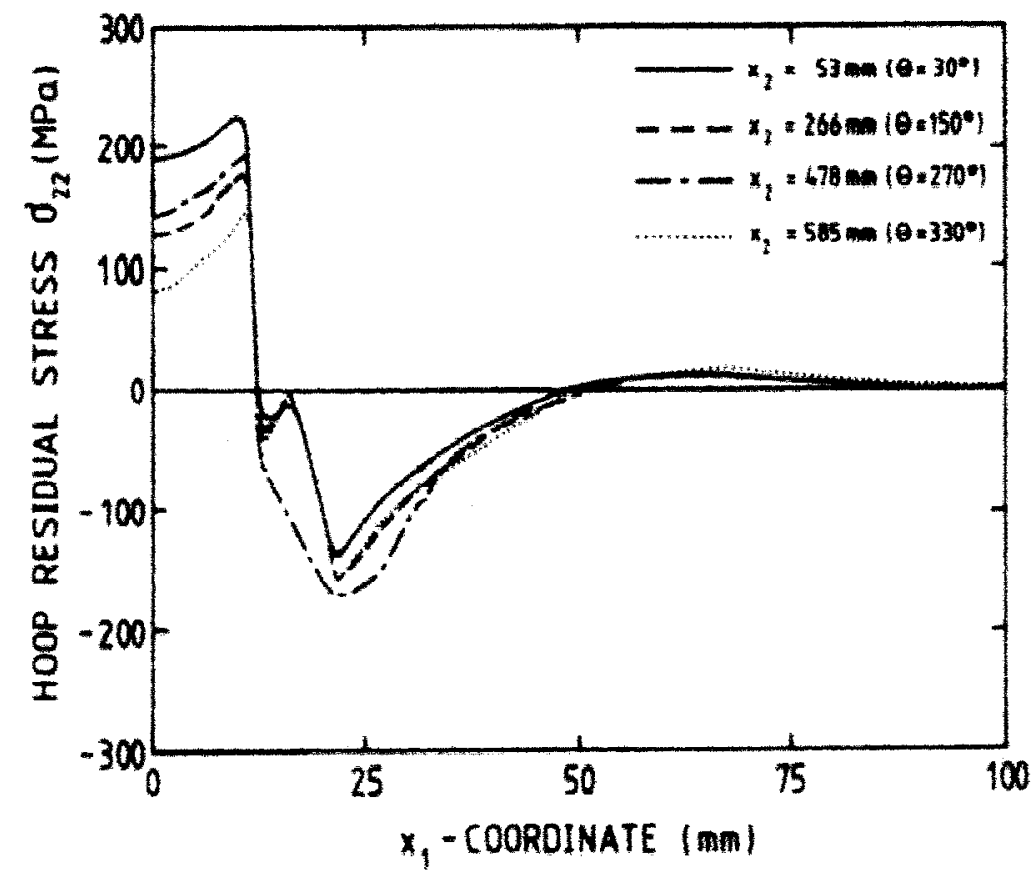

Figure 3.10: Calculated residual hoop stresses on the outer surface -FE analysis [14].

\section{Initial and boundary conditions}

a) Thermal Analysis

It was considered that the ambient temperature is $300 \mathrm{~K}$.

The heating effect of the arc is described by a Dirichlet boundary condition on nodes in the weld pool. The temperature in the weld pool is assumed to vary parabolically from the melting point at the boundary of the weld pool $(1750 \mathrm{~K})$ to a maximum temperature of $2200 \mathrm{~K}$ in the center of the weld pool.

External boundaries are assumed to be in still air and to have a convection boundary condition with an ambient temperature $300 \mathrm{~K}$ and convection coefficient of $10 \mathrm{~W} / \mathrm{m}^{2} \mathrm{~K}$. 


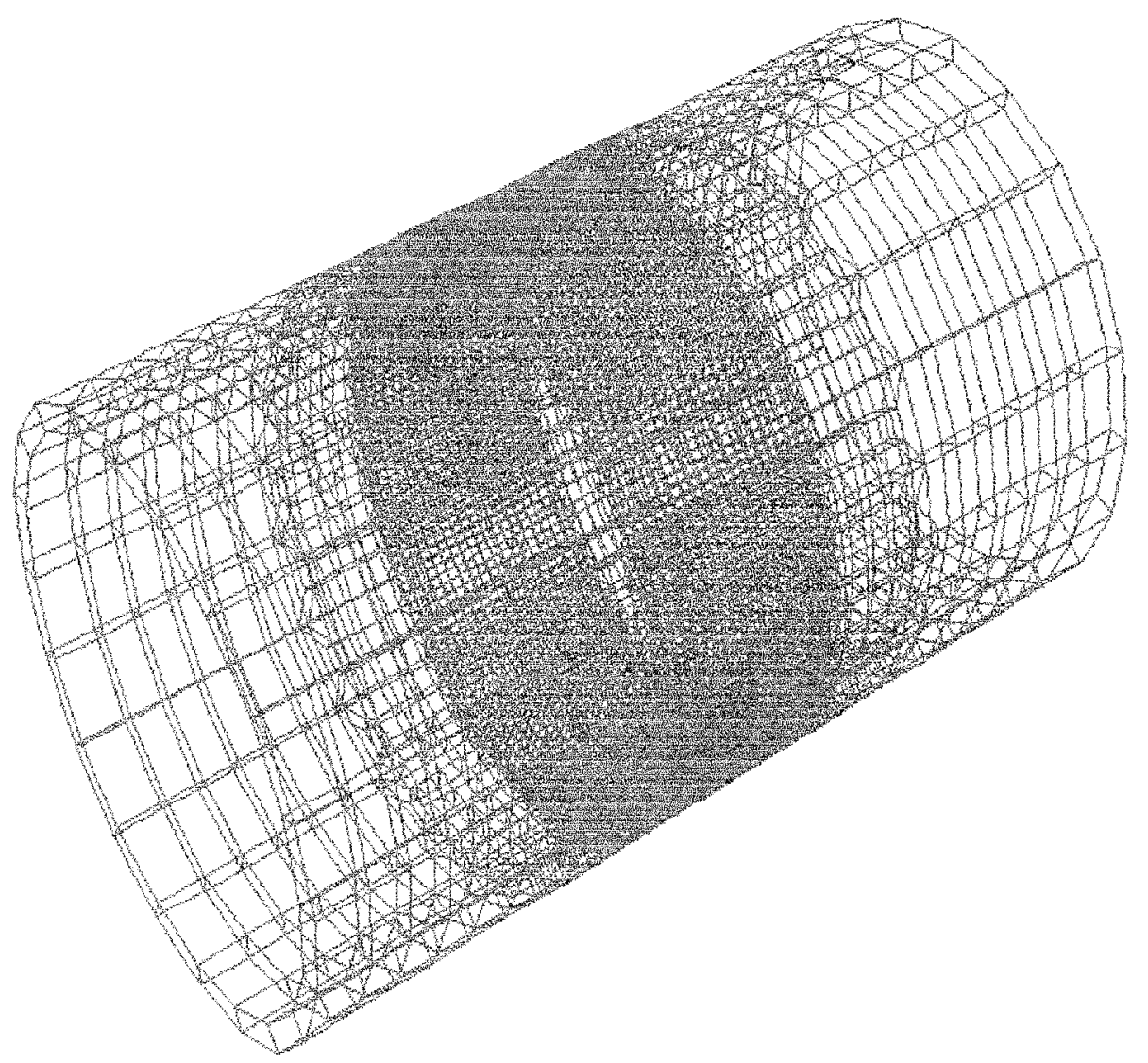

Figure 3.11: But-welded pipe model - Graded brick mesh.

b) Stress Analysis

Rigid body modes in the pipe were constrained. Nodes from both ends of the pipe were constrained to have zero displacement in any direction. 


\begin{tabular}{|l|l|}
\hline Total number of elements & 4480 \\
\hline Total number of nodes & 9000 \\
\hline Element type & 8 node brick $8 \mathrm{GP}$ \\
steady state analysis & 8 node brick $8 \mathrm{GP}$ \\
thermal mapping & 8 node brick $8 \mathrm{GP}$ \\
\hline Element dimensions & $3.2 \times 4 \times 8.8 \mathrm{~mm}$ \\
smallest element & $30 \times 20 \times 8.8 \mathrm{~mm}$ \\
\hline
\end{tabular}

Table 3.7: Discretization parameters for 3D FEM simulation.

\section{Material Model}

Temperature dependent material properties are specified in Amex 1 - Temperature Dependent Material Properties used in $3 D$ FEM Computer Simulation of Welding for a Butt-Welded Pipe as per Table 3.8. All the properties are measured in SI units.

\section{FEM computer simulation parameters}

Besides obtaining the transient temperatures, strains and stress the aim of this simulation is to achieve a real-time simulation. In order to diminish the computing time the thermal simulation is performed on a smaller mesh (see Figure 3.12). This mesh is designed to capture the temperature gradients near the weld pool using a 10 times smaller elements. (1312 elements and 2025 nodes). The time step size is the same as in the rest of the welding 


\begin{tabular}{|l|l|l|}
\hline Material Property & Value & SI units \\
\hline \hline Density & Annex 1 - Fig 3.20 & $\mathrm{kg} / \mathrm{m}^{2}$ \\
\hline Melting Temperature & 1750 & $\mathrm{~K}$ \\
\hline Liquidus Temperature & 1800 & $\mathrm{~K}$ \\
\hline Latent Heat & $2.05 \mathrm{e}+9$ & $\mathrm{~J} / \mathrm{m}^{3}$ \\
\hline Young's Modulus & Annex 1 - Fig 3.22 & $\mathrm{N} / \mathrm{m}^{2}$ \\
\hline Coeff. Linear Thermal Expansion & Annex 1 - Fig 3.21 & $1 / \mathrm{K}$ \\
\hline Yield Stress & Annex 1 - Fig 3.23 & $\mathrm{N} / \mathrm{m}^{2}$ \\
\hline Poisson's Ratio & Annex 1 - Fig 3.24 & - \\
\hline Specific Heat & Annex 1 - Fig 3.25 & $\mathrm{J} / \mathrm{kg} . K$ \\
\hline Thermal Conductivity & Annex 1 - Fig 3.26 & $\mathrm{W} / \mathrm{m} . K$ \\
\hline Viscosity & 1e10 & $\mathrm{N.s} / \mathrm{m} 2$ \\
\hline Volumetric Strain & Annex 1 - Fig 3.27 & - \\
\hline
\end{tabular}

Table 3.8: Temperature dependent material properties 
simulation, e.g. $0.49 \mathrm{~s}$. When the process reaches steady state the thermal analysis for the start phase performed on the small plate model is stopped. In our case the process is considered to reach steady state after 15 seconds (see Figure 3.28 - Annex 2). The thermal results are mapped to the pipe model mesh. Then the transient temperature field from mapping is applied to each time step in the stress analysis. The computation time for the 3D computer simulation preformed in MMO Laboratory was $5.06 \mathrm{~h}$ (3141 s for the thermal analysis in the small plate model, $2528 \mathrm{~s}$ for mapping to the pipe model and $12543 \mathrm{~s}$ for stress analysis).

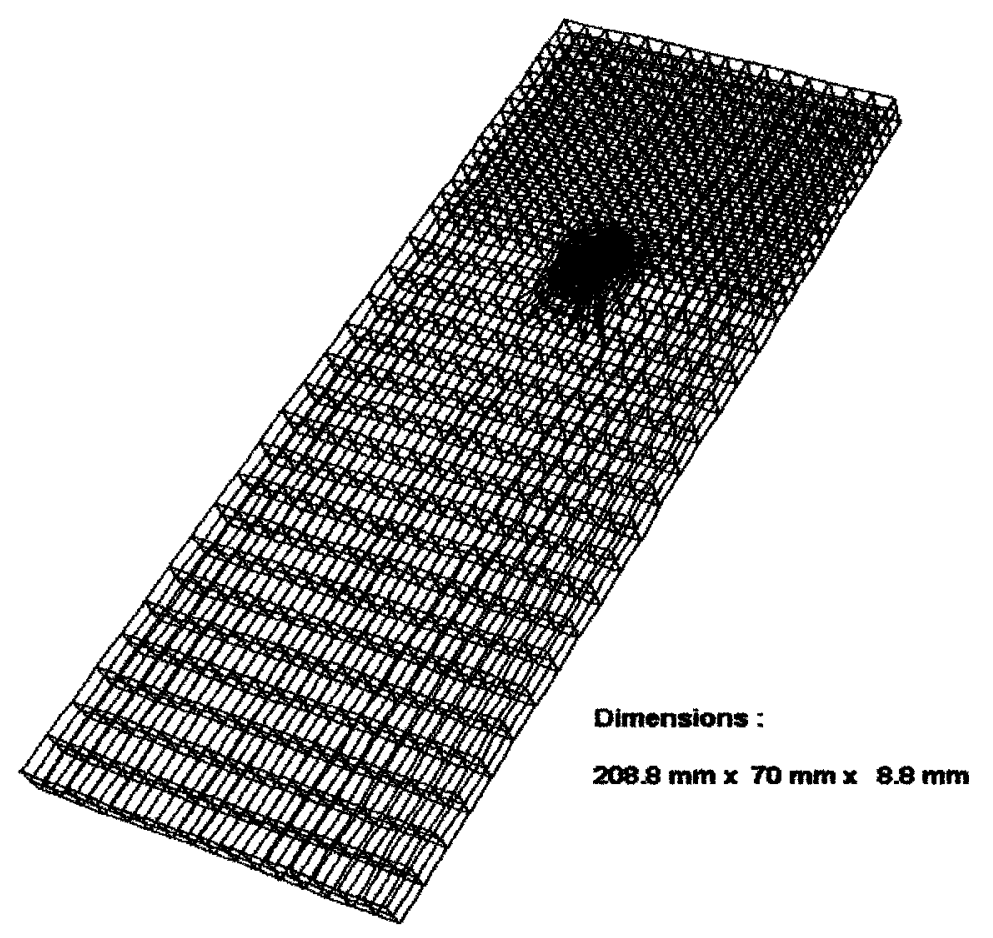

Figure 3.12: Small Plate Mesh. 


\begin{tabular}{|l|l|}
\hline Start time & $0 \mathrm{~s}$ \\
\hline End welding time & $89 \mathrm{~s}$ \\
\hline End cooling time & $14000 \mathrm{~s}$ \\
\hline Welding time step size & $0.49 \mathrm{~s}$ \\
\hline Cooling time step size & exponential \\
\hline Number of time steps for welding & 182 \\
\hline Number of time steps for cooling & 43 \\
\hline
\end{tabular}

Table 3.9: 3D FEM computer simulation parameters.

\section{Thermal Analysis Results}

The results for transient temperature field are presented in Annex 2 - Transient temperature fields in 3D FEM Computer Simulation of Welding for a Butt-Welded Pipe Model.

The calculated temperature field for the small plate is shown in Figure 3.28 - Annex 2. The weld pool boundary isotherm is represented by the $1750 \mathrm{~K}$ solidus temperature.

The evolution of the temperature field during the simulation is cached for the start phase both in Figure 3.28 - Annex 2 for the small plate and in Figure 3.29 - Annex 2 for the pipe model . Figures 3.30 and 3.31 - Annex 2 depict the temperature evolution in the pipe model during the steady state and cooling phase respectively.

Both figures Figure 3.28 and Figure 3.29 indicate that the isotherms in front of the weld pool are compressed while those behind the weld pool are expanded because of the heat source motion as expected. 
The temperature profile, as one can see from Figure 3.13 clearly shows the penetration characteristic to GMAW welding.

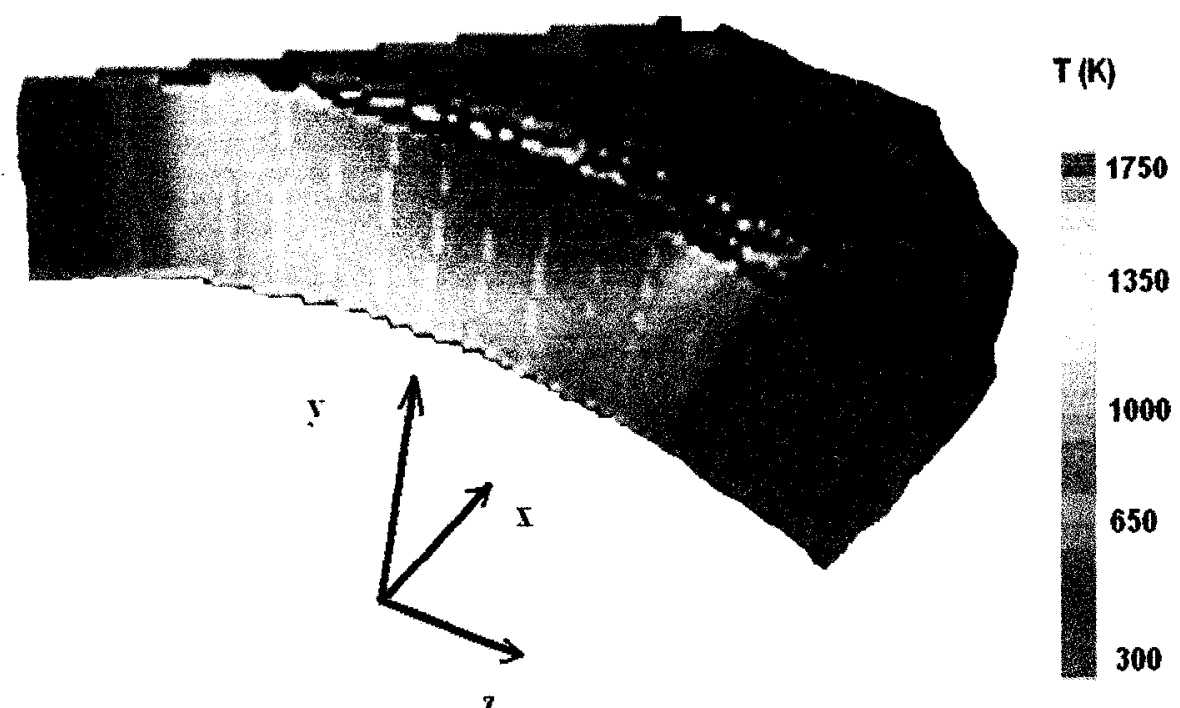

z

Figure 3.13: Temperature field through pipe thickness.

The thermal cycles are calculated by converting the distance into time using the welding speed. It can be seen that the heating rate is much steeper than the cooling rate.

As expected the peak temperatures are higher at locations close to the weld pool and decrease with distance from this location. 


\section{Mechanical Analysis Results}

Annex 3 includes the results for stresses and deformations.

Figure 3.32 gives an overall representation of the transient effective stress distributions.

With raising temperatures ahead of the moving heat source, the points close to the weld line start to experience compression in the longitudinal direction (Figure 3.33). Stresses in the regions at short distance from the arc are compressive because the expansion of these areas is restrained by the surrounding metal where the temperature is lower. However stresses in the areas further away from the weld arc are tensile and in balance with compressive stresses in the area near the weld.

At some distance behind the welding arc, the temperature drops sufficiently for the material to be stiff enough to resist the deformation caused by temperature change. Due to cooling the areas close to the weld contract and cause tensile stresses.

Analysis of the data presented in Figures 3.33, 3.34 and 3.35 allows us to conclude that in the $\mathrm{HAZ}$, during the welding process, the relationship between stresses $\sigma_{x x}, \sigma_{y y}$ and $\sigma_{z z}$ may differ significantly from that of the final residual state. The transverse stresses, which are quite significant in the first stages of the process, considerably diminish when cooling to the ambient temperature.

\section{Residual Axial Stress}

Residual axial stress results for the outer surface of the pipe obtained by post processing nodal stresses in 3D FEM computer simulation are shown in Figure 3.14. 


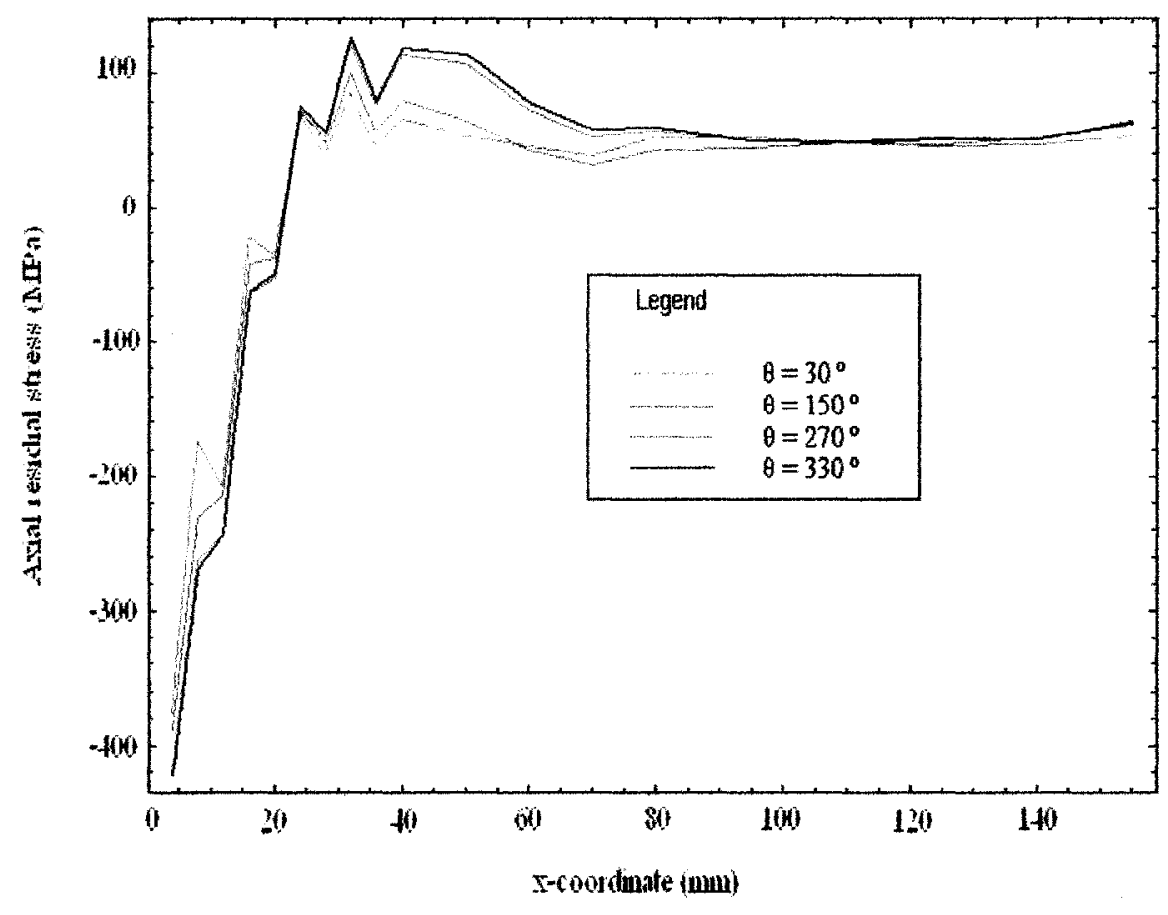

Figure 3.14: Residual Axial Stresses on outer surface of the pipe - 3D FEM computer simulation. 


\section{Residual Hoop Stress}

Residual hoop stress results for the outer surface of the pipe obtained by post processing nodal stresses in 3D FEM computer simulation are shown in Figure 3.15.

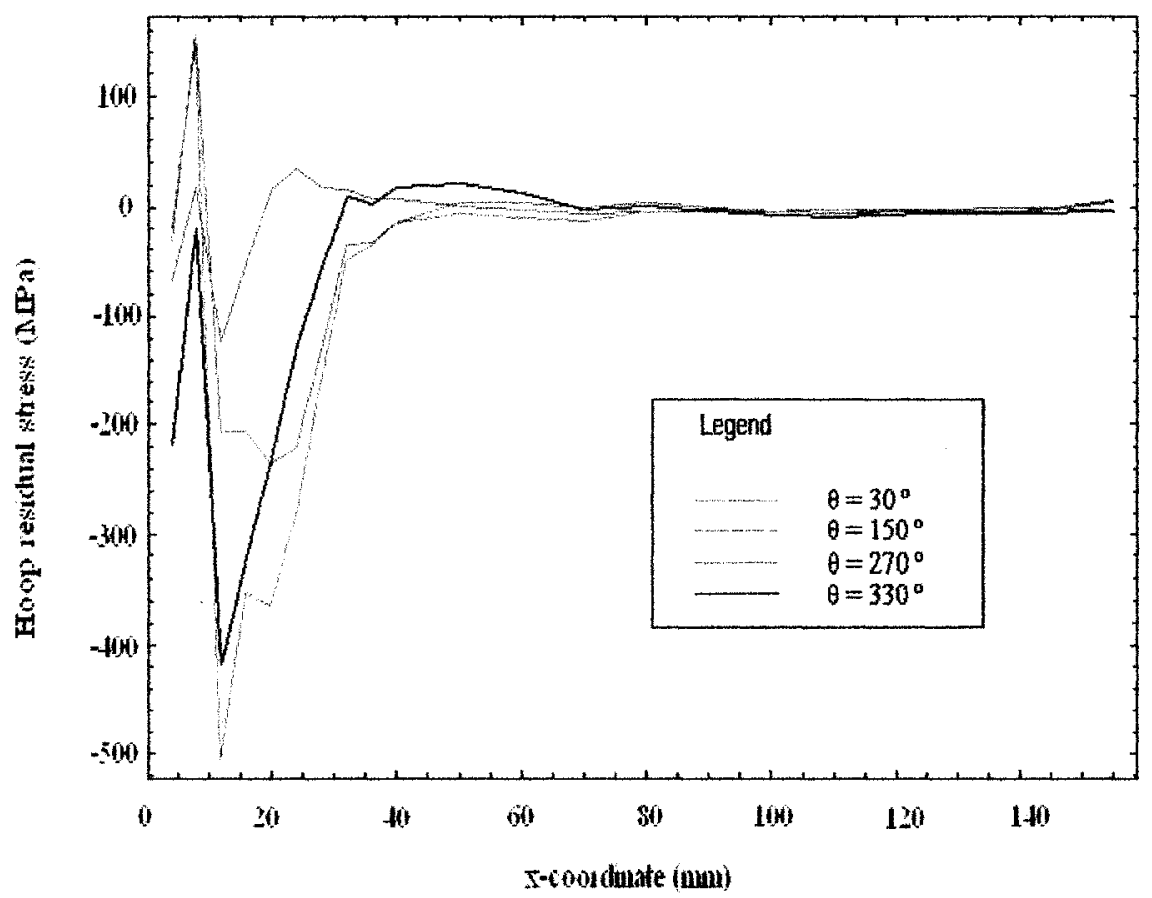

Figure 3.15: Residual Hoop Stresses on outer surface of the pipe -3D FEM computer simulation. 


\section{Deformations}

Deformations and stresses are closely related phenomena. During the welding process thermal strains occur in the weld and adjacent area. The strains produced in the heating stage are always accompanied by plastic deformation of the metal. The resulted stresses combine and react to produce internal forces that cause a variety of distortions.

Deformations are inevitably induced into the welded structures [11]. Residual deformations can lead to distorted shape or incorrect dimensions of the welded components and may make the welded assembly useless.

Figure 3.36 - Annex 3 shows the deformations development during welding and cooling by using a scale factor of 10 . It can be seen that starting with the second time step it reaches the peak deformation. During the welding phase the main deformation remain constant in the weld pool and the adjacent zone while the tail of the weld is cooling down so the deformations has approximately the same value with the residual deformation.

\section{Diametrical Deflection}

The results for diametrical deflection by using 3D FEM computer simulation are shown in Figure 3.16. These were post processed from the displacement of the last time step of the stress analysis. 


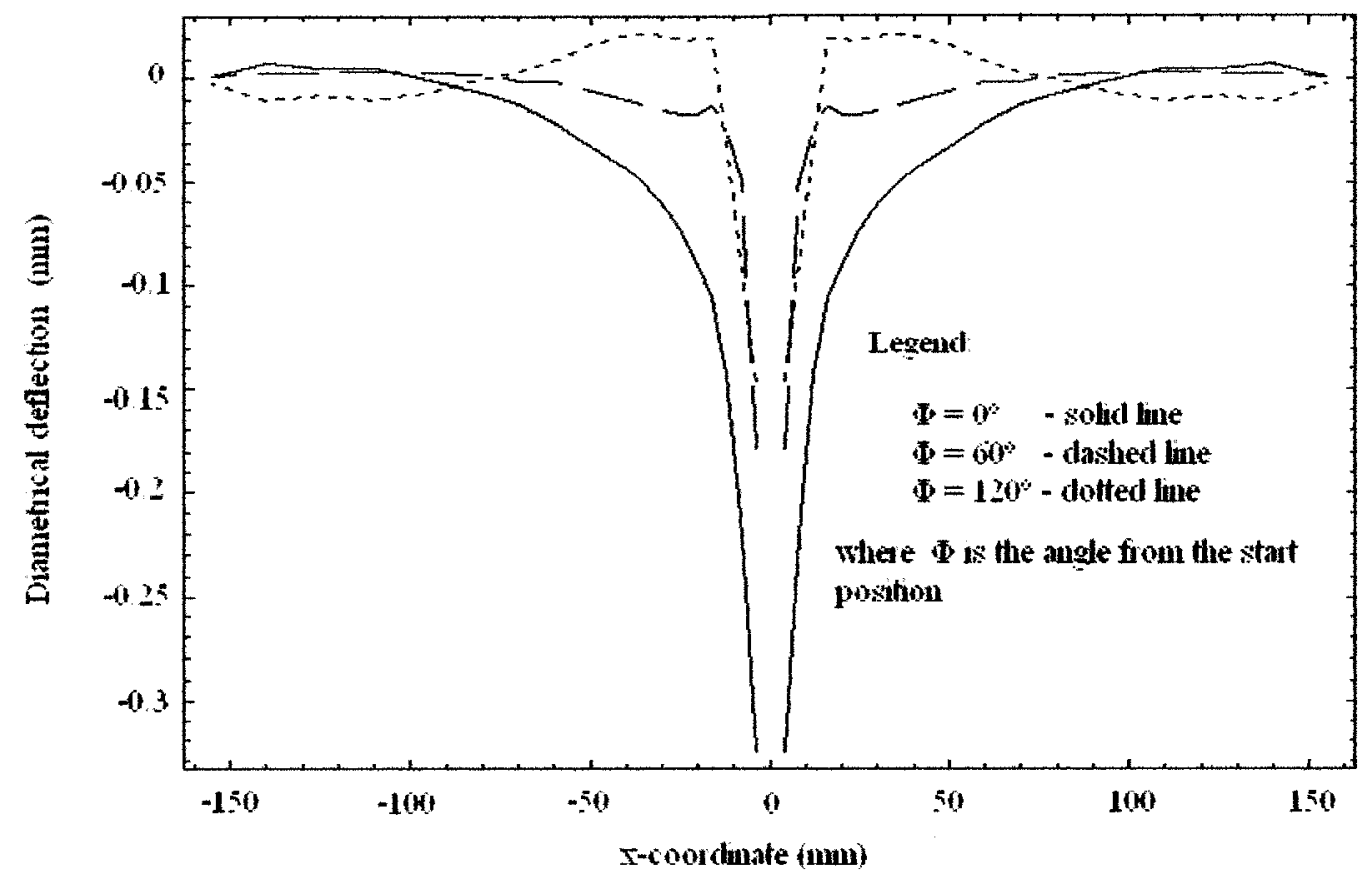

Figure 3.16: Diametrical Deflection - 3D FEM simulation.

\section{Error estimation for residual stress FEM computation}

Error analysis provides information about the global quality of the solution and the distribution of the error in domain. The global error estimate assesses the accuracy of the approximate solution. If it is not acceptable, a new mesh should be created following a remeshing criterion based on the error distribution. Elements are added where the approximate solution is less accurate. The goal is a new solution with a uniform error distribution and a specified global error. 
When performing the simulation by using the SimManTec software, one has the opportunity to assess the error by using the error bound instead of using error estimator techniques. The advantage of error bound over the error estimator resides in the possibility of error bound to predict the error in the finite element approximate solutions with respect to the exact solution while the error estimator techniques can only tell us the finite element solutions in a particular region are more or less accurate than those in the rest of the domain. Implicitly the real error cannot be greater than error bound while an error estimator can be less than the real error [16].

The error bound analysis employs both a statically admissible stress (SAS) field and kinematically admissible stress (KAS) field to compute a bound on the error in the finite element solution. This error gives us a bound on the error of the particular problem. Using the error bound, one can more accurately evaluate the finite element approximate solutions and control the processes of mesh refinement [16].

A kinematically admissible stress (KAS) field is defined as the stress field, whose displacement field satisfies the equation of continuity in the interior and on the boundary of the domain, where the displacement boundary conditions are prescribed.

A statically admissible stress (SAS) field is defined as the stress field that satisfies the equation of equilibrium pointwise in the interior of the domain and the stress vector satisfies the traction boundary conditions pointwise on the external boundaries of the domain.

For each element we recorded the computed values for SAS strain energy, KAS strain energy and the error bound. We post processed these results by calculating the norm of 
each kind of strain energy in the whole domain as being the sum of its components over the total number of elements:

$$
\begin{gathered}
\Delta S E_{t o t}=\sum_{i=1}^{N} \Delta S E_{i} \\
S E_{t o t S A S}=\sum_{i=1}^{N} S E_{S A S_{i}} \\
S E_{t o t K A S}=\sum_{i=1}^{N} S E_{K A S_{i}}
\end{gathered}
$$

where:

$\Delta S E_{i}=$ relative error bound;

$S E_{S A S_{i}}=$ relative SAS strain energy;

$S E_{K A S_{i}}=$ relative KAS strain energy;

$N=$ number of elements.

The contribution of element $i$ to the global error in strain energy is considered to be :

$$
\begin{gathered}
E_{i}=\frac{\Delta S E_{i}}{0.5 \times\left(S E_{t o t K A S}+S E_{t o t S A S}\right)} \\
E_{t o t}=\sum_{i=1}^{N} E_{i}
\end{gathered}
$$

We define constants $a=0.1$ and $b=0.2$, so that,

if $E_{i}<a \times E_{t o t} / N$, then this element could be coarsened.

if $E_{i}>b \times E_{t o t} / N$, then this element could be refined.

If each element makes exactly the same contribution to the total error $E_{t o t}$, then this mesh is optimal. No mesh with this number of elements could provide a more accurate solution.

By viewing the results for the error analysis in Table 3.10 one may conclude that there still are possibilities to reduce both the CPU time and the overall error by coarsening some 


\begin{tabular}{|l|l|}
\hline Error Bound & $3.6739 \mathrm{E}-04$ \\
\hline Maximum relative energy error & 0.003950292 \\
\hline Minimum relative energy error & $2.32765 \mathrm{E}-07$ \\
\hline Number of elements which should be coarsened & 2207 \\
\hline Number of elements which should be refined & 1532 \\
\hline Number of elements which are correct & 741 \\
\hline
\end{tabular}

Table 3.10: Last time step - Error analysis results.

elements far away form the weld center line while some of the elements near the weld center line should be further refined. To refine a mesh in the zone near the weld center line would require modifications to the graded mesher software which will allow different number of elements through thickness in different zones of the model. Meanwhile a bound in relative error of 0.0037 in the strain energy is considered acceptable.

The global strain energy error is shown in Annex 4 - Transient global strain energy error. One may see that the biggest errors are recorded in the weld pool elements during the welding start $(0.221$ at $t=0.49 \mathrm{~s})$ and when the welding stops $(0.07$ at $t=89 \mathrm{~s})$. This leads to the same conclusion that a finer mesh is desired for the weld center line vicinity as a function of time. 


\subsection{Discussion and conclusion}

Welding processes are based on a local heating of manufactured parts up to the melting temperature and then cooling them down. The temperature distribution is highly nonuniform both in spatial coordinates and in time. This nonuniform heating causes a welded structure to deform.

A very important step towards resolving of any kind of deformation and stress is the thermal field and it's evolution with respect of time. Figures 3.28, 3.29, 3.30 and 3.31 Annex 2 clearly indicate the existence of a peak temperature corresponding to the heat source moving on the pipe model circumference.

According to the 3D model, the length of the weld pool on the top side of the plate is $16.5 \mathrm{~mm}$. The width of heat affected zone (defined by the $700^{\circ} \mathrm{C}$ isotherm) on the top of the pipe is larger than on the bottom side (15 mm and $5 \mathrm{~mm}$, respectively).

Welding stresses and deformations have various effects on the welded structure performance. Mostly, they have negative influence.

Due to the non-uniform heating process during butt-welding of the pipe, a stress state with a high level of volumetric stress may arise. In the case investigated in this work, the most important temperature gradient is the one in the direction transverse to the welding. Correspondingly, the case reviewed here is characteristic of the butt-welding of relatively thin and long pipes at moderate welding speed. Going further, at some distance behind the weld arc, the temperature drops sufficiently for the material to be stiff enough to resist 
the deformation caused by the temperature change. Due to cooling the areas close to the weld contract and cause tensile stresses. After a certain time, the temperature change due to welding diminishes. High tensile longitudinal stresses are produced near the weld, and in the regions away from the weld, compressive longitudinal stresses arise (Figures 3.33, 3.34, 3.35 - Annex 3). Ahead of the heat source, we first meet a hump in the tensile stresses, while the temperature is still close to zero. Further follows an abrupt decrease to compression, reaching the yield limit at slightly elevated temperatures. Then with rising temperature and, hence, lower yield stress, the transverse stresses climb up close to a zero values. This highly compressed region just ahead of heat source is in the equilibrium state with the tensile hump. Thus, the region in tension is in equilibrium with the unavoidable compression area around the hot elements trying to expand. Following further along the time axis, at some distance behind the welding arc, the temperature drops sufficiently for the material to be stiff enough to resist the deformation caused by the temperature change. Due to cooling the areas close to the weld contract and cause gradually growing tensile stresses.

The results for residual stresses obtained in the finite element analysis using shell elements (axial stresses - Figure 3.9 and hoop stresses - Figure 3.10) and in the 3D FEM computer simulation using brick elements (axial stresses - Figure 3.14 and hoop stresses Figure 3.15) are in good agreement with the experimentally measured results (Fig 3.3 and 3.4 respectively).

The computed compressive residual axial stresses at the outer surface near the weld line 
in the finite element analysis using brick elements returns maximum values between $\mathbf{4 5 0}$ - $380 \mathrm{MPa}$ for $\sigma_{y y}$ while that of the finite element analysis using shell elements returns maximum values between $300-220 M P a$ respectively (see Figure 3.17). At a distance of 20 $\mathrm{mm}$ from the weld line both finite element analysis start to return almost the same values and at a distance of $35 \mathrm{~mm}$ from the weld line both reach the maximum tensile value of 120 $M P a$; this tensile residual axial stress on the outer surface of the pipe model decay with distance from the weld line following the same pattern.

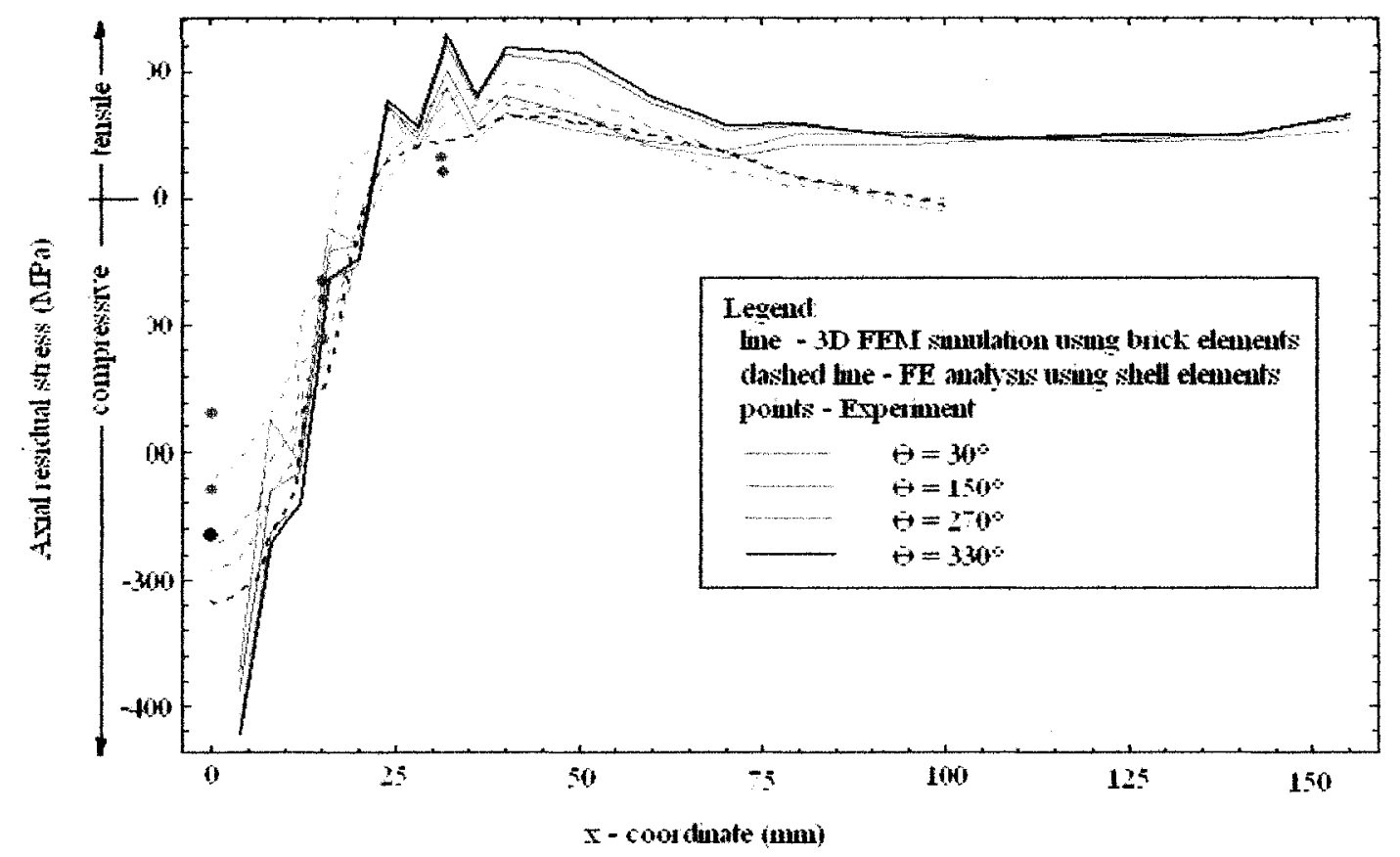

Figure 3.17: Axial residual stress on the outer surface of the pipe - compared results.

For the hoop stresses on the outer surface the differences are bigger than that for the axial stresses but there are in the same range of values (see Figure 3.18). 


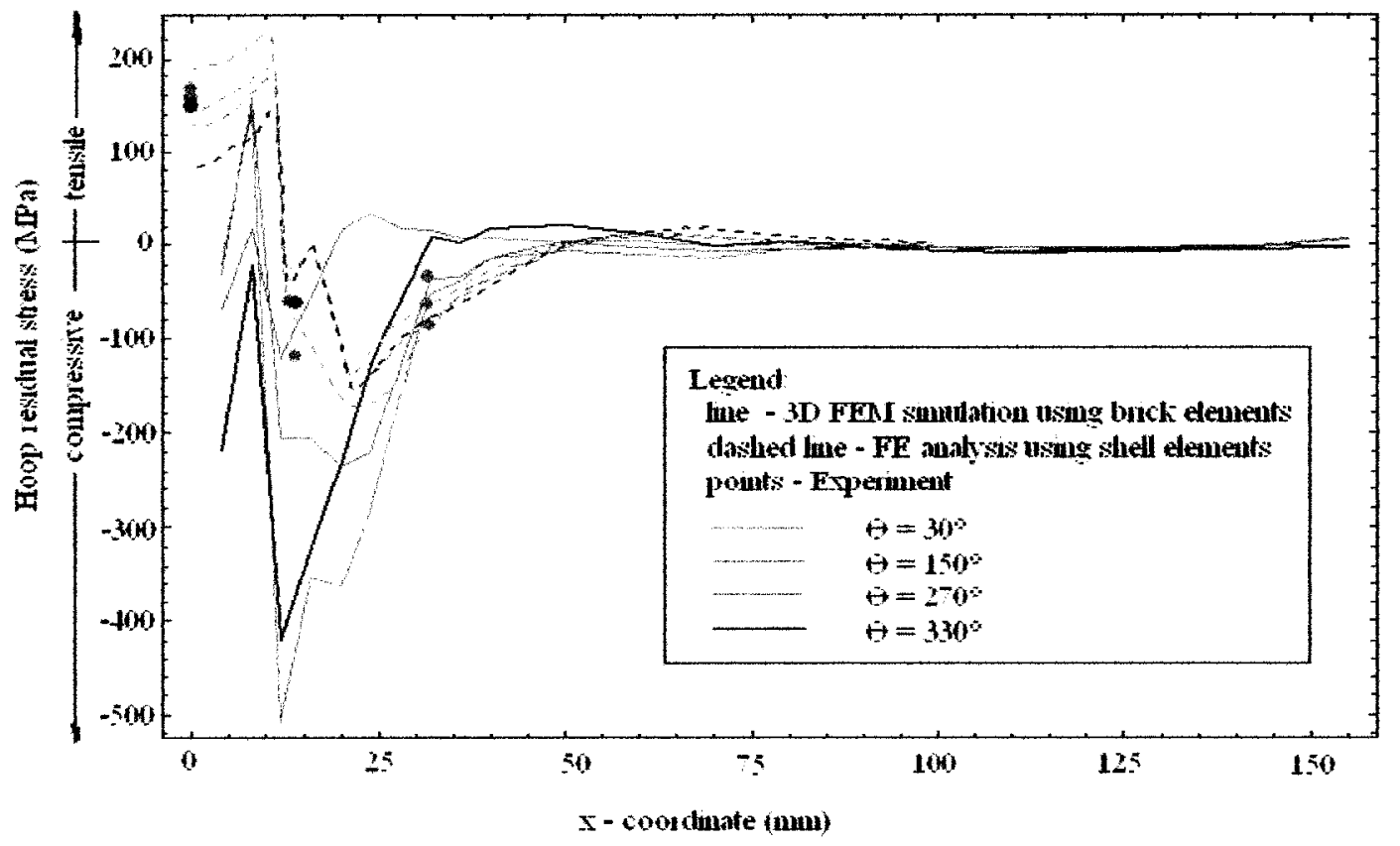

Figure 3.18: Hoop residual stress on the outer surface of the pipe - compared results.

The maximum compressive hoop stress in the finite element analysis with brick elements is $500 \mathrm{MPa}$ at a distance of approximately $15 \mathrm{~mm}$ from the weld line and very close from the start-end point of the weld, while in the finite element analysis with shell elements the maximum compressive hoop stress is approximately $200 \mathrm{MPa}$ at $20 \mathrm{~mm}$ far from the weld line and almost opposite with the start-end weld point. It is quite interesting to observe that the values for this late position with respect of the start - end weld point are almost equal for both analysis and in very good agreement with the experimentally determined results. Furthermore the value $130 M P a$ for the residual hoop stress experimentally measured for $\theta=30^{0}$ at a distance of $17 \mathrm{~mm}$ from the weld line agrees well with the one obtained at the 
same angle and distance in the finite element analysis with brick elements, while the finite element analysis with shell elements can not explain this value of the residual hoop stress at this point. At $50 \mathrm{~mm}$ from the weld line the residual hoop stress goes to zero in both analysis.

Even if the values are slightly different, the graph's position follow the same pattern with respect of $\theta$ in both brick and shell finite element analysis and experimentally measured data (e.g., near the weld line for $\theta=330^{\circ}$ one can see that the residual compressive axial stress has bigger values than that for $\theta=270^{\circ}$, which are bigger than that for $\theta=150^{\circ}$ and bigger than that for $\theta=30^{\circ}$, while after a distance of about $20 \mathrm{~mm}$ from the weld line the tensile values for the residual axial stresses the pattern is opposite)

Differences can be attributed to:

a) inadequacies in the material model used by the finite element analysis with shell element, especially with respect to the material behavior during solid-state phase transformation by not considering the local yield stress variations and volume changes.

b) the approximations introduced by using shell elements in the finite element analysis (e.g., the linear variation through-thickness, and the small number of integration points two by two Gauss Points are used for normal stress and one Gauss Point for in-plane and traverse shear stresses [15]).

From the measured diametrical deflection shown in Figure 3.2 one can see that this deflection is not symmetric with respect to the weld center line. Since the experiment followed a non symmetrical welding procedure (e.g., the pipe was held only at its right end and it was 
rotated while the torch was held fixed) it is natural to obtain a non symmetrical deflection field. The magnitude of the diametrical deflections calculated by using the finite element analysis with shell elements (Figure 3.8) and the post processed diametrical deflection from the results obtained in the finite element analysis using brick elements (Figure 3.16) are in good agreement with the right side of the experimentally measured data. The differences between experiment and calculated data (see Figure 3.19) can be explained taking into account the inherent imperfections from the manufacturing of the pipe and groove preparation (e.g., deviation form a perfect circular pipe) and the errors in measurement which were considered to be $10 \%[13]$.

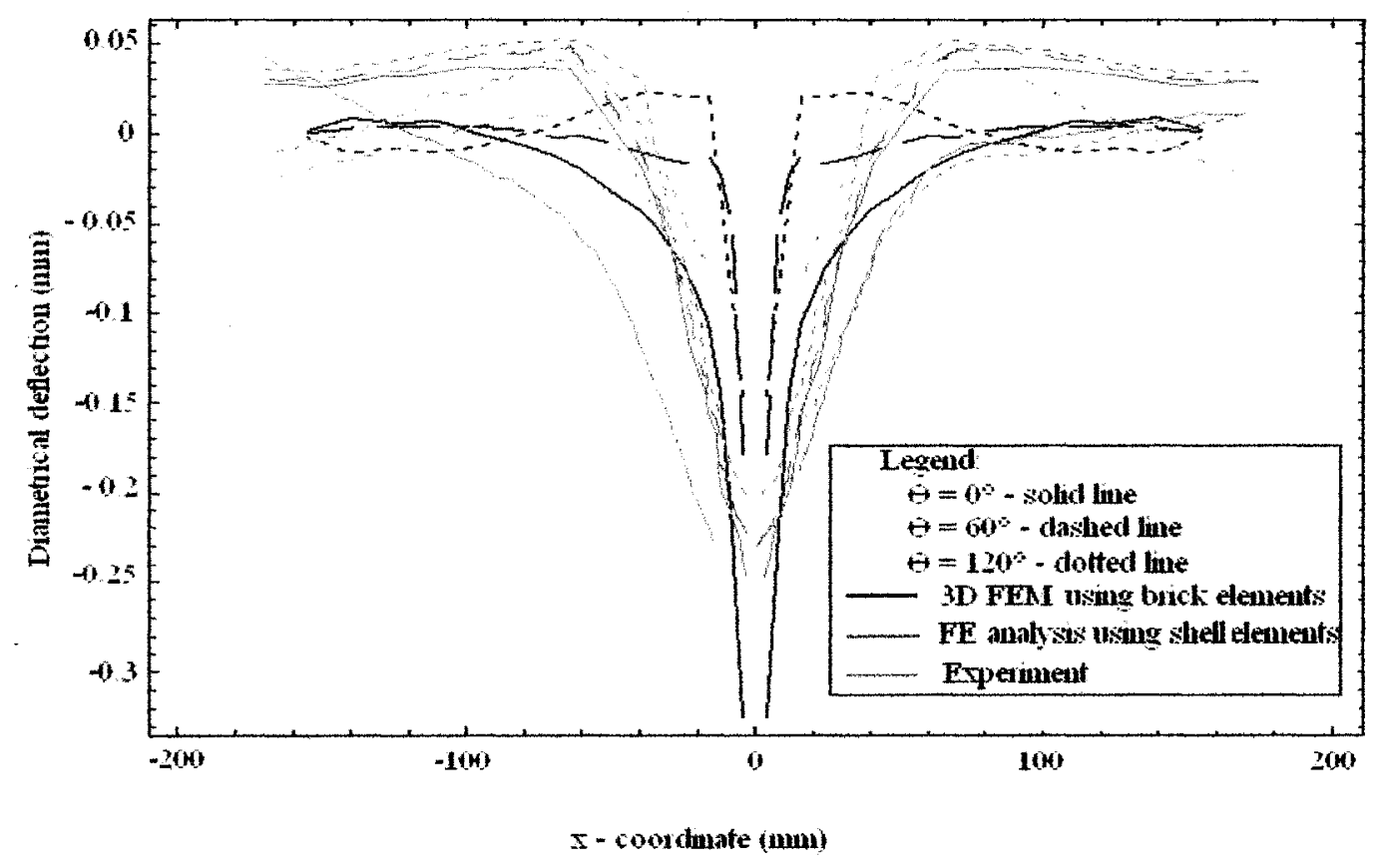

Figure 3.19: Diametrical deflection - compared results. 
The main observation regarding diametrical deflection is that the residual deformation is not restricted to a narrow region close to the weld center line, but is noticeable throughout the pipe length. The diametrical deflection versus distance graph obtained by post processing the nodal displacement in the finite element analysis using brick elements (Figure 3.16) show modulation points for two of the positions $\theta=60^{\circ}$ and $\theta=120^{\circ}$ at $x= \pm 15 \mathrm{~mm}$; this points can be useful in crack predictions.

\section{Conclusions:}

There are some notable points of the finite element analysis using brick elements performed as a computer simulation of a single pass-welded pipe model :

The discretization technique and the element type used in the finite element analysis for welded structures are important for the accuracy of the results and reducing the computation time. Small elements near the weld pool and near the weld center line and large elements far away from the weld center line will give accurate results and reduce the computation time. When performing highly non-linear calculations more complex elements are to be preferred instead simple ones even though it will increase the computation time.

The weld pool model with prescribed temperatures used to model the welding arc in the 3D FEM computer simulation is much more realistic than the point heat source model used in the FE analysis with shell elements.

The interactions between thermal and mechanical processes present in a weld were included by coupling the thermal and stress analysis. The thermal analysis computes an FEM approximate solution to the transient 3D equation in a Lagrangian formulation. The 
model gives the thermal history at every point in the welded structure.

The results of the thermal analysis were used for the strain and stress field computation. Rate independent, rate dependent and viscous constitutive models were changed as a function of temperature to model the material behavior. The thermal analysis does not use the deformed geometry or plastic work from stress analysis results.

Satisfactory results are obtained. Computed stresses and diametrical deflection have been compared with experimental results. The accuracy of the simulation was limited primarily by the knowledge of input data: nonlinear material properties, convection coefficient, and high temperature viscosity. 


\section{Bibliography}

[1]

Mark E. Sapp, History of Welding - from Hephaestus to Apollo, www.weldinghistory.org,

[2] Lars-Erik Lindgren, Finite element modeling and simulation of welding. Part 2: Improved material Modeling, Journal of Thermal Stress, vol. 24, pp. 195 213, 2001.

[3] Lars-Erik Lindgren, Finite element modeling and simulation of welding. Part 1: Increased complexity, Journal of Thermal Stress,vol. 24, pp. 141 - 192, 2001.

[4] John Goldak, M.J. Bibby, D. Downey and M. Gu, Heat and Fluid Flow in Welds, Advanced joining technologies, North, T.H., (ed.), London, 1990.

[5] M.Gu, J.A. Goldak and E. Hughes, Steady state thermal analysis of welds with filler metal addition, Canadian Metallurgical Quarterly, vol. 32, no. 1, pp. $49-55,1993$.

97 
[6] John A. Goldak, Aditya Chakravati, and Malcolm Bibby, A new finite element model for welding heat sources, Metallurgical Transactions B, vol. 15B, pp. 299 - 305, June 1984.

[7] John A. Goldak, Computational Weld Mechanics, unpublished, 2003.

[8] M. Gu, John Goldak, Steady-State Formulation for Stress and Distortion of Welds, Journal of Engineering for Industry, vol. 116, pp. 467 - 474, November 1994.

[9] John Goldak, V. Bereiguine, N. Dai and J. Zhou, Thermal Stress Analysis in Welds for Hot Cracking, Welding-induced residual stresses in pressure vessels and piping, ASME PVP Conference, Montreal, Quebec, Canada, 1996.

[10] John A. Goldak and Victor Breignine, Plasticity in Welds, in Physics and Mechanics of Finite Plastic and Viscoplastic Deformation, Proceedings of Plasticity '97, Juneau, Alaska, USA, July 14-18, 1997, Ed. Akhtar S. Khan, pp. $391-392$.

[11] ASM Handbook, Vol.6, Welding, Brazing and Soldering, ASM INTERNATIONAL, Materials Park, OH, 1993.

[12] John Goldak, Balvatrai Patel, Malcom Bibby, James Moore, Computational Weld Mechanics, Conference Proceedings No. 398, Advanced Joining of Aerospace Materials, AGARD, June 1985. 

ual Stresses in a Butt-Welded Pipe", Journal of Strain Analysis for Engineering Design, Vol. 23, No. 1, pp. 25 - 31, 1988. mental Verification, Doctoral Thesis, Division of Computer Aided Design, Lulea University of Technology,1992.

[15] L.E. Lindgren, and L. Karlsson, Deformations and Stresses in Welding of Shell Structures, International Journal for Numerical Methods in Engineering,Vol. 25, pp. 635-665, 1988.

[16] B. Cheng, A Posteriori Error Estimates of Finite Element Solutions, Master of Applied Science Thesis, Mechanical and Aerospace Department, Carleton University, 2003. T. Zacharia, J. M. Vitek, J. A. Goldak, T. A. DebRoy, M. Rappaz, and H.K.D.H. Badeshia, Modeling of fundamental phenomena in welds, Modeling Simul. Mater. Sci. Eng. 3, pp. 266 - 288, 1995. sidering Phase Transformations, ASME Journal of Engineering Materials and Technology, vol. 100, pp. 356-362, 1978. 


\section{Annex 1}

Temperature Dependent Material Properties used in 3D FEM

Computer Simulation of Welding for a Butt-Welded Pipe Model

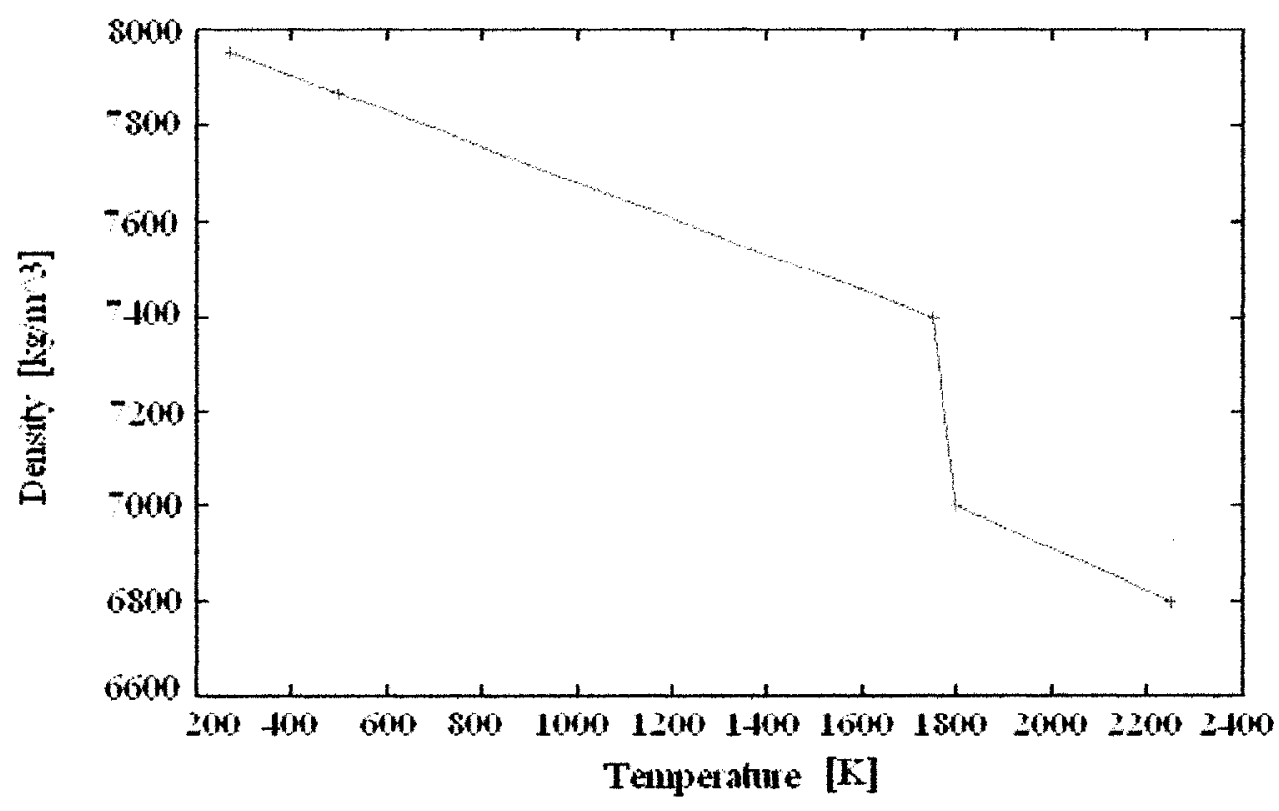

Figure 3.20: Density versus Temperature [18]. 


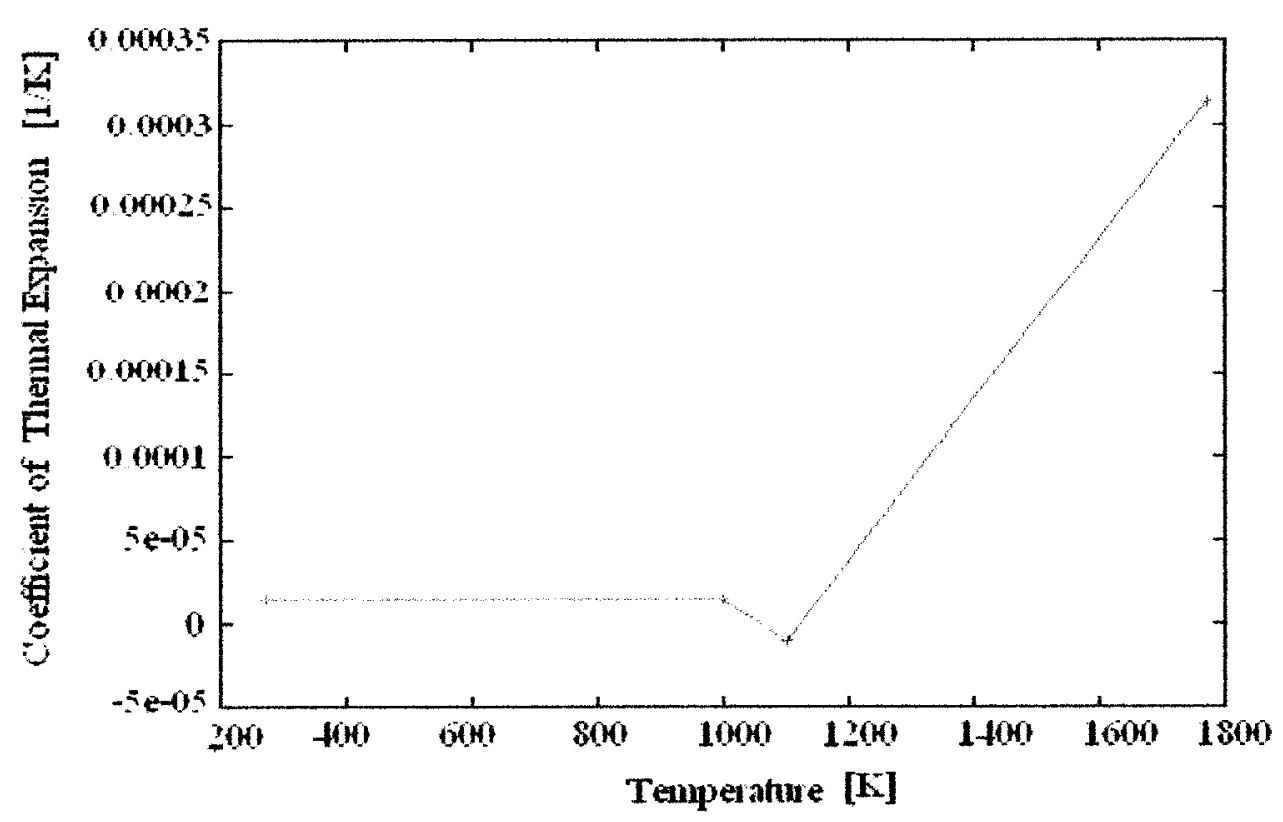

Figure 3.21: Coefficient of Thermal Expansion versus Temperature [18]. 


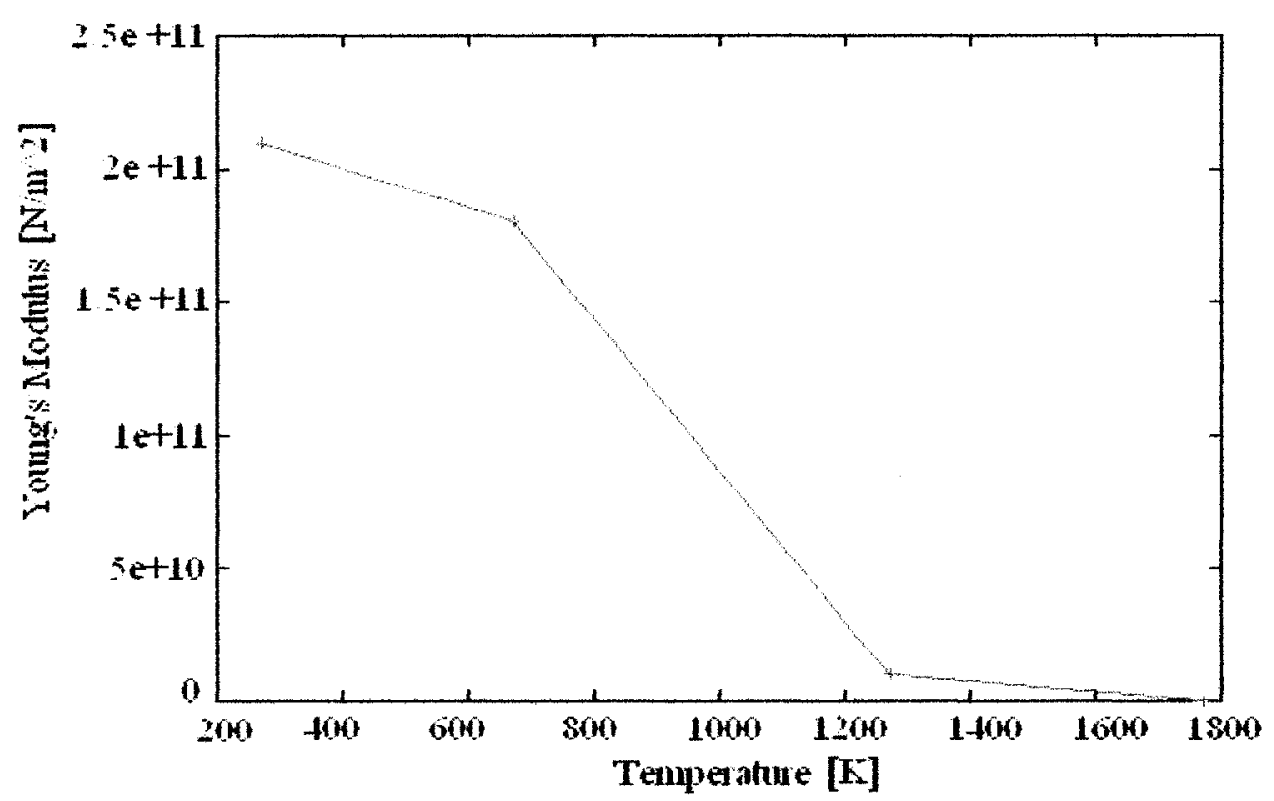

Figure 3.22: Young's Modulus versus Temperature [18]. 


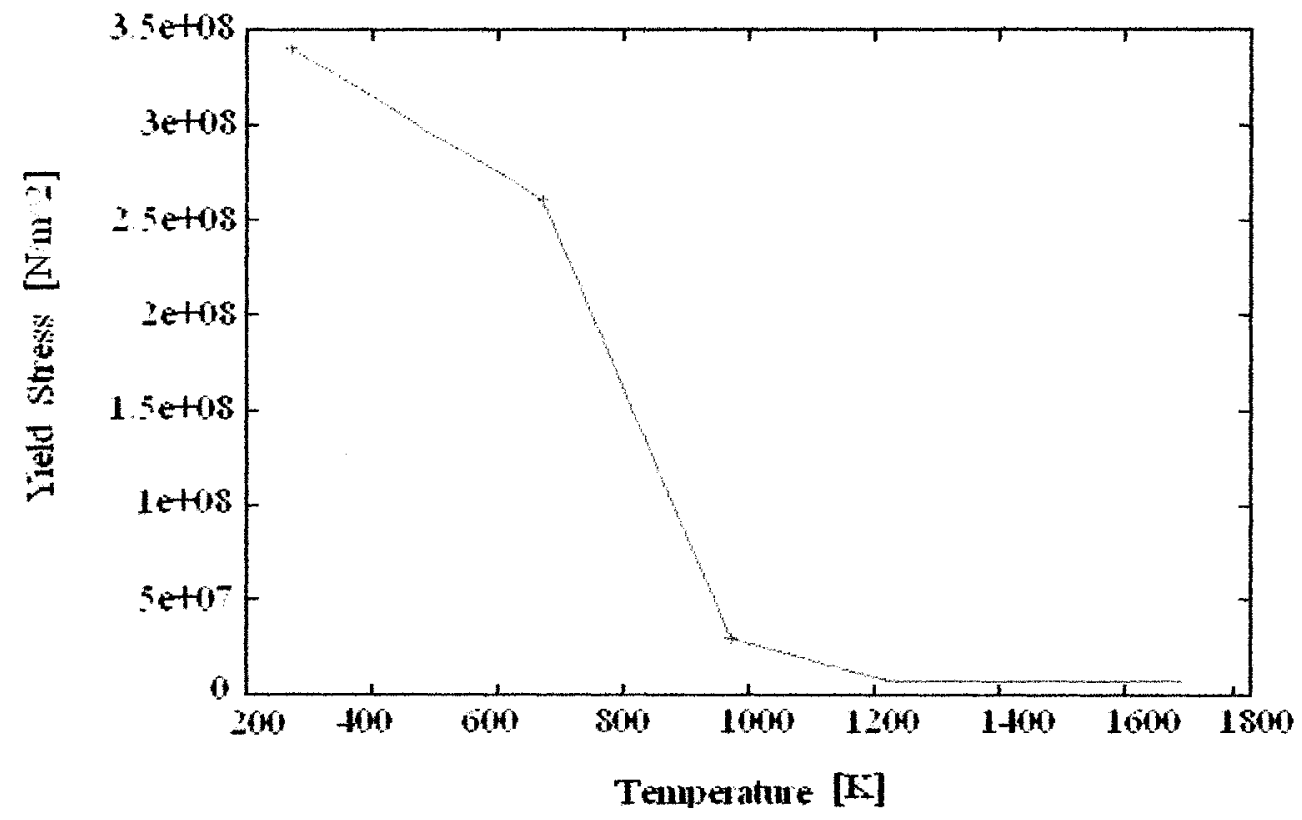

Figure 3.23: Yield Stress versus Temperature [18]. 


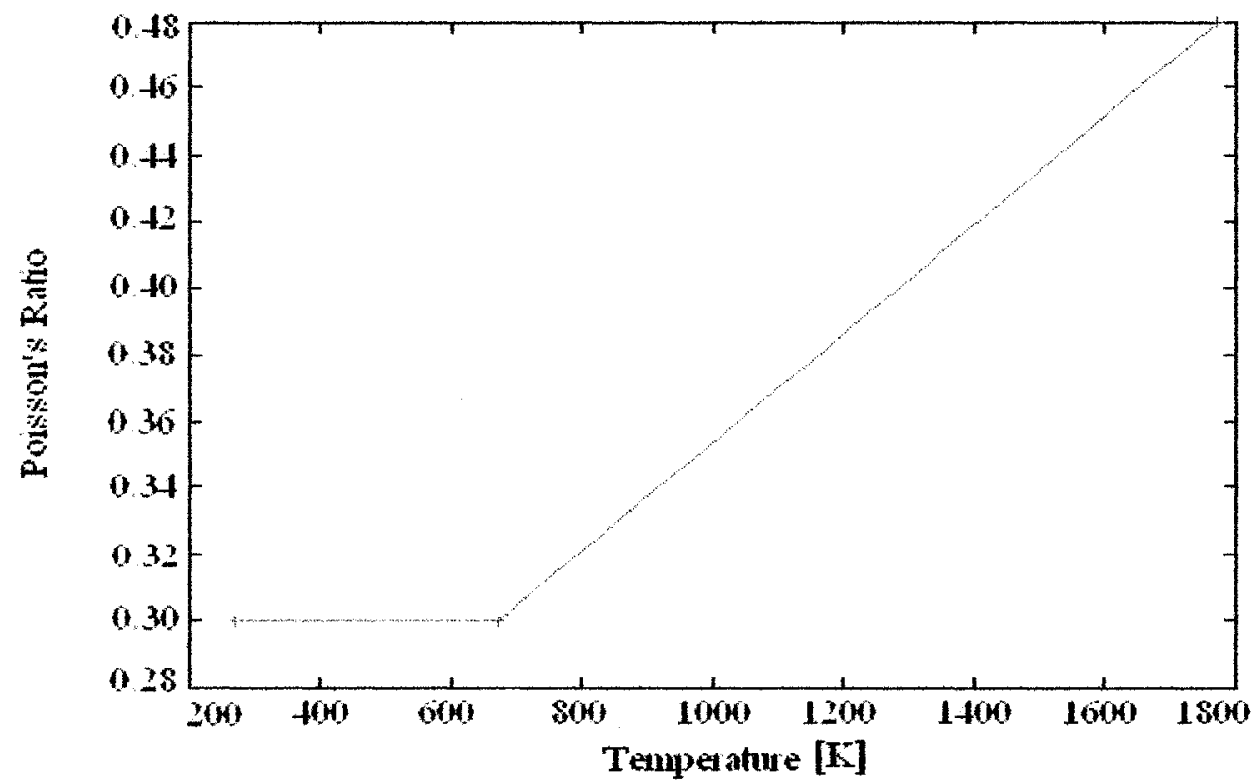

Figure 3.24: Poisson's Ratio versus Temperature [18]. 


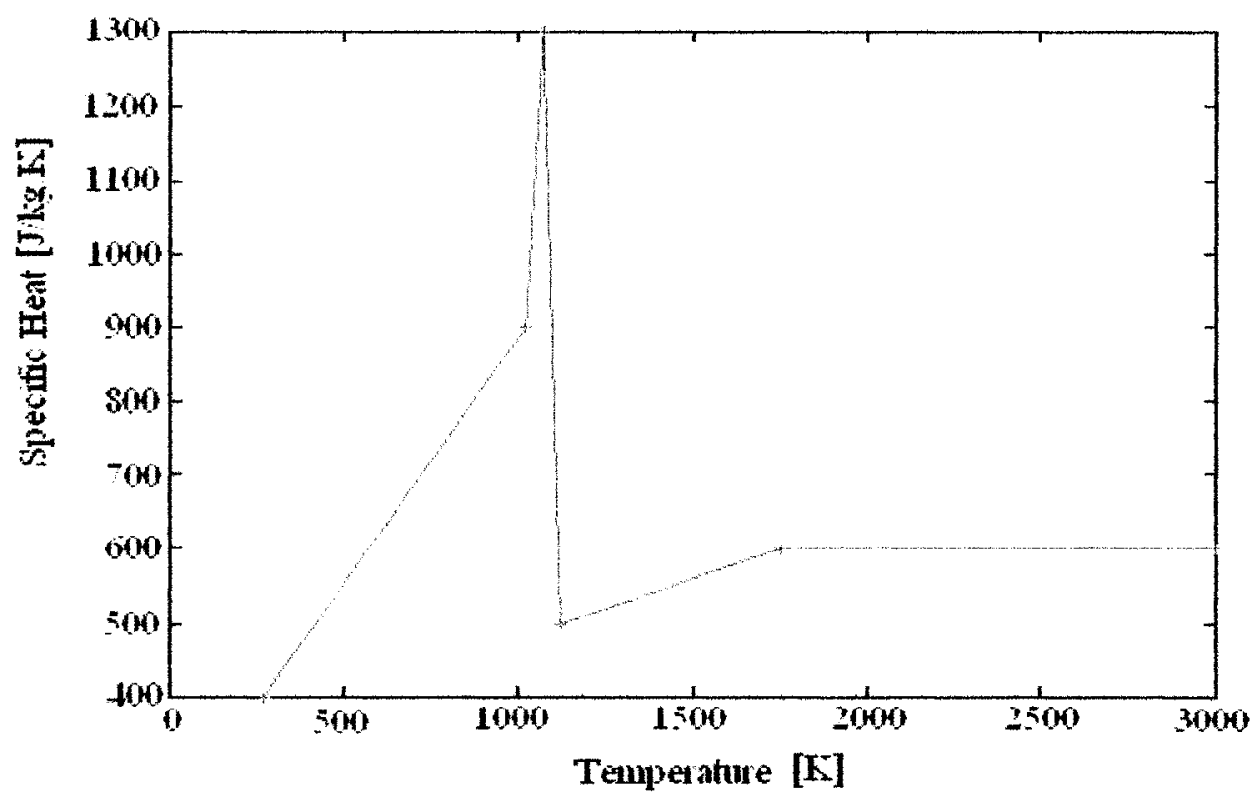

Figure 3.25: Specific Heat versus Temperature [18]. 


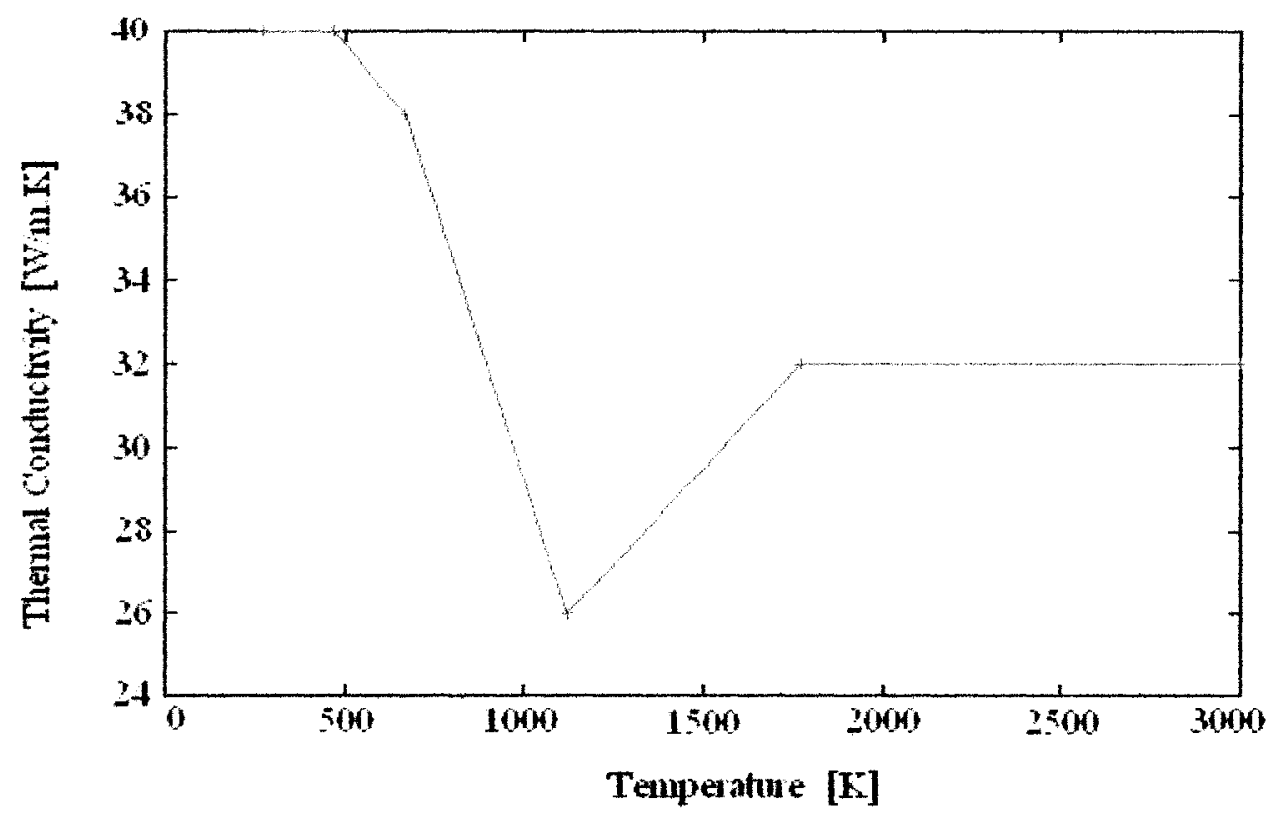

Figure 3.26: Coefficient of Thermal Conductivity versus Temperature [18]. 


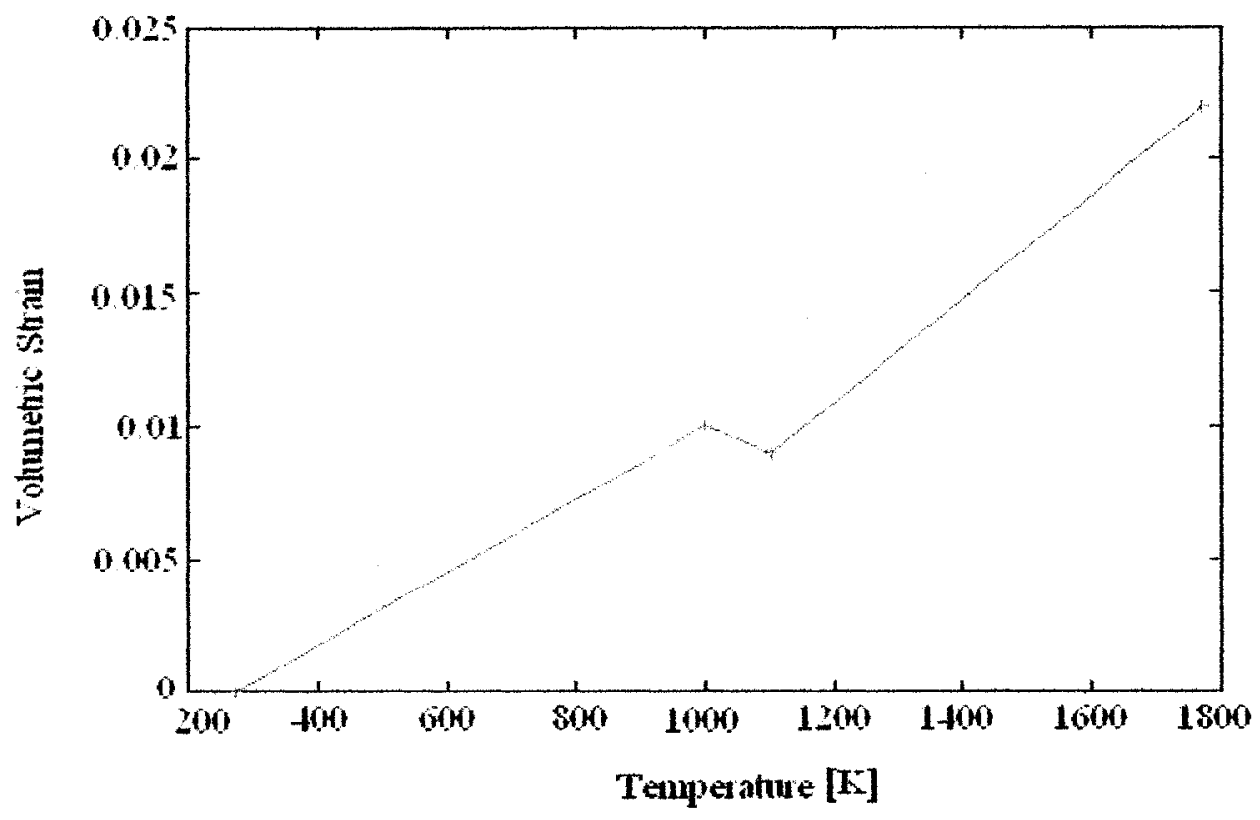

Figure 3.27: Volumetric Strain versus Temperature [18]. 


\section{Annex 2}

Transient temperature fields in 3D FEM Computer Simulation of Welding for a Butt-Welded Pipe Model 


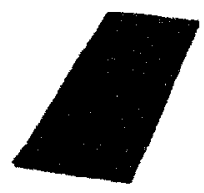

Time $=0 \mathrm{~s}$

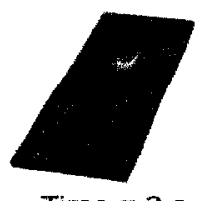

Time $=3 \mathrm{~s}$
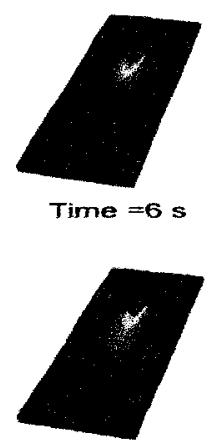

Time $=8 \mathrm{~s}$

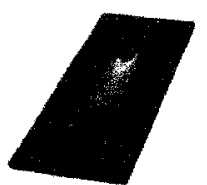

Time $=11 \mathrm{~s}$

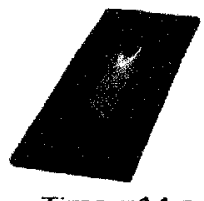

Time $=14 \mathrm{~s}$

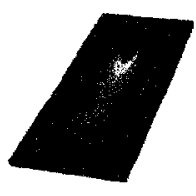

Time $=16.5 \mathrm{~s}$

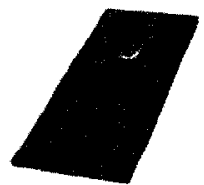

Time $=1.5 \mathrm{~s}$

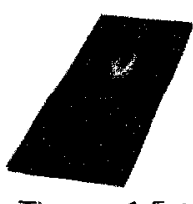

$T(E)$

Time $=4.5 \mathrm{~s}$

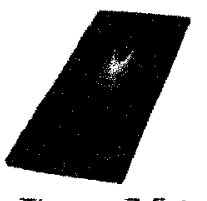

$1+20$

1350

1280

$11-10$

$10^{-0}$

tomo

Time $=9.5 \mathrm{~s}$

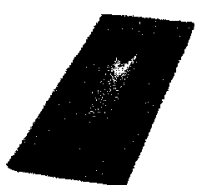

Time $=12.5 \mathrm{~s}$

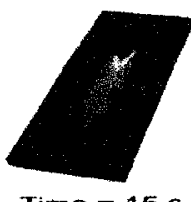

Time $=15 \mathrm{~s}$

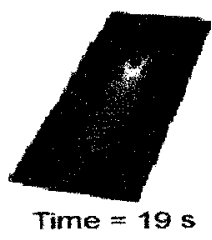

40

370

300

Figure 3.28: Temperatures field in the small plate. 

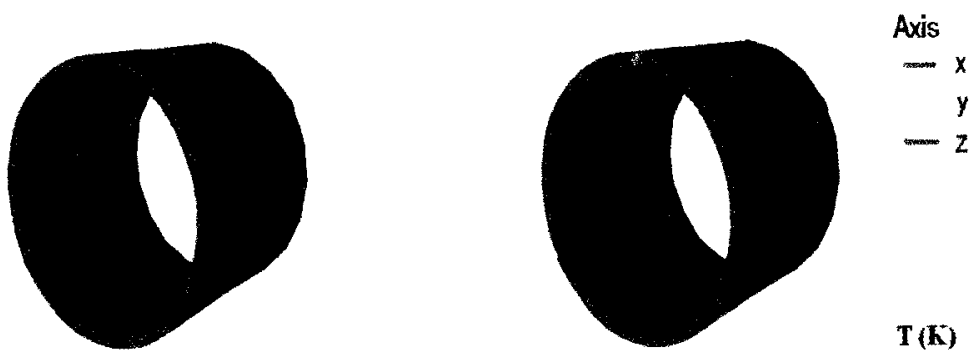

Time $=0 \mathrm{~s}$

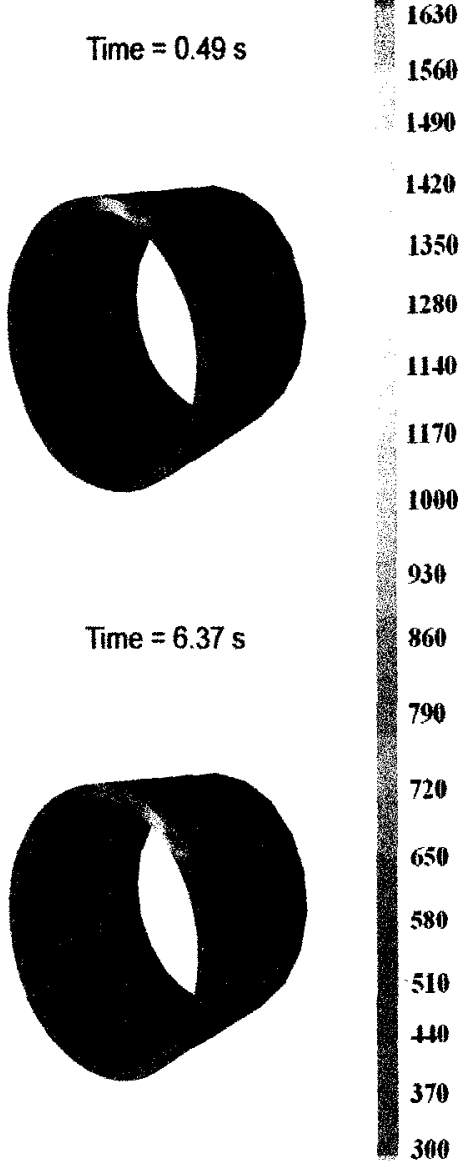

Time $=9.31 \mathrm{~s}$

Time $=12.25 \mathrm{~s}$

Figure 3.29: Temperatures field mapped to the pipe model (Welding start phase).

110 

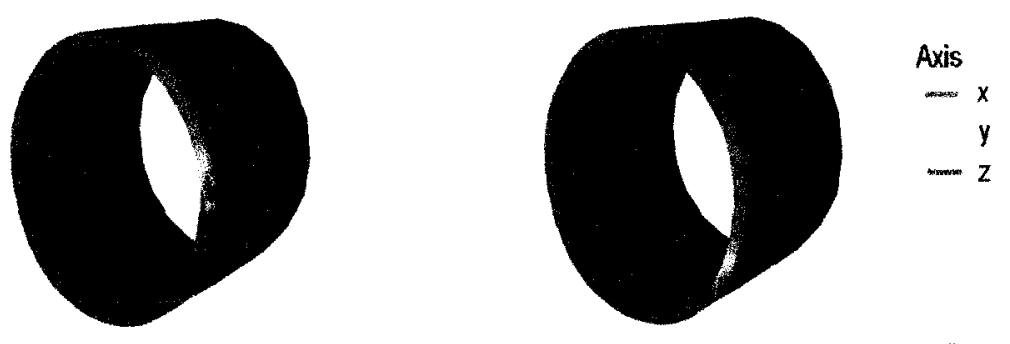

$\mathrm{T}(\mathbf{K})$

Time $=22.05 \mathrm{~s}$

Time $=31.85 \mathrm{~s}$

1750
1630
1560

1560
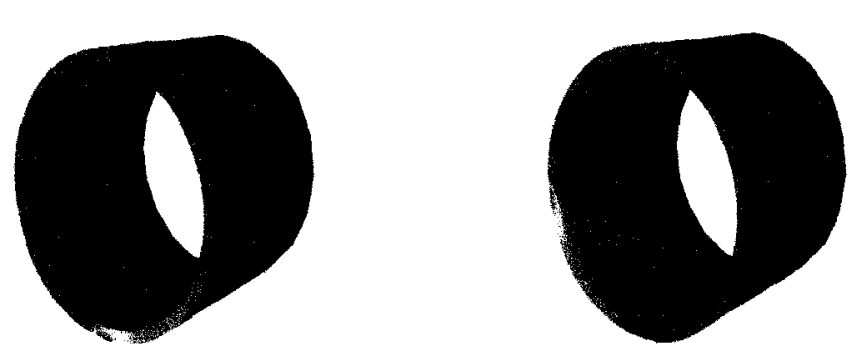

$1+20$

1350

1280

1140

1170

1000

Time $=46.55 \mathrm{~s}$

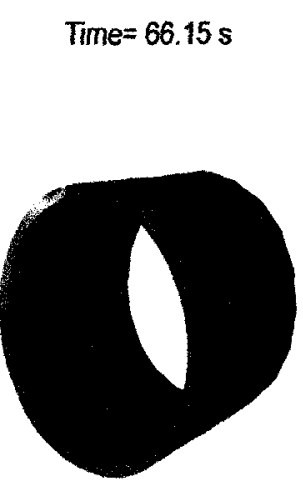

930

860

790

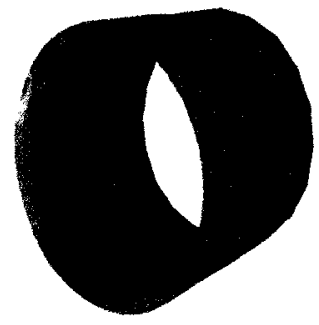

Time $=75.95 \mathrm{~s}$

Time $=89 \mathrm{~s}$

Figure 3.30: Temperatures field mapped to the pipe model (Welding steady state phase). 

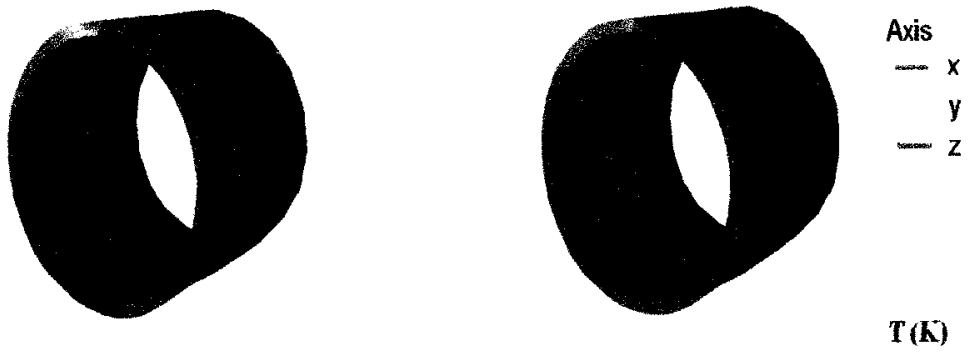

Time $=90.65 \mathrm{~s} . j p g$

Time -4500s $\begin{gathered}1750 \\ 1630 \\ 1560\end{gathered}$

1490
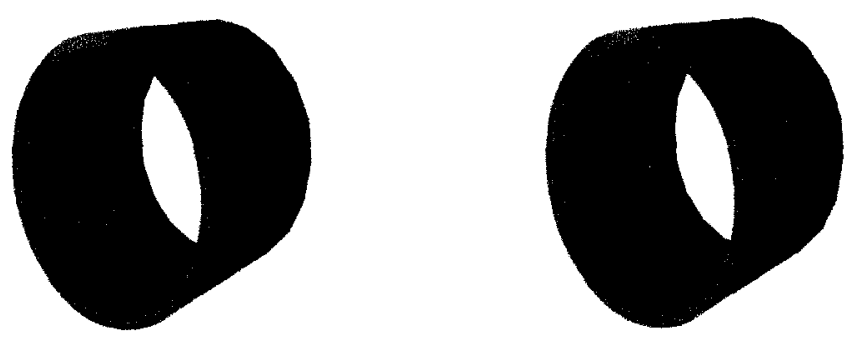

$1+20$

1350

1280

1140

1170

1000

Time $\sim 8000 \mathrm{~s}$

, Time $\sim 10500 \mathrm{~s}$

930

860

790
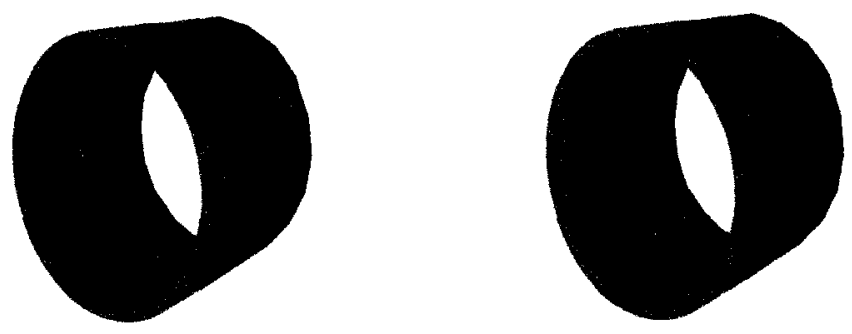

720

650

580

510

440

370

E Time $\sim 13000 \mathrm{~s}$

F Time $\sim 14000 \mathrm{~s}$

Figure 3.31: Temperatures field mapped to the pipe model (Cooling phase). 


\section{Annex 3}

Stress and Deformation fields in 3D FEM Computer Simulation of Welding for a Butt-Welded Pipe Model 

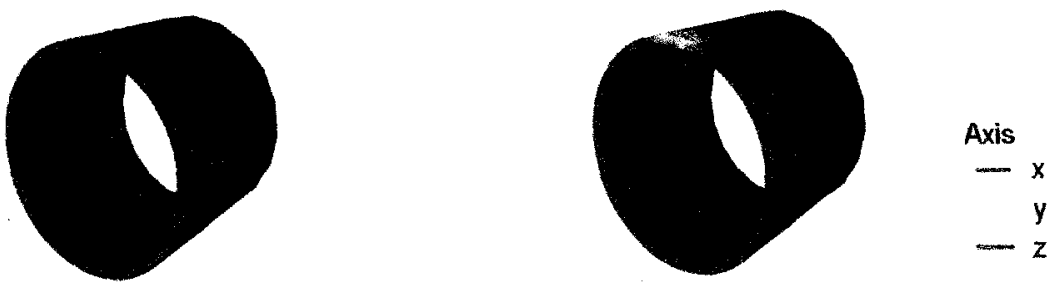

Time $=0 \mathrm{~s}$

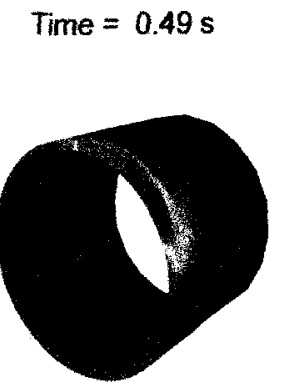

\section{Effective}

Stress (Pa)

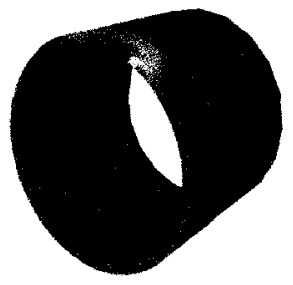

$7.51 \mathrm{e}+08$

警

$6.76 \mathrm{e}+08$

Time $=16.66 \mathrm{~s}$

$6.01 e+08$

Time $=5.88 \mathrm{~s}$
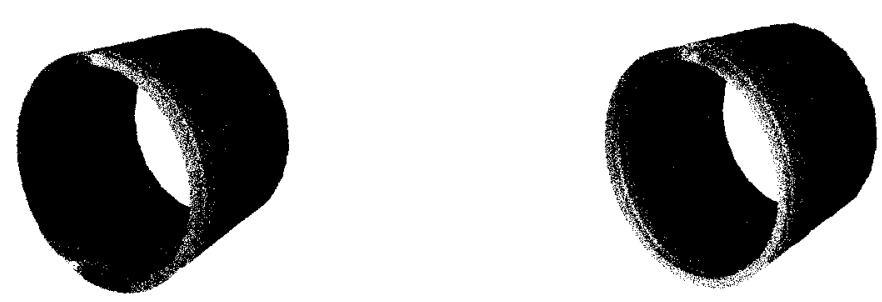

$4.88 \mathrm{e}+08$

Time $=49 \mathrm{~s}$

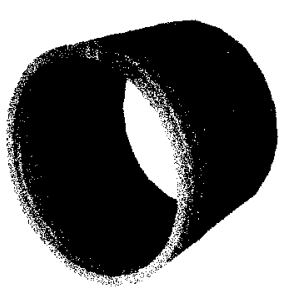

Time $=5000 \mathrm{~s}$

Time $=89 \mathrm{~s}$

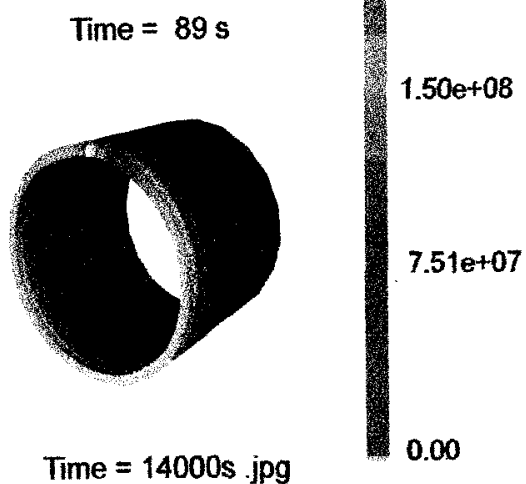

Figure 3.32: Transient effective stress.

114 


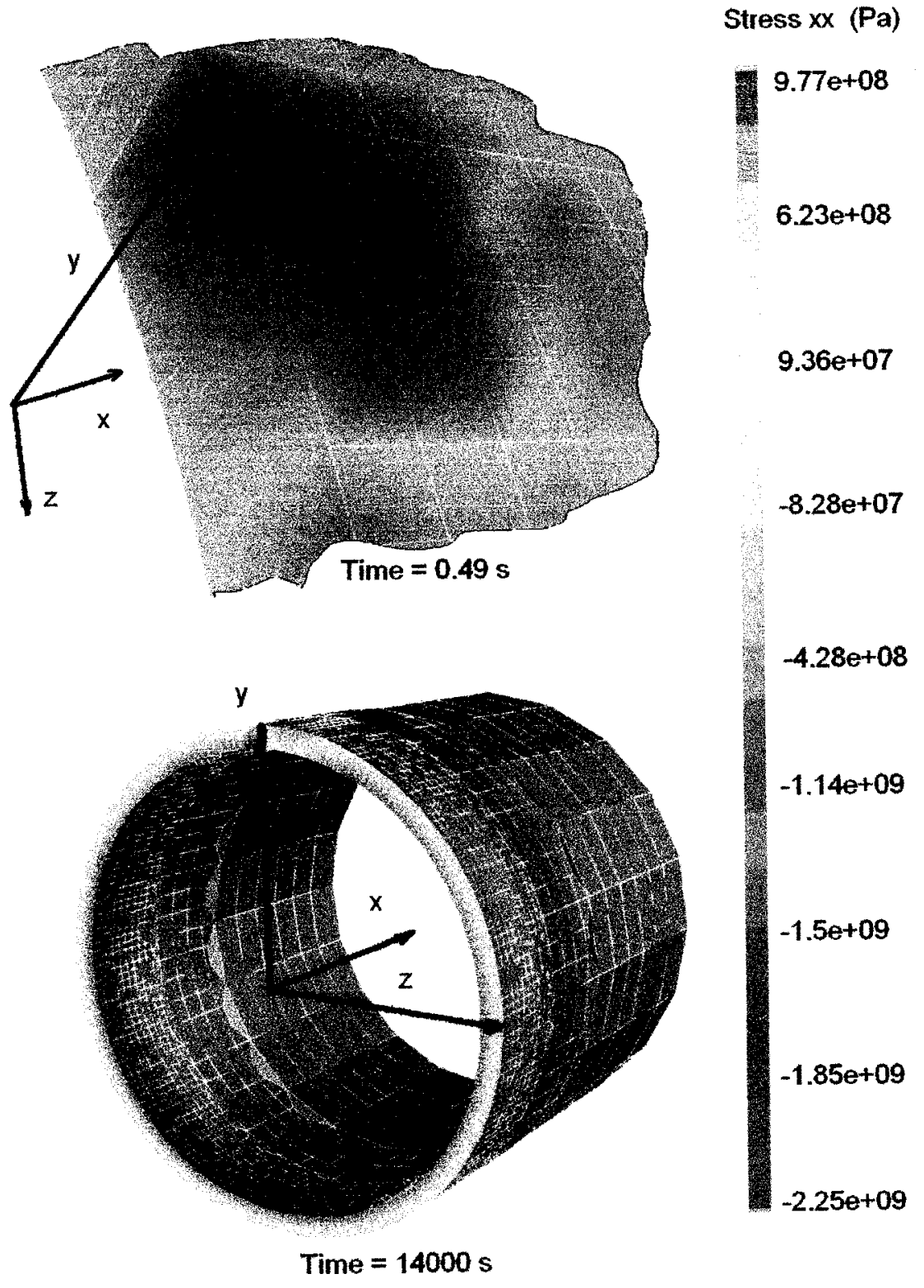

Figure 3.33: Longitudinal stress.

115 


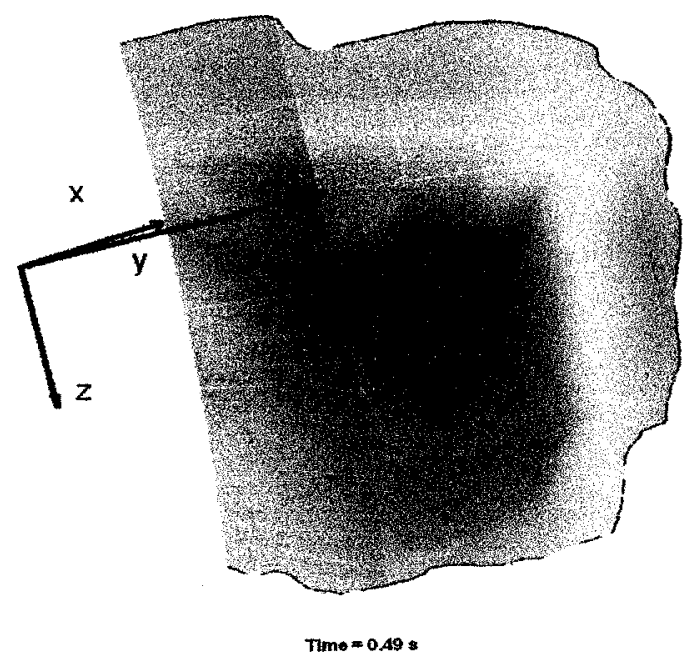

Stress yy (Pa)

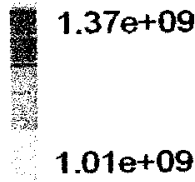

$6.57 e+08$

$4.80 e+08$
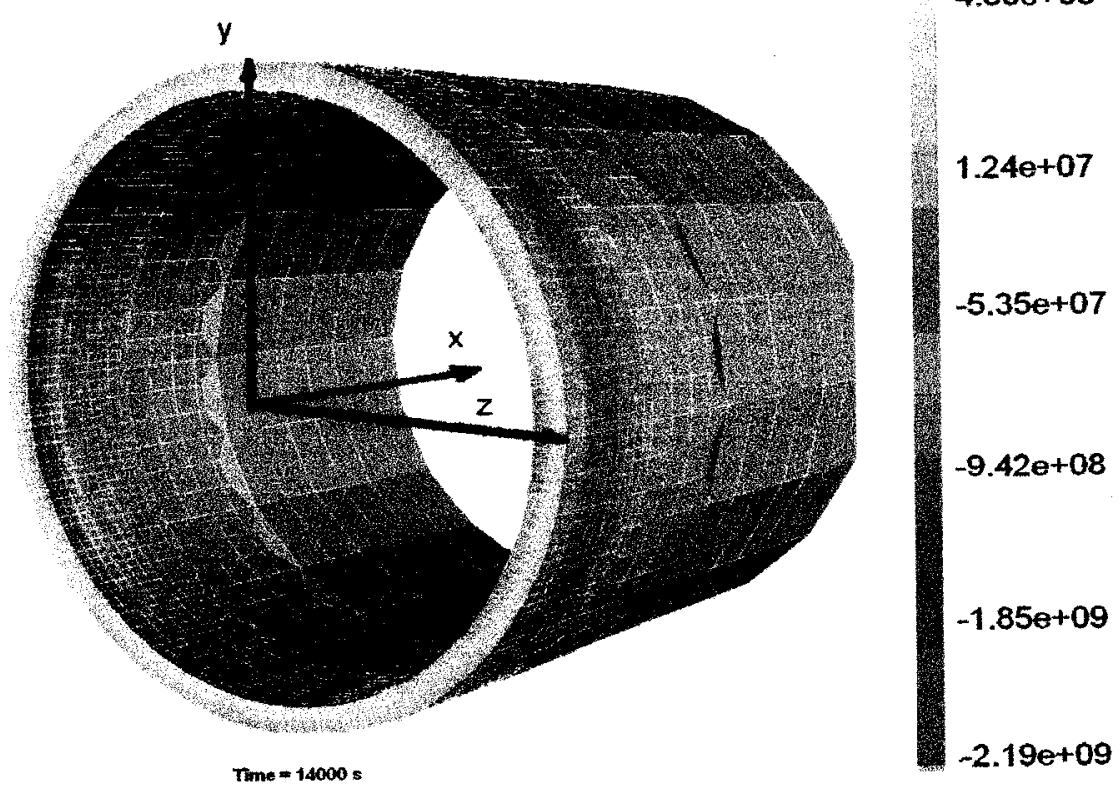

Figure 3.34: Stress transverse to weld. 


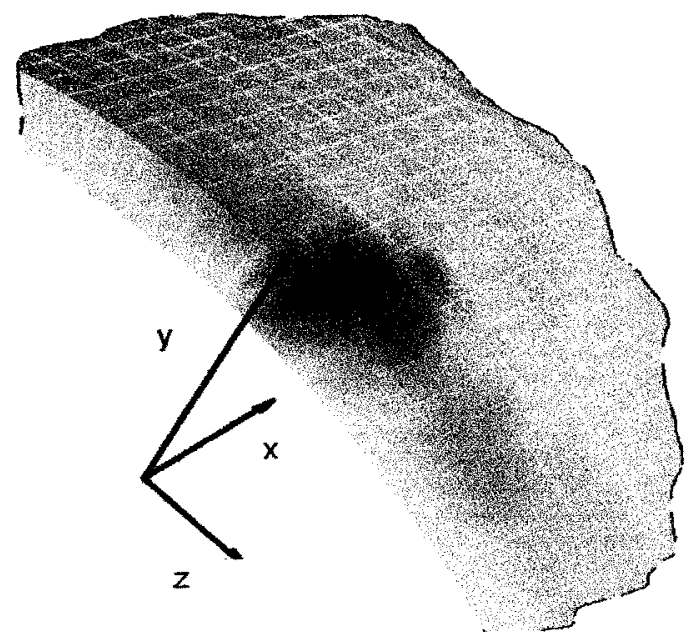

Stress zz (Pa)

$1.17 \mathrm{e}+09$

致

$8.15 e+08$

Time $=0.49 \mathrm{~s}$

$1.06 \mathrm{e}+08$

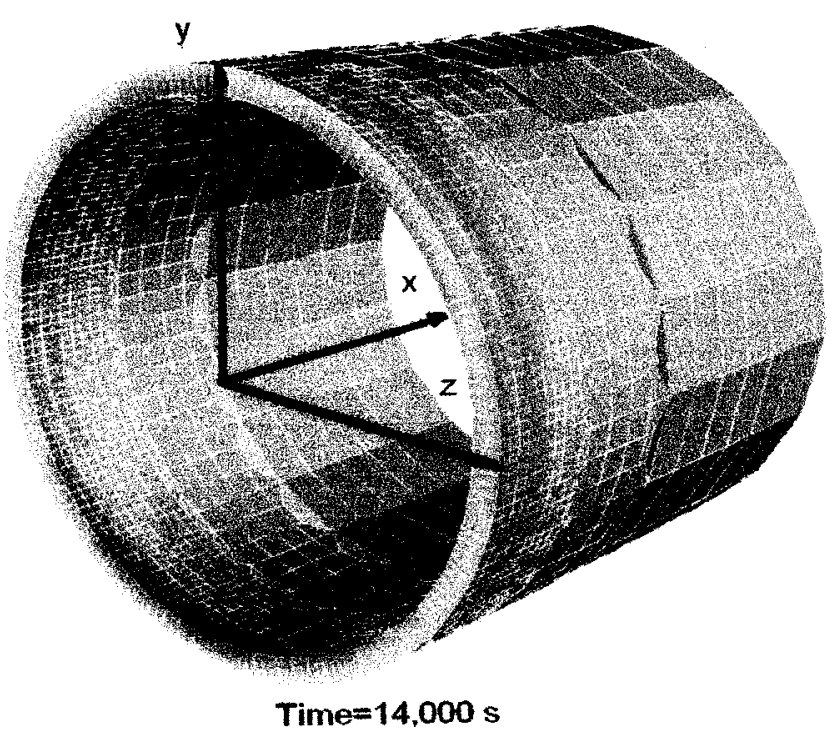

$-7.07 e+07$

$-4.25 e+08$

$-1.17 e+09$

$-1.83 e+09$

$-2.37 e+09$

Figure 3.35: Radial or through-thickness stress. 


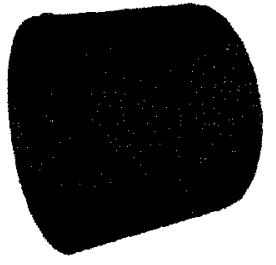

Time $=0.49 \mathrm{~s}$

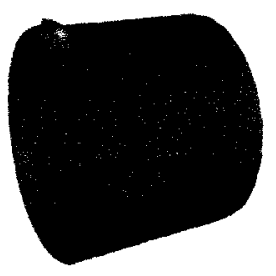

Time $=3.43 \mathrm{~s}$

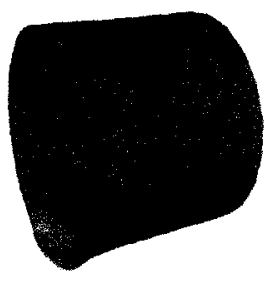

Time $=49 \mathrm{~s}$

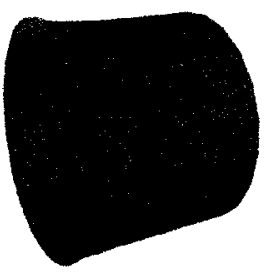

Time $\sim 4500 \mathrm{~s}$

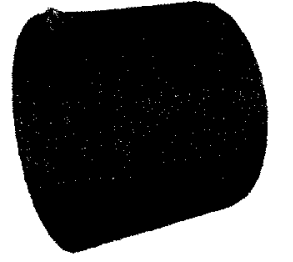

Axis

$x$
$y$

Time $=0.98 \mathrm{~s}$

Displacement (m)

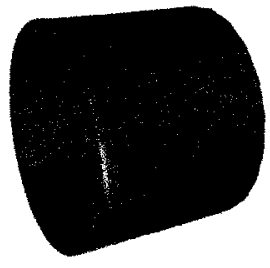

0.000757

鑃

0.000682

Time $=25.97 \mathrm{~s}$

0.000606

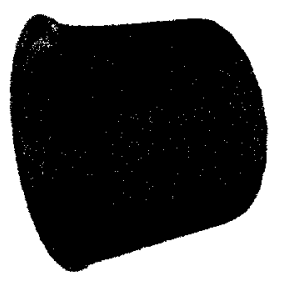

0.00053

0.000454

0.000341

Time $=89 \mathrm{~s}$

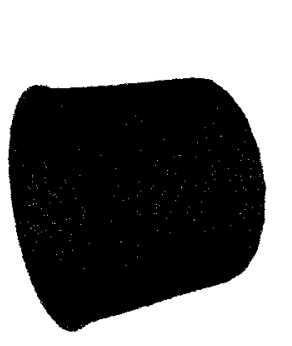

0.000227

0.000151

$7.57 \mathrm{e}-05$

Time $=14000 \mathrm{~s}$

0.00

Figure 3.36: Deformations during welding and cooling - 3D FEM simulation. 


\section{Annex 4}

\section{Transient global strain energy error}

The error in strain energy in each element is defined as the difference between the Statically Admissible Stress (SAS) strain energy and Kinematically Admissible Stress (KAS) strain energy.

The SAS and KAS strain energy in an element is evaluated by integrating over Gauss points in the element.

The total of SAS and KAS strain energy in the whole domain is the SAS and KAS strain energy in the element summed over the total number of elements.

The relative error in strain energy is defined as the error in strain energy in the element divided by the averaged of the SAS strain energy and KAS strain energy per element.

The total error in strain energy is computed as the difference between SAS strain energy and the KAS strain energy in the whole domain.

Because the software cannot visualize element data, we visualize the relative error in strain energy in each element mapped to nodes and averaged. 

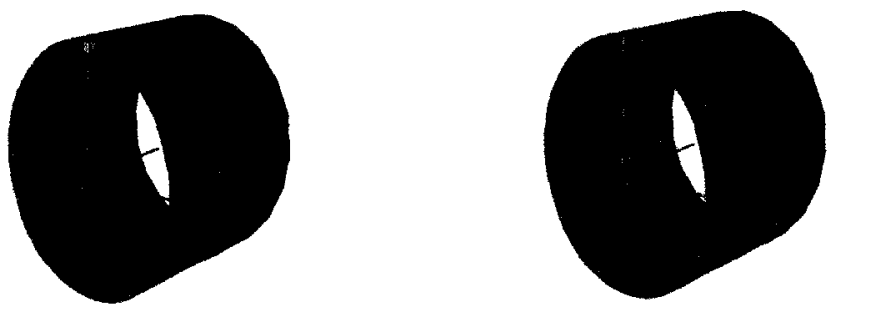

$$
\begin{array}{r}
\text { Axis } \\
-x \\
y \\
-z
\end{array}
$$

Time $=0.49 \mathrm{~s}$

$$
\text { Time }=0.98 \mathrm{~s}
$$

Global Strain

Energy Error
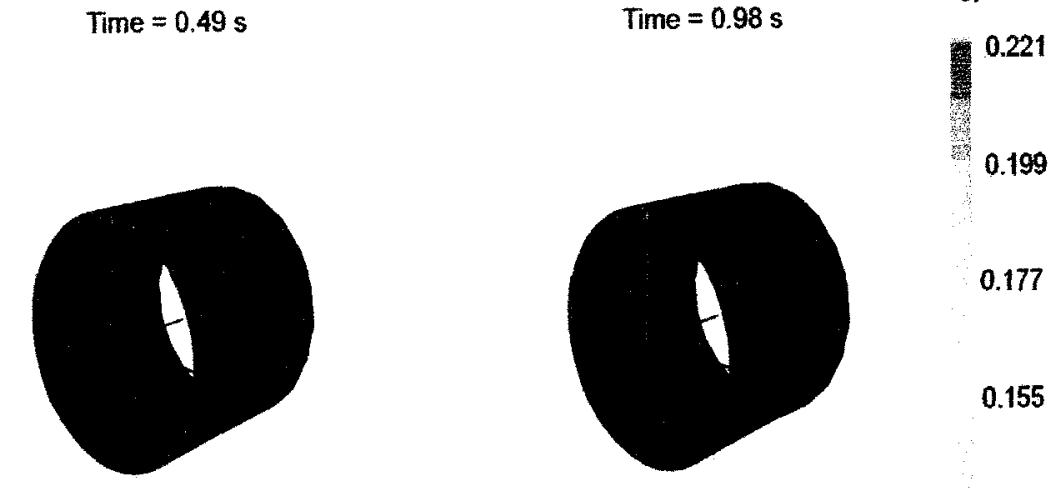

0.199

0.177

0.155

0.133

Time $=44.1 \mathrm{~s}$

Time $=89.18$
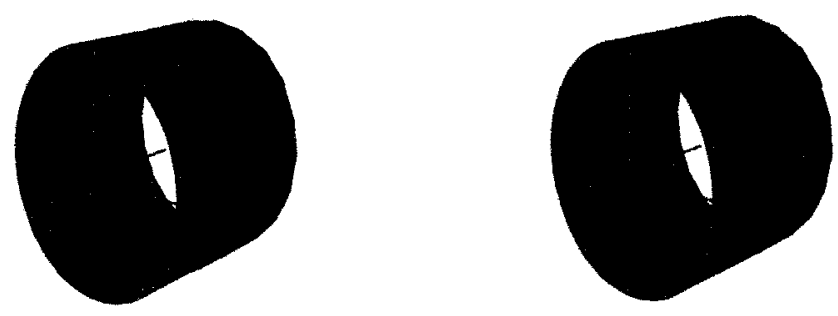

0.0885

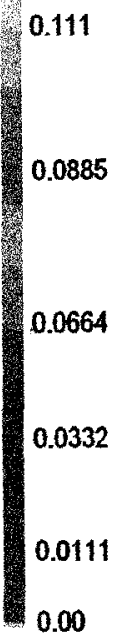

Time $=89.67$

Time $=14000 \mathrm{~s}$

0.00

Figure 3.37: Transient global strain energy error.

120 